Supporting Information

\title{
Design, Synthesis, And Binding Affinities Of Pyrrolinone-Based Somatostatin Mimetics.
}

Amos B. Smith, III, ${ }^{* 1}$ Adam K. Charnley, ${ }^{1}$ Eugen F. Mesaros, ${ }^{1}$ Osamu Kikuchi, ${ }^{1}$ Wenyong Wang, ${ }^{1}$ Andrew Benowitz, ${ }^{1}$ Chi-Lien Chu, ${ }^{2}$ Jin-Jye Feng, ${ }^{2}$ Kuo-Hsin Chen, ${ }^{2}$ Atsui Lin, ${ }^{2}$ Fong-Chi Cheng, ${ }^{2}$ Laurie Taylor, ${ }^{* 3}$ and Ralph Hirschmann ${ }^{\star 1}$

${ }^{1}$ Department of Chemistry, University of Pennsylvania, Philadelphia, PA 19104.

${ }^{2}$ MDS Pharma Services - Taiwan Ltd., Pharmacology Laboratories, 158 Li-Teh Road, Peitou, Taipei, Taiwan 112.

${ }^{3}$ MDS Pharma Services, $2201130^{\text {th }}$ Drive SE, Bothel, WA 98021.

smithab@sas.upenn.edu 


\section{Experimental Section}

\section{Materials and Methods.}

Reactions were carried out in oven or flame-dried glassware under an argon atmosphere, unless otherwise noted. All solvents were reagent grade. Diethyl ether $\left(\mathrm{Et}_{2} \mathrm{O}\right)$ and tetrahydrofuran $(\mathrm{THF})$ were freshly distilled from sodium / benzophenone under argon. Reactions were magnetically stirred and monitored by thin layer chromotography (TLC) with $0.25 \mathrm{~mm}$ E. Merck pre-coated silica gel plates. Progress of the imine forming reactions can be monitored by NMR $\left(\mathrm{C}_{6} \mathrm{D}_{6}\right)$. Flash chromatography was performed with silica gel 60 (particle size $0.040-0.062 \mathrm{~mm}$ ) supplied by Silicycle and Sorbent Technologies. Yields refer to chromatographically and spectroscopically pure compounds, unless otherwise stated. All melting points were obtained on a Thomas-Hoover apparatus and are corrected. Infrared spectra were recorded on a Perkin-Elmer Model 283B spectrophotometer or a Jasco Model FT/IR-480 Plus spectrometer. Proton and carbon-13 NMR spectra were recorded on a Bruker AMX-500 spectrometer. Chemical shifts are reported relative to chloroform ( $\delta 7.26)$, methylene chloride ( $\delta$ 5.32), methanol ( $\delta 3.31)$, or benzene $(\delta 7.15)$ for ${ }^{1} \mathrm{H}-\mathrm{NMR}$ and chloroform $(\delta$ 77.0), methylene chloride $(\delta 53.8)$, methanol $(\delta 49.15)$, or benzene $(\delta 128.0)$ for ${ }^{13} \mathrm{C}$ NMR. Optical rotations were measured on a Perkin-Elmer model 241 polarimeter. High resolution mass spectra were measured at the University of Pennsylvania Mass Spectrometry Service Center on either a VG Micromass 70/70 H or VG ZAB-E spectrometer. Microanalyses were performed at the University of Pennsylvania.

Molecular Modeling Calculations were performed on a Silicon Graphics Iris 4D/440 VGX (Unix operating system). Minimization and Monte Carlo calculations were performed using the Batchmin accessory of MacroModel [Version 6.0 (Iris)]. The low energy conformation of 2 for overlay with L-363,301 was determined through a 20,000 step Monte Carlo conformational search using the $M M 2^{* 1}$ force field and the GB/SA solvation continuum $\left(\mathrm{CHCl}_{3}\right)^{2}$

\section{Preparation of SRIF Mimetics 1-3}

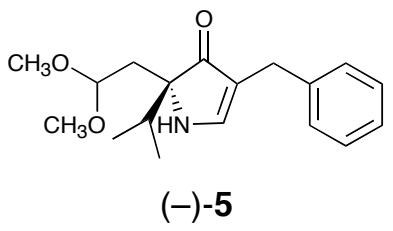

Monpyrrolinone (-)-5. A solution of (+)-A $(3.86 \mathrm{~g}, 17.6 \mathrm{mmol})$ in benzene $(176 \mathrm{~mL})$ was treated with hydrocinnamaldehyde $(2.64 \mathrm{~mL}, 19.26 \mathrm{mmol})$. Condensation was effected with concentration in vacuo followed by azeotropic dehydration with toluene $(5 \times 50 \mathrm{~mL})$. The resultant oil was subjected to high vacuum for $1 \mathrm{~h}$. After

(1) (a) Mohamadi, F.; Richards, N. G. J.; Guida, W. C.; Liskamp, R.; Lipton, M.; Caufield, C.; Chang, G.; Hendrickson, T.; Still W. C. J. Comput. Chem. 1990, 4, 440-467. (b) Allinger, N. L. J. Am. Chem. Soc. 1977, 99, 8127-8134.

(2) Hasel, W.; Hendrickson, T. F.; Still, W. C. Tetrahedron Comput. Method 1988, 1, 103. 
addition of THF (176 mL), 0.5 M KHMDS in toluene $(140.8 \mathrm{~mL}, 70.41 \mathrm{mmol})$ was added dropwise rapidly at room temperature. The reaction mixture was stirred for another $15 \mathrm{~min}$ and quenched with $10 \%$ aqueous $\mathrm{NaHSO}_{4}(100 \mathrm{~mL})$. The layers were separated and the organic layer was then washed with saturated aqueous $\mathrm{NaHCO}_{3}$ and brine (100 mL each), dried over anhydrous $\mathrm{MgSO}_{4}$, concentrated in vacuo, and purified by flash chromatography using ethyl acetate-hexanes (50:50) as eluent to give (-)-5 (4.50 g, 84\% yield) as a pale yellow oil: $[\alpha]_{\mathrm{D}}^{23}-100.00\left(c 0.33, \mathrm{CHCl}_{3}\right)$; IR $\left(\mathrm{CHCl}_{3}\right) 3431(\mathrm{~m}), 3018(\mathrm{~s}), 1758(\mathrm{w}), 1660(\mathrm{~s}), 1586(\mathrm{~s}), 1453(\mathrm{~m}), 1422$ (w), $1216(\mathrm{~s}), 1120(\mathrm{~m}), 1063(\mathrm{~m}) \mathrm{cm}^{-1}$; ${ }^{1} \mathrm{H}$ NMR $\left(500 \mathrm{MHz}, \mathrm{CDCl}_{3}\right) \delta 7.72(\mathrm{~s}, 1 \mathrm{H}), 7.30-7.18(\mathrm{~m}, 5 \mathrm{H}), 5.28(\mathrm{~s}, 1$ H), 4.29 (apparent t, $J=5.5 \mathrm{~Hz}, 1 \mathrm{H}$ ), $3.47(\mathrm{~d}, J=15.7 \mathrm{~Hz}, 1 \mathrm{H}), 3.43(\mathrm{~d}, J=15.7 \mathrm{~Hz}, 1 \mathrm{H}), 3.27(\mathrm{~s}, 3 \mathrm{H}), 3.21$ (s, $3 \mathrm{H}$ ), 2.08 (dd, $J=5.5,14.4 \mathrm{~Hz}, 1 \mathrm{H}$ ), 1.91 (app sept., $J=6.8 \mathrm{~Hz}, 1 \mathrm{H}$ ), 1.89 (dd, $J=5.5,14.4 \mathrm{~Hz}, 1 \mathrm{H}$ ), 0.89 (d, $J=6.8 \mathrm{~Hz}, 3 \mathrm{H}$ ), $0.88(\mathrm{~d}, J=6.8 \mathrm{~Hz}, 3 \mathrm{H}) ;{ }^{13} \mathrm{C} \mathrm{NMR}\left(125 \mathrm{MHz}, \mathrm{CDCl}_{3}\right) \delta 204.4,161.9,141.0,128.6,128.4$, $125.9,115.0,102.3,70.0,53.7,53.4,37.8,33.8,28.5,17.0,16.0$; high resolution mass spectrum (ES, Na) $\mathrm{m} / \mathrm{z}$ $326.1744\left[(\mathrm{M}+\mathrm{Na})^{+}\right.$; calcd for $\left.\mathrm{C}_{18} \mathrm{H}_{25} \mathrm{NO}_{3} \mathrm{Na}: 326.1732\right]$.

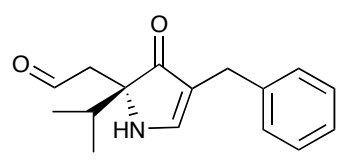

$(-)-\mathbf{S 1}$

Monpyrrolinone Aldehyde (-)-S1. To a solution of (-)-5 (1.82 g, $6.00 \mathrm{mmol})$ in THF and $\mathrm{H}_{2} \mathrm{O}(3: 1,60 \mathrm{~mL})$ was added $p$-toluenesulfonic acid $(2.40 \mathrm{~g}, 12.62 \mathrm{mmol})$. The mixture ws stirred under argon at $40^{\circ} \mathrm{C}$ for $5 \mathrm{~h}$. The reaction was allowed to cool to room temperature and quenched by addition of saturated aqueous $\mathrm{NaHCO}_{3}(20$ $\mathrm{mL})$. The layers were separated, the aqueous layer was extracted with ethyl acetate $(3 \times 20 \mathrm{~mL})$, and the combined organic layers were washed with brine $(40 \mathrm{~mL})$. The organic layer was dried over $\mathrm{MgSO}_{4}$, concentrated in vacuo and purified by flash chromatography using methanol-methylene chloride (3:97) as eluant to afford monopyrrolinone aldehyde $(-)-\mathrm{S} 1,\left(1.46 \mathrm{~g}, 95 \%\right.$ yield) as a pale yellow oil: $[\alpha]_{\mathrm{D}}^{23}-12.55(c 0.51$, $\left.\mathrm{CHCl}_{3}\right)$; IR $\left(\mathrm{CHCl}_{3}\right) 3444$ (m), 3019, (s), 2970 (w), 1721 (s), 1662 (s), 1585 (s), 1494 (w), 1220 (s), $1143(\mathrm{~m}) \mathrm{cm}^{-}$ 1; ${ }^{1} \mathrm{H}$ NMR $\left(500 \mathrm{MHz}, \mathrm{CDCl}_{3}\right) \delta 9.48(\mathrm{dd}, J=1.2,3.6 \mathrm{~Hz}, 1 \mathrm{H}), 7.60(\mathrm{~d}, J=3.7 \mathrm{~Hz}, 1 \mathrm{H}), 7.26-7.16(\mathrm{~m}, 5 \mathrm{H}), 5.40$ $(\mathrm{s}, 1 \mathrm{H}), 3.48(\mathrm{~d}, J=15.6 \mathrm{~Hz}, 1 \mathrm{H}), 3.45(\mathrm{~d}, J=15.6 \mathrm{~Hz}, 1 \mathrm{H}), 2.75(\mathrm{dd}, J=3.6,15.4 \mathrm{~Hz}, 1 \mathrm{H}), 2.71$ (dd, $J=1.1$, $15.4 \mathrm{~Hz}, 1 \mathrm{H}$ ), 2.07 (app sept., $J=6.8 \mathrm{~Hz}, 1 \mathrm{H}$ ), 0.91 (d, $J=6.8 \mathrm{~Hz}, 3 \mathrm{H}), 0.82\left(\mathrm{~d}, J=6.8 \mathrm{~Hz}, 3 \mathrm{H}\right.$ ); ${ }^{13} \mathrm{C} \mathrm{NMR}$ $\left(125 \mathrm{MHz}, \mathrm{CDCl}_{3}\right) \delta 203.1,199.6,161.7,140.4,128.5,128.5,126.1,114.8,70.1,48.1,33.9,28.3,17.0,16.1$; high resolution mass spectrum (ES, Na) $m / z 258.1497$ [(M+H) ${ }^{+}$, calcd for $\left.\mathrm{C}_{16} \mathrm{H}_{20} \mathrm{NO}_{2}: 258.1494\right]$. 


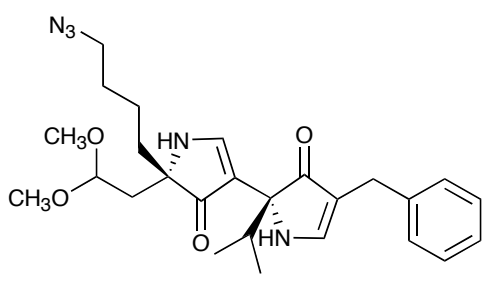

$(+)-6$

Bispyrrolinone (+)-6. To a solution of (-)-B $(1.10 \mathrm{~g}, 4.01 \mathrm{mmol})$ in benzene $(40 \mathrm{~mL})$ was added (-)-S1 (1.14 $\mathrm{g}, 4.43 \mathrm{mmol}$ ), and the solution was heated to $60^{\circ} \mathrm{C}$ for $2 \mathrm{~h}$. The solution was concentrated in vacuo, followed by azeotropic dehydration with toluene $(5 \times 50 \mathrm{~mL})$. The resultant oil was subjected to high vacuum for $1 \mathrm{~h}$ and then was dissolved in THF (40 mL). $0.5 \mathrm{M} \mathrm{KHMDS} \mathrm{in} \mathrm{toluene}(40.1 \mathrm{~mL}, 20.05 \mathrm{mmol})$ was added dropwise rapidly at room temperature. The reaction mixture was stirred for another $15 \mathrm{~min}$, and quenched with $10 \%$ aqueous $\mathrm{NaHSO}_{4}(100 \mathrm{~mL})$. The organic layer was then washed with saturated aqueous $\mathrm{NaHCO}_{3}$ and brine $(100 \mathrm{~mL}$ each), dried over anhydrous $\mathrm{MgSO}_{4}$, concentrated in vacuo, and purified by flash chromatography using ethyl acetate-hexanes $(60: 40-80: 20)$ as eluent to give $(+)-6(1.50 \mathrm{~g}, 79 \%$ yield $)$ as a pale yellow foam: $[\alpha]^{23}+104.4$ (c 0.525, $\left.\mathrm{CHCl}_{3}\right)$; IR $\left(\mathrm{CHCl}_{3}\right) 3440$ (w), 3010 (s), 2100 (s), 1730 (m), 1645 (s), 1580 (s), 1440 (m), 1205 (s), 1040 (s), 710 (s) $\mathrm{cm}^{-1} ;{ }^{1} \mathrm{H}$ NMR (500 MHz, $\mathrm{CDCl}_{3}$ ) $\delta 8.40(\mathrm{~d}, J=4.1 \mathrm{~Hz}, 1 \mathrm{H}), 7.22(\mathrm{~m}, 2 \mathrm{H}), 7.13(\mathrm{~m}, 3 \mathrm{H}), 7.06(\mathrm{~s}, 1$ H), $6.06(\mathrm{~d}, J=3.5 \mathrm{~Hz}, 1 \mathrm{H}), 4.37$ (dd, $J=3.8,7.6 \mathrm{~Hz}, 1 \mathrm{H}), 3.45(\mathrm{~d}, J=15.6 \mathrm{~Hz}, 1 \mathrm{H}), 3.38(\mathrm{~d}, J=15.7 \mathrm{~Hz}, 1$ H), 3.24 (s $3 \mathrm{H}$ ), 3.20 (m, $2 \mathrm{H}$ ), 3.19 (s, $3 \mathrm{H}), 2.01$ (app sept, J=6.8 Hz, $1 \mathrm{H}$ ), 1.82 (dd, J=3.8, $14.4 \mathrm{~Hz}, 1 \mathrm{H}$ ), $1.68(\mathrm{~m}, 3 \mathrm{H}), 1.54(\mathrm{~m}, 2 \mathrm{H}), 1.26(\mathrm{~m}, 1 \mathrm{H}), 1.19(\mathrm{~m}, 1 \mathrm{H}), 1.19(\mathrm{~m}, 1 \mathrm{H}), 0.91(\mathrm{~d}, J=6.9 \mathrm{~Hz}, 3 \mathrm{H}), 0.76(\mathrm{~d}, J=$ $6.9 \mathrm{~Hz}, 3 \mathrm{H}) ;{ }^{13} \mathrm{C}$ NMR $\left(125 \mathrm{MHz}, \mathrm{CDCl}_{3}\right) \delta$ 203.6, 203.1, 163.6, 162.2, 140.8, 128.4, 128.3, 125.8, 113.3, 109.2, $101.9,70.9,68.6,54.2,52.9,51.2,39.3,37.8,34.1,29.0,28.4,20.6,17.4,16.4$; high resolution mass spectrum (ESI, positive ion) $m / z 504.2599\left[(\mathrm{M}+\mathrm{Na})^{+}\right.$, calcd for $\left.\mathrm{C}_{26} \mathrm{H}_{35} \mathrm{~N}_{5} \mathrm{O}_{4} \mathrm{Na}: 504.2587\right]$

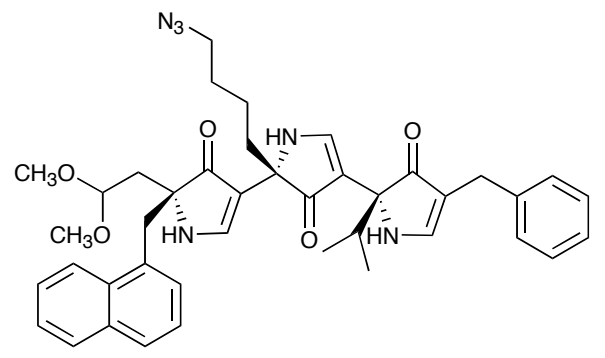

$(-)-7$

Trispyrrolinone (-)-7. To a solution of $(+)-6(420 \mathrm{mg}, 0.873 \mathrm{mmol})$ in THF $(13 \mathrm{~mL})$ was added freshly prepared, argon sparged aqueous $4 \mathrm{~N} \mathrm{HCl}(4.4 \mathrm{~mL})$ dropwise over $1 \mathrm{~min}$. The reaction was heated at $50^{\circ} \mathrm{C}$ for 1 h. The reaction was quenched by pouring directly into sat. aqueous $\mathrm{NaHCO}_{3}(20 \mathrm{~mL})$. The aqueous layer was then extracted with ethyl acetate $(3 \times 10 \mathrm{~mL})$. The organic layer was washed with sat. aqueous $\mathrm{NaHCO}_{3}(20$ $\mathrm{mL})$, brine $(20 \mathrm{~mL})$, dried over $\mathrm{MgSO}_{4}$, and concentrated in vacuo to provide the resulting aldehyde $6 \mathrm{~A}$ as a yellow oil. 
Amino ester (-)-C $\alpha$ (249 $\mathrm{mg}, 0.786 \mathrm{mmol}$ ) was added to a solution of aldehyde 6A (taken on directly from the previous reaction) in benzene $(10 \mathrm{~mL})$. The solution was concentrated in vacuo, and condensation was effected by azeotropic removal of water with toluene $(30 \times 10 \mathrm{~mL})$. The resultant oil was dissolved in THF (20 $\mathrm{mL})$ and added to a precooled $\left(0^{\circ} \mathrm{C}\right)$ solution of 18-crown-6 $(2.42 \mathrm{~g}, 9.17 \mathrm{mmol})$ in THF $(15 \mathrm{~mL})$ and $0.5 \mathrm{M}$ KHMDS in toluene $(17.5 \mathrm{~mL}, 8.73 \mathrm{mmol})$. The reaction was allowed to warm to room temp. After $5 \mathrm{~h}$ the reaction was quenched by addition of $10 \%$ aqueous $\mathrm{NaHSO}_{4}(30 \mathrm{~mL})$ and the layers were separated. The aqueous layer was extracted with ethyl acetate $(3 \times 20 \mathrm{~mL})$, and the combined organic layers were washed with sat. $\mathrm{NaHCO}_{3}$ (30 $\mathrm{mL})$, brine $(30 \mathrm{~mL})$, dried over $\mathrm{MgSO}_{4}$, and concentrated in vacuo. The resultant yellow oil was purified by flash chromatography using ethyl acetate : methylene chloride (35:65-50:50) as the eluent, to provide (-)-7 (229.2 mg, 37\% yield) as a yellow foam: : $[\alpha]_{\mathrm{D}}^{23}-61.2\left(c \mathrm{c} 0.15, \mathrm{CHCl}_{3}\right)$; IR (neat) 3313 (s, br), $3058(\mathrm{w}), 2935$ (s), 2098 (s), 1643 (s), 1569 (s), 1450 (m), 1261 (m), 1164 (s), $1056(\mathrm{~m}), 960$ (w), $783(\mathrm{~m}), 736(\mathrm{~m}) \mathrm{cm}^{-1} ;{ }^{1} \mathrm{H}$ $\operatorname{NMR}\left(500 \mathrm{MHz}, \mathrm{C}_{6} \mathrm{D}_{6}\right) \delta 8.25(\mathrm{~d}, J=4.1 \mathrm{~Hz}, 1 \mathrm{H}), 8.08(\mathrm{~d}, J=8.6 \mathrm{~Hz}, 1 \mathrm{H}), 7.64(\mathrm{~d}, J=7.8 \mathrm{~Hz}, 1 \mathrm{H}), 7.56(\mathrm{~d}, J=$ $7.8 \mathrm{~Hz}, 1 \mathrm{H}), 7.53(\mathrm{~d}, J=4.1 \mathrm{~Hz}, 1 \mathrm{H}), 7.35$ (ddd, 1.1, 6.7, 8.9 Hz, $1 \mathrm{H}), 7.27$ (ddd, J=1.1, 6.7, 8.2 Hz, $1 \mathrm{H}$ ), 7.23-7.20 (m, $2 \mathrm{H}), 7.18(\mathrm{~d}, J=7.8 \mathrm{~Hz}, 1 \mathrm{H}), 7.16$ (br s, $2 \mathrm{H}), 7.12(\mathrm{~s}, 2 \mathrm{H}), 7.11$ (s, br, $1 \mathrm{H}), 7.04-7.00(\mathrm{~m}, 2 \mathrm{H})$, $6.92(\mathrm{~d}, J=3.3 \mathrm{~Hz}, 1 \mathrm{H}), 5.15(\mathrm{~d}, J=4.1 \mathrm{~Hz}, 1 \mathrm{H}), 4.13(\mathrm{dd}, J=4.4,7.1 \mathrm{~Hz}, 1 \mathrm{H}), 3.47(\mathrm{~d}, J=15.3 \mathrm{~Hz}, 1 \mathrm{H})$, 3.39 (d, $J=13.8 \mathrm{~Hz}, 1 \mathrm{H}$ ), 3.29 (d, J=15.3 Hz, 1 H), 3.17 (d, J=13.8 Hz, 1 H), $2.95(\mathrm{~s}, 3 \mathrm{H}), 2.94(\mathrm{~s}, 3 \mathrm{H}), 2.58$ (ddd, $J=1.9,7.0,7.1 \mathrm{~Hz}, 1 \mathrm{H}$ ), 2.12 (app sept, $J=6.7 \mathrm{~Hz}, 1 \mathrm{H}$ ), 1.93 (dd, $J=7.1,14.1 \mathrm{~Hz}, 1 \mathrm{H}$ ), 1.89 (dd, $J=$ 4.5, $14.5 \mathrm{~Hz}, 1 \mathrm{H}$ ), 1.25 (ddd, $J=4.1,11.9,13.4 \mathrm{~Hz}, 1 \mathrm{H}), 1.15$ (ddd, $J=5.2,11.5,12.7 \mathrm{~Hz}, 1 \mathrm{H}), 1.10(\mathrm{~m}, 2 \mathrm{H})$, $1.02(\mathrm{~d}, J=6.7 \mathrm{~Hz}, 3 \mathrm{H}), 1.0-0.92(\mathrm{~m}, 1 \mathrm{H}), 0.91(\mathrm{~d}, J=6.7 \mathrm{~Hz}, 3 \mathrm{H}), 0.85-0.76(\mathrm{~m}, 1 \mathrm{H}) ;{ }^{13} \mathrm{C} \mathrm{NMR}(125 \mathrm{MHz}$, $\left.\mathrm{C}_{6} \mathrm{D}_{6}\right) \delta 203.3,202.3,202.1,162.8,162.7,159.4,141.5,134.2,133.3,132.0,129.0,128.8,128.7,128.5,128.3$, $127.9,126.0,125.7,125.1,124.9,113.9,109.5,108.3,102.1,70.7,69.0,67.8,53.9,52.7,50.9$, 39.2, 38.5, 38.0, 37.4, 28.92, 28.88, 20.7, 17.6, 16.7; high resolution mass spectrum (ESI, positive ion) $\mathrm{m} / \mathrm{z} 725.3399$ $\left[(\mathrm{M}+\mathrm{Na})^{+}\right.$, calcd for $\mathrm{C}_{41} \mathrm{H}_{46} \mathrm{~N}_{6} \mathrm{O}_{5} \mathrm{Na:}$ 725.3427].

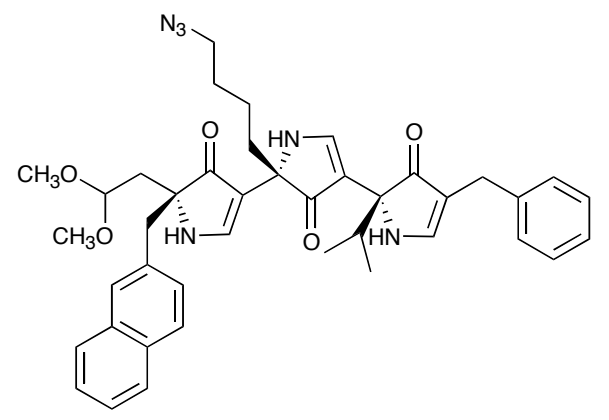

$(-)-8$

Trispyrrolinone (-)-8. To a solution of (+)-6 (289 $\mathrm{mg}, 0.60 \mathrm{mmol})$ in THF $(9 \mathrm{~mL})$ was added freshly prepared, argon sparged aqueous $4 \mathrm{~N} \mathrm{HCl}(3 \mathrm{~mL})$ dropwise over $1 \mathrm{~min}$. The reaction was heated at $45^{\circ} \mathrm{C}$ for $2.5 \mathrm{~h}$. The reaction was quenched by pouring directly into sat. aqueous $\mathrm{NaHCO}_{3}(20 \mathrm{~mL})$. The aqueous layer was then 
extracted with ethyl acetate $(3 \times 10 \mathrm{~mL})$. The organic layer was washed with brine $(20 \mathrm{~mL})$, dried over $\mathrm{MgSO}_{4}$, and concentrated in vacuo to provide the resulting aldehyde $6 \mathrm{~A}$ as a yellow oil.

Amino ester (-)-C $\beta$ (190 $\mathrm{mg}, 0.60 \mathrm{mmol}$ ) was added to a solution of aldehyde $\mathbf{6 A}$ (taken on directly from the previous reaction) in benzene $(20 \mathrm{~mL})$. The solution was concentrated in vacuo, and condensation was effected by azeotropic removal of water with benzene $(10 \times 20 \mathrm{~mL})$. The resultant oil was dissolved in THF (9 $\mathrm{mL})$ and added to a precooled $\left(0^{\circ} \mathrm{C}\right)$ solution of 18-crown-6 $(1.22 \mathrm{~g}, 4.63 \mathrm{mmol})$ in THF $(9 \mathrm{~mL})$ and $0.5 \mathrm{M}$ KHMDS in toluene $(9.0 \mathrm{~mL}, 4.50 \mathrm{mmol})$. The reaction was stirred at $0^{\circ} \mathrm{C}$ for $2 \mathrm{~h}$ before the addition of additional $0.5 \mathrm{M} \mathrm{KHMDS}$ in toluene ( $9 \mathrm{~mL}, 4.5 \mathrm{mmol}$ ) followed by warming to room temp. After an additional $15 \mathrm{~min}, 10 \%$ aqueous $\mathrm{NaHSO}_{4}(20 \mathrm{~mL})$ was added, and the layers were separated. The aqueous layer was extracted with ethyl acetate $(3 \times 20 \mathrm{~mL})$, and the combined organic layers were washed with sat. $\mathrm{NaHCO}_{3}(30 \mathrm{~mL})$, brine $(30$ $\mathrm{mL}$ ), dried over $\mathrm{MgSO}_{4}$, and concentrated in vacuo. The resultant yellow oil was purified by flash chromatography using neutral alumina (activity II) using ethyl acetate : methylene chloride (50:50-100:0) as the eluent, to provide (-)-8 (149.8 $\mathrm{mg}, 35 \%$ yield) as a yellow foam: $[\alpha]^{23}-56.08\left(c 0.79, \mathrm{CHCl}_{3}\right)$; IR (neat) 3307 (m, br), $2928(\mathrm{~m}), 2095$ (s), 1640 (s), 1573 (s), $1452(\mathrm{~m}), 1364$ (w), $1252(\mathrm{w}), 1159(\mathrm{~m}), 1053(\mathrm{w}), 955(\mathrm{w}), 700$ (m) $\mathrm{cm}^{-1} ;{ }^{1} \mathrm{H}$ NMR $\left(500 \mathrm{MHz}, \mathrm{CDCl}_{3}\right) \delta 8.38(\mathrm{~d}, J=4.1 \mathrm{~Hz}, 1 \mathrm{H}), 7.85(\mathrm{~d}, J=4.1 \mathrm{~Hz}, 1 \mathrm{H}), 7.78(\mathrm{~m}, 2 \mathrm{H}), 7.69(\mathrm{~d}$, $J=8.2 \mathrm{~Hz}, 1 \mathrm{H}), 7.61(\mathrm{~s}, 1 \mathrm{H}), 7.59(\mathrm{~d}, J=3.7 \mathrm{~Hz}, 1 \mathrm{H}), 7.46(\mathrm{~m}, 3 \mathrm{H}), 7.30(\mathrm{~d}, J=4.0 \mathrm{~Hz}, 1 \mathrm{H}), 7.30-7.22(\mathrm{~m}, 3$ H), 7.19-7.15 (m, 3 H), 7.05 (d, J=3.3 Hz, 1 H), 6.40 (d, J=3.3 Hz, 1 H), 4.48 (dd, J = 3.7, 7.8 Hz, 1 H), 3.46 (d, J=15.6 Hz, $1 \mathrm{H}), 3.33(\mathrm{~d}, J=15.6 \mathrm{~Hz}, 1 \mathrm{H}), 3.29$ (s, $3 \mathrm{H}), 3.25$ (s, $3 \mathrm{H}), 3.15(\mathrm{~d}, J=13.0 \mathrm{~Hz}, 1 \mathrm{H}), 3.09(\mathrm{~d}, J$ $=13.0 \mathrm{~Hz}, 1 \mathrm{H}), 2.77(\mathrm{~m}, 2 \mathrm{H}), 2.07$ (dd, $J=4.1,14.5 \mathrm{~Hz}, 1 \mathrm{H}), 1.99$ (app sept, $J=6.7 \mathrm{~Hz}, 1 \mathrm{H}), 1.91$ (dd, $J=$ 7.4, $14.5 \mathrm{~Hz}, 1 \mathrm{H}), 1.20-1.11(\mathrm{~m}, 1 \mathrm{H}), 1.08-0.93(\mathrm{~m}, 2 \mathrm{H}), 0.93-0.83(\mathrm{~m}, 1 \mathrm{H}), 0.88(\mathrm{~d}, J=6.7 \mathrm{~Hz}, 3 \mathrm{H}), 0.76(\mathrm{~d}$, $J=6.7 \mathrm{~Hz}, 3 \mathrm{H}), 0.73-0.63(\mathrm{~m}, 1 \mathrm{H}) ;{ }^{13} \mathrm{C}$ NMR $\left(125 \mathrm{MHz}, \mathrm{CDCl}_{3}\right) \delta 203.4,202.0,201.8,163.1,162.5,159.8$, 140.7, 133.0, 132.3, 132.1, 128.8, 128.4, 128.4, 128.3, 128.3, 127.5, 127.5, 127.1, 126.0, 125.8, 113.2, 109.4, 108.0, 102.1, 70.7, 69.1, 67.6, 54.6, 53.0, 50.5, 41.0, 38.9, 379, 37.3, 28.3, 28.2, 20.0, 17.2, 16.3; high resolution mass spectrum (ESI, positive ion) $\mathrm{m} / \mathrm{z} 725.3423\left[(\mathrm{M}+\mathrm{Na})^{+}\right.$, calcd for $\mathrm{C}_{41} \mathrm{H}_{46} \mathrm{~N}_{6} \mathrm{O}_{5} \mathrm{Na}$ : 725.3427]

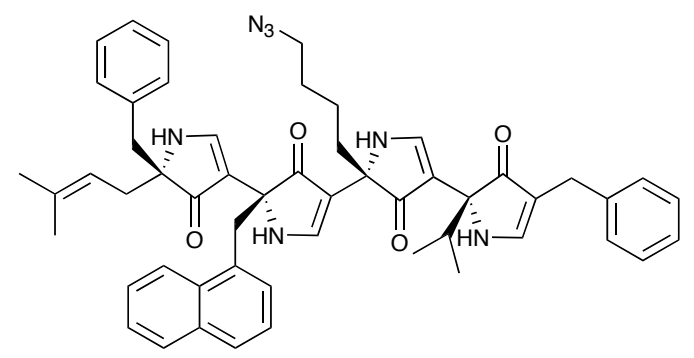

$(-)-\mathbf{S 2}$

Tetrapyrrolinone Azide (-)-S2. A solution of (-)-7 (117.2 $\mathrm{mg}, 0.167 \mathrm{mmol})$ in THF $(2.5 \mathrm{~mL})$ was added dropwise to freshly prepared, argon sparged aqueous $4 \mathrm{~N} \mathrm{HCl}(0.8 \mathrm{~mL})$ over $1 \mathrm{~min}$. The reaction was heated at $45^{\circ} \mathrm{C}$ for $2 \mathrm{~h}$. The reaction was quenched by pouring directly into sat. aqueous $\mathrm{NaHCO}_{3}(5 \mathrm{~mL})$. The aqueous 
layer was then extracted with ethyl acetate $(3 \times 10 \mathrm{~mL})$. The organic layer was washed with brine $(20 \mathrm{~mL})$, dried over $\mathrm{MgSO}_{4}$, and concentrated in vacuo to provide the resulting aldehyde 7A as a yellow oil.

Amino ester (-)-D (34 mg, $0.139 \mathrm{mmol}$ ) was added to a solution of aldehyde 7A (taken on directly from the previous reaction) in benzene $(10 \mathrm{~mL})$ and stirred at room temp. for $30 \mathrm{~min}$. The solution was concentrated in vacuo, and condensation was effected by azeotropic removal of water with toluene $(7 \times 10 \mathrm{~mL})$ and subjected to high vacuum overnight. The resultant oil was dissolved in THF (5 mL) and added to solution of 18-crown-6 $(0.441 \mathrm{~g}, 1.67 \mathrm{mmol})$ in THF $(5 \mathrm{~mL})$ and $0.5 \mathrm{M} \mathrm{KHMDS}$ in toluene $(3.34 \mathrm{~mL}, 1.67 \mathrm{mmol})$. After $4.5 \mathrm{~h}$ the reaction was quenched by addition of $10 \%$ aqueous $\mathrm{NaHSO}_{4}(10 \mathrm{~mL})$ and the layers were separated. The aqueous layer was extracted with ethyl acetate $(3 \times 20 \mathrm{~mL})$, and the combined organic layers were washed with sat. $\mathrm{NaHCO}_{3}$ $(30 \mathrm{~mL})$, brine $(30 \mathrm{~mL})$, dried over $\mathrm{MgSO}_{4}$, and concentrated in vacuo. The resultant yellow foam was purified by flash chromatography using methanol : methylene chloride $(2: 98-5: 95)$ as the eluent, to provide the tetrapyrrolinone azide (-)-S2 $\left(41.6 \mathrm{mg}, 29 \%\right.$ yield) as a yellow foam: $[\alpha]^{23}-22.69\left(c 0.26, \mathrm{CHCl}_{3}\right)$; IR (neat) 3282 (s, br), 2932 (m), 2095 (s), 1634 (s), 1565 (s), $1454(\mathrm{~m}), 1159$ (s), 938 (w), $837(\mathrm{w}), 783(\mathrm{~m}), 700(\mathrm{~m}) \mathrm{cm}^{-1}$; ${ }^{1} \mathrm{H}$ NMR $\left(500 \mathrm{MHz}, \mathrm{CD}_{2} \mathrm{Cl}_{2}\right) \delta 8.29(\mathrm{~d}, J=4.1 \mathrm{~Hz}, 1 \mathrm{H}), 8.25(\mathrm{~d}, J=8.9 \mathrm{~Hz}, 1 \mathrm{H}), 8.00(\mathrm{~d}, J=4.1 \mathrm{~Hz}, 1 \mathrm{H}), 7.82$ (d, $J=8.2 \mathrm{~Hz}, 1 \mathrm{H}), 7.73(\mathrm{~d}, J=8.2 \mathrm{~Hz}, 1 \mathrm{H}), 7.62(\mathrm{~d}, J=4.1 \mathrm{~Hz}, 1 \mathrm{H}), 7.60(\mathrm{~d}, J=3.0 \mathrm{~Hz}, 1 \mathrm{H}), 7.57$ (ddd, 1.1, 6.7, 7.8 Hz, $1 \mathrm{H}$ ), 7.48 (dd, J= 7.4, 7.4 Hz, 1 H), 7.31 (dd, J= 7.4, 7.4 Hz, 1 H), 7.27-7.17 (m, $10 \mathrm{H})$, 7.14-7.08 (m, 4 H), 6.04 (s, br, $1 \mathrm{H}), 4.92(\operatorname{app~t}, J=7.1 \mathrm{~Hz}, 1 \mathrm{H}), 3.46$ (d, $J=14.1 \mathrm{~Hz}, 1 \mathrm{H}), 3.39(\mathrm{~d}, J=15.6 \mathrm{~Hz}, 1 \mathrm{H})$, $3.23(\mathrm{~d}, J=15.6 \mathrm{~Hz}, 1 \mathrm{H}), 3.10(\mathrm{~d}, J=7.1 \mathrm{~Hz}, 1 \mathrm{H}), 3.08(\mathrm{~d}, J=7.1 \mathrm{~Hz}, 1 \mathrm{H}), 2.94(\mathrm{~d}, J=14.1 \mathrm{~Hz}, 1 \mathrm{H}), 2.88$ (d, $J=15.6 \mathrm{~Hz}, 1 \mathrm{H}$ ), $2.85(\mathrm{~d}, J=13.7 \mathrm{~Hz}, 1 \mathrm{H}), 2.30(\mathrm{~m} 2 \mathrm{H}), 1.93$ (app sept, $J=6.7 \mathrm{~Hz}, 1 \mathrm{H}), 1.54$ (s, $3 \mathrm{H}), 1.51$ (s, $3 \mathrm{H}), 1.38-1.22(\mathrm{~m}, 3 \mathrm{H}), 1.05-0.95(\mathrm{~m}, 2 \mathrm{H}), 0.86(\mathrm{~d}, J=6.7 \mathrm{~Hz}, 3 \mathrm{H}), 0.84-0.74(\mathrm{~m}, 1 \mathrm{H}), 0.72(\mathrm{~d}, J=6.7 \mathrm{~Hz}$, $3 \mathrm{H}) ;{ }^{13} \mathrm{C}$ NMR $\left(125 \mathrm{MHz}, \mathrm{CD}_{2} \mathrm{Cl}_{2}\right) \delta 203.8,203.3,202.0,201.2,163.8,162.1,160.3,160.1,141.3,136.5,135.7$, 133.9, 133.4, 132.0, 130.5, 128.8, 128.7, 128.6, 128.6, 128.3, 127.8, 127.2, 126.1, 125.6, 125.2, 125.1, 117.1, 113.0, 112.9, 109.5, 108.6, 108.1, 71.6, 70.9, 68.5, 67.8, 51.4, 41.4, 39.8, 38.3, 37.7, 34.8, 29.0, 28.7, 26.0, 20.6, 18.2, 17.5, 16.5; high resolution mass spectrum (ESI, positive ion) $\mathrm{m} / z 876.4276\left[(\mathrm{M}+\mathrm{Na})^{+}\right.$, calcd for $\left.\mathrm{C}_{53} \mathrm{H}_{55} \mathrm{~N}_{7} \mathrm{O}_{4} \mathrm{Na:} 876.4213\right]$

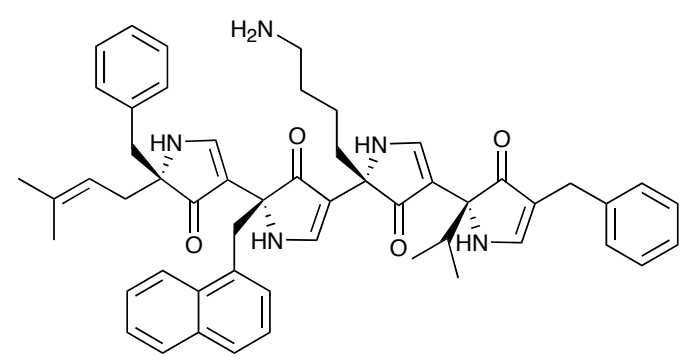

$(-)-1$

Tetrapyrrolinone SRIF Mimetic (-)-1. To a solution of azide (-)-S2 (41.6 mg, $0.0487 \mathrm{mmol})$ in THF (1 mL), was added $\mathrm{PPh}_{3}(64 \mathrm{mg}, 0.244 \mathrm{mmol})$ followed by $\mathrm{H}_{2} \mathrm{O}(50 \mu \mathrm{L})$. The resulting solution was heated at $60^{\circ} \mathrm{C}$ for 2 $\mathrm{h}$, then concentrated in vacuo, and purified by flash chromatography using methanol : methylene chloride (5:95- 
50:50) as eluent, to provide (-)-1 (24.5 mg, 61\% yield) as a colorless foam: $[\alpha]_{\mathrm{D}}^{23}-28.33\left(c 0.3, \mathrm{CH}_{2} \mathrm{Cl}_{2}\right) ; \mathrm{IR}$ (neat) 3296 (s, br), 2929 (m), 1634 (s), 1574 (s), 1494 (w), 1362 (w), 1160 (s), 942(w), 839 (w), 783 (m) cm ${ }^{-1} ;{ }^{1} \mathrm{H}$ $\operatorname{NMR}\left(500 \mathrm{MHz}, \mathrm{CD}_{2} \mathrm{Cl}_{2}\right) \delta 8.26(\mathrm{~d}, J=3.2 \mathrm{~Hz}, 1 \mathrm{H}), 8.23(\mathrm{~d}, J=8.5 \mathrm{~Hz}, 1 \mathrm{H}), 7.95(\mathrm{~d}, J=4.1 \mathrm{~Hz}, 1 \mathrm{H}), 7.80(\mathrm{~d}, J$ $=7.6 \mathrm{~Hz}, 1 \mathrm{H}), 7.70(\mathrm{~d}, J=8.1 \mathrm{~Hz}, 1 \mathrm{H}), 7.58-7.54(\mathrm{~m}, 3 \mathrm{H}), 7.45$ (ddd, $J=0.8,7.9,7.9 \mathrm{~Hz}, 1 \mathrm{H}), 7.29-7.24(\mathrm{~m}, 3$ H), 7.23-7.16 (m, 6 H), 7.13-7.09 (m, 4 H), $7.04(\mathrm{~d}, J=3.6 \mathrm{~Hz}, 1 \mathrm{H}), 5.69(\mathrm{~s}, \mathrm{br}, 1 \mathrm{H}), 4.89(\mathrm{~m}, 1 \mathrm{H}), 3.46(\mathrm{~d}, J=$ $13.9 \mathrm{~Hz}, 1 \mathrm{H}), 3.38$ (d, $J=15.6 \mathrm{~Hz}, 1 \mathrm{H}), 3.21(\mathrm{~d}, J=15.6 \mathrm{~Hz}, 1 \mathrm{H}), 2.90(\mathrm{~d}, J=13.9 \mathrm{~Hz}, 1 \mathrm{H}), 2.86(\mathrm{~d}, J=13.7$ $\mathrm{Hz}, 1 \mathrm{H}), 2.82(\mathrm{~d}, J=13.7 \mathrm{~Hz}, 1 \mathrm{H}), 2.47(\mathrm{t}, J=6.7 \mathrm{~Hz}, 1 \mathrm{H}), 2.28-2.26(\mathrm{~m}, 1 \mathrm{H}), 1.89$ (app sept, $J=6.7 \mathrm{~Hz}, 1$ $\mathrm{H}), 1.53(\mathrm{~s}, 3 \mathrm{H}), 1.50(\mathrm{~s}, 3 \mathrm{H}), 1.50-1.30(\mathrm{br}, 2 \mathrm{H}), 1.33-1.26(\mathrm{~m}, 2 \mathrm{H}), 1.2-1.14(\mathrm{~m}, 2 \mathrm{H}), 1.05-0.95(\mathrm{~m}, 3 \mathrm{H})$, $0.83(\mathrm{~d}, J=6.9 \mathrm{~Hz}, 3 \mathrm{H}), 0.78-0.75(\mathrm{~m}, 1 \mathrm{H}), 0.68(\mathrm{~d}, J=6.7 \mathrm{~Hz}, 3 \mathrm{H}) ;{ }^{13} \mathrm{C} \mathrm{NMR}\left(125 \mathrm{MHz}, \mathrm{CD}_{2} \mathrm{Cl}_{2}\right) \delta 203.8$, 203.3, 202.1, 201.3, 163.7, 162.0, 160.3, 160.1, 141.4, 136.5, 135.8, 133.9, 133.5, 132.0, 130.5, 128.8, 128.7, 128.6, 128.5, 128.3, 127.8, 127.2, 126.1, 126.0, 125.6, 125.2, 125.0, 117.1, 113.0, 109.7, 108.9, 108.0, 71.5, $70.9,68.4,68.1,42.1,41.4,39.8,38.3,38.1,34.7,28.7,28.7,26.0,20.7,18.2,17.5,16.5$; high resolution mass spectrum (ESI, positive ion) $m / z 828.4483\left[(\mathrm{M}+\mathrm{H})^{+}\right.$, calcd for $\left.\mathrm{C}_{53} \mathrm{H}_{58} \mathrm{~N}_{5} \mathrm{O}_{4}: 828.4489\right]$

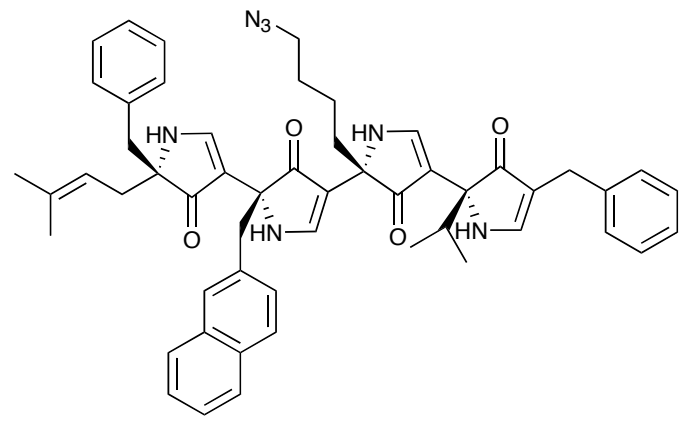

$(+)-$ S3

Tetrapyrrolinone Azide (+)-S3.To a solution of (-)-8 (134 mg, $0.191 \mathrm{mmol})$ in THF (3 mL) was added freshly prepared, argon sparged aqueous $4 \mathrm{~N} \mathrm{HCl}(1 \mathrm{~mL})$ dropwise over 1 min. The reaction was heated at $45^{\circ} \mathrm{C}$ for $4 \mathrm{~h}$. The reaction was quenched by pouring directly into sat. aqueous $\mathrm{NaHCO}_{3}(50 \mathrm{~mL})$. The aqueous layer was then extracted with ethyl acetate $(3 \times 10 \mathrm{~mL})$. The organic layer was washed brine $(20 \mathrm{~mL})$, dried over $\mathrm{MgSO}_{4}$, and concentrated in vacuo to provide the resulting aldehyde $\mathbf{8 A}$ as a yellow oil.

Amino ester (-)-D (45 mg, $0.191 \mathrm{mmol}$ ) was added to a solution of aldehyde 8A (taken on directly from the previous reaction) in benzene $(10 \mathrm{~mL})$ and stirred at room temp. for $30 \mathrm{~min}$. The solution was concentrated in vacuo, and condensation was effected by azeotropic removal of water with benzene $(8 \times 20 \mathrm{~mL})$ and subjected to high vacuum for $30 \mathrm{~min}$. The resultant oil was dissolved in THF ( $3 \mathrm{~mL})$ and added to a precooled $\left(0^{\circ} \mathrm{C}\right)$ solution of 18-crown-6 $(0.5 \mathrm{~g}, 1.91 \mathrm{mmol})$ in THF $(4 \mathrm{~mL})$ and $0.5 \mathrm{M} \mathrm{KHMDS}$ in toluene $(3.82 \mathrm{~mL}, 1.91$ $\mathrm{mmol})$. The reaction was allowed to warm to room temp. After $1 \mathrm{~h}$ additional KHMDS was added (3.81 $\mathrm{mL}, 1.91$ $\mathrm{mmol}$ ) followed $15 \mathrm{~min}$ later by the quenching the reaction $10 \%$ aqueous $\mathrm{NaHSO}_{4}(10 \mathrm{~mL})$. After separating the layers, the aqueous layer was extracted with ethyl acetate $(3 \times 20 \mathrm{~mL})$, and the combined organic layers were washed with sat. $\mathrm{NaHCO}_{3}(30 \mathrm{~mL})$, brine $(30 \mathrm{~mL})$, dried over $\mathrm{MgSO}_{4}$, and concentrated in vacuo. The resultant 
yellow foam was purified by flash chromatography on $\mathrm{NEt}_{3}$ buffered silica gel using ethyl acetate : methylene chloride (50:50-100:0) as the eluent, to provide the tetrapyrrolinone azide (+)-S3 (62.6 $\mathrm{mg}, 38 \%$ yield) as a pale yellow foam: $[\alpha]_{D}^{23}+13.89\left(c\right.$ 0.18, $\mathrm{CHCl}_{3}$ ); IR (neat) 3286 (s, br), 2932 (m), 2094 (s), 1634 (s), 1563 (s), 1453 (s), 1365 (w), 1250 (w), 1158 (s), 938 (w), 842 (w), 746 (w), $700(\mathrm{~m}) \mathrm{cm}^{-1} ;{ }^{1} \mathrm{H}$ NMR (500 MHz, CDCl $) \delta 8.33$ (d, J $=4.1 \mathrm{~Hz}, 1 \mathrm{H}), 8.01(\mathrm{~d}, J=4.1 \mathrm{~Hz}, 1 \mathrm{H}), 7.78(\mathrm{~d}, \mathrm{~J}=4.1 \mathrm{~Hz}, 1 \mathrm{H}), 7.76-7.71(\mathrm{~m}, 2 \mathrm{H}), 7.64(\mathrm{~d}, J=8.2 \mathrm{~Hz}, 1 \mathrm{H})$, $7.55(\mathrm{~d}, J=3.4 \mathrm{~Hz}, 1 \mathrm{H}), 7.50(\mathrm{~s}, 1 \mathrm{H}), 7.44-7.40(\mathrm{~m}, 3 \mathrm{H}), 7.25-7.14(\mathrm{~m}, 10 \mathrm{H}), 7.13-7.10(\mathrm{~m}, 2 \mathrm{H}), 7.06(\mathrm{~d}, J=$ 3.7 Hz, 1 H), $5.63(\mathrm{~d}, J=4.5 \mathrm{~Hz}, 1 \mathrm{H}), 4.95(\operatorname{app~t}, J=7.4 \mathrm{~Hz}, 1 \mathrm{H}), 3.43(\mathrm{~d}, J=15.6 \mathrm{~Hz}, 1 \mathrm{H}), 3.24(\mathrm{~d}, J=15.6$ Hz, 1 H), 3.04 (d, J=11.5 Hz, 1 H), 3.01 (d, J=11.5 Hz, 1 H), 2.89 (d, J=13.4 Hz, 1 H), 2.74-2.64 (m, 2 H), 2.61 (d, J = 13.4 Hz, $1 \mathrm{H}$ ), 2.32 (app d, $7.8 \mathrm{~Hz}, 2 \mathrm{H}$ ), 1.91 (app sept, J = 6.7 Hz, $1 \mathrm{H}$ ), 1.57 (s, $3 \mathrm{H}$ ), 1.55 (s, 3 H), 0.97-0.91 (m, $1 \mathrm{H}), 0.90-0.84(\mathrm{~m}, 2 \mathrm{H}), 0.82(\mathrm{~d}, J=6.7 \mathrm{~Hz}, 3 \mathrm{H}), 0.80-0.70(\mathrm{~m}, 2 \mathrm{H}), 0.69(\mathrm{~d}, J=6.7 \mathrm{~Hz}, 3$ $\mathrm{H}), 0.60-0.54(\mathrm{~m}, 1 \mathrm{H}) ;{ }^{13} \mathrm{C} \mathrm{NMR}\left(125 \mathrm{MHz}, \mathrm{CDCl}_{3}\right) \delta 204.0,203.0,201.7,200.9,163.6,162.2,160.3,159.9$, 140.6, 136.6, 134.9, 133.0, 132.4, 132.4, 130.4, 128.9, 128.7, 128.5, 128.3, 128.1, 127.6, 127.5, 127.1, 127.0, 126.0, 125.9, 125.7, 116.7, 113.3, 109.3, 108.8, 108.0, 71.4, 70.9, 68.1, 67.6, 50.6, 44.0, 41.2, 38.4, 37.5, 34.5, 28.4, 28.2, 25.9, 20.0, 18.3, 17.3, 16.3; high resolution mass spectrum (ESI, positive ion) $\mathrm{m} / \mathrm{z} 876.4197$ $\left[(\mathrm{M}+\mathrm{Na})^{+}\right.$, calcd for $\mathrm{C}_{53} \mathrm{H}_{55} \mathrm{~N}_{7} \mathrm{O}_{4} \mathrm{Na:}$ 876.4213]

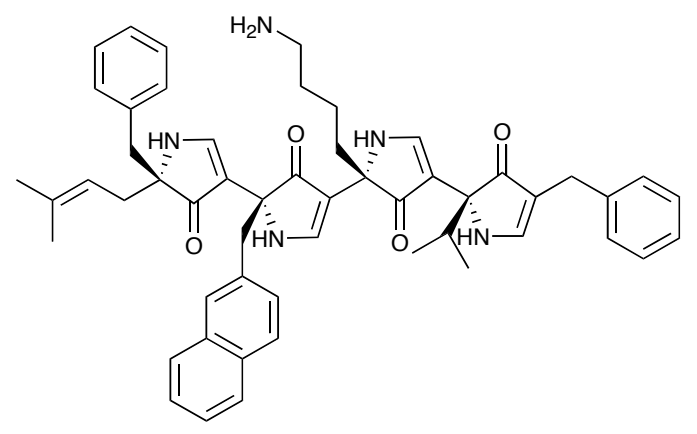

$(+)-2$

Tetrapyrrolinone SRIF Mimetic (+)-2. To a solution of azide (+)-S3 (13 mg, $0.0152 \mathrm{mmol})$ in THF $(0.3 \mathrm{~mL})$, was added $\mathrm{PPh}_{3}(20 \mathrm{mg}, 0.0761 \mathrm{mmol})$ followed by $\mathrm{H}_{2} \mathrm{O}(15 \mu \mathrm{L})$. The resulting solution was heated at $55^{\circ} \mathrm{C}$ for 3 $\mathrm{h}$, then concentrated in vacuo. The resultant solid was dissolved in acetonitrile $(5 \mathrm{~mL})$ and washed with heptane $(3 \times 5 \mathrm{~mL})$ to remove the excess $\mathrm{PPh}_{3}$. The acetonitrile layer was concentrated in vacuo and purified by flash chromatography using methanol : methylene chloride (10:90-30:70) as eluent, to provide (+)-2 (8.5 mg, 67\% yield) as a tan foam: $[\alpha]_{D}^{23}+51.53\left(c 0.59, \mathrm{CH}_{2} \mathrm{Cl}_{2}\right)$; IR (neat) $3298(\mathrm{~m}, \mathrm{br}), 2925(\mathrm{~m}), 1635(\mathrm{~s}), 1568(\mathrm{~m}), 1452$

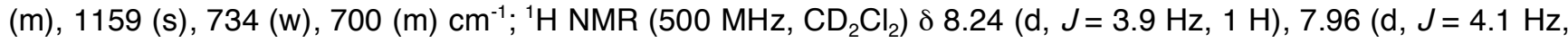
$1 \mathrm{H}), 7.75(\mathrm{~m}, 3 \mathrm{H}), 7.66(\mathrm{~d}, J=8.4 \mathrm{~Hz}, 1 \mathrm{H}), 7.58(\mathrm{~d}, J=3.7 \mathrm{~Hz}, 1 \mathrm{H}), 7.42(\mathrm{~m}, 2 \mathrm{H}), 7.33(\mathrm{~d}, J=3.9 \mathrm{~Hz}, 1 \mathrm{H})$, 7.27-7.16 (m, 9 H), $7.11(\mathrm{~m}, 2 \mathrm{H}), 7.03(\mathrm{~d}, J=3.6 \mathrm{~Hz}, 1 \mathrm{H}), 5.66(\mathrm{~d}, J=3.9 \mathrm{~Hz}, 1 \mathrm{H}), 4.92(\mathrm{t}, J=6.1 \mathrm{~Hz}, 1 \mathrm{H})$, 3.39 (d, $J=15.6 \mathrm{~Hz}, 1 \mathrm{H}$ ), $3.23(\mathrm{~d}, J=15.6 \mathrm{~Hz}, 1 \mathrm{H}$ ), 3.01 (dd, $J=12.7,13.1 \mathrm{~Hz}, 2 \mathrm{H}), 2.87$ (d, J = $13.5 \mathrm{~Hz}, 1$ H), $2.64(\mathrm{~d}, J=13.5 \mathrm{~Hz}, 1 \mathrm{H}$ ), 2.29 (d, $7.75 \mathrm{~Hz}, 2 \mathrm{H}$ ), $2.2(\mathrm{~m}, 2 \mathrm{H}), 1.88$ (app sept, $J=6.7 \mathrm{~Hz}, 1 \mathrm{H}$ ), 1.54 (s, 3 H), $1.54(\mathrm{~s}, 3 \mathrm{H}), 1.50-1.20(\mathrm{br}, 2 \mathrm{H}), 1.19(\mathrm{~m}, 2 \mathrm{H}), 0.92-0.70(\mathrm{~m}, 4 \mathrm{H}), 0.82(\mathrm{~d}, J=6.9 \mathrm{~Hz}, 3 \mathrm{H}), 0.68(\mathrm{~d}, J=6.6$ 
$\mathrm{Hz}, 3 \mathrm{H}), 0.65-0.58$ (m, $2 \mathrm{H}) ;{ }^{13} \mathrm{C}$ NMR $\left(125 \mathrm{MHz}, \mathrm{CDCl}_{3}\right.$ ) $\delta$ 204.0, 203.0, 201.9, 200.9, 163.6, 162.0, 160.3, $159.9,140.6,136.6,134.9,133.0,134.4,132.3,130.0,128.9,128.7,128.5128 .3,128.1,127.7,127.5,127.1$, 127.0, 125.8, 125.8, 125.5, 116.7, 113.3, 109.3, 109.0, 107.9, 71.4, 70.9, 68.0, 67.9, 44.0, 41.5, 41.2, 38.3, $37.9,34.4,33.3,28.4,25.9,20.1,18.2,17.3,16.3$; high resolution mass spectrum (ESI, positive ion) $\mathrm{m} / \mathrm{z}$ 828.4461 $\left[(\mathrm{M}+\mathrm{H})^{+}\right.$, calcd for $\mathrm{C}_{53} \mathrm{H}_{58} \mathrm{~N}_{5} \mathrm{O}_{4}:$ : 828.4489]

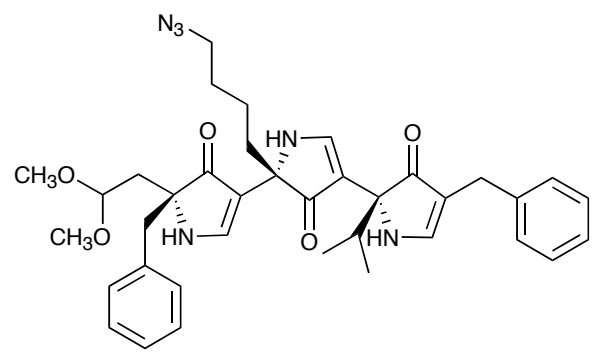

$(-)-9$

Trispyrrolinone (-)-9. A solution of bispyrrolinone aldehyde 6A (769 mg, $1.766 \mathrm{mmol}$ ) and amino ester (-)-C $(450 \mathrm{mg}, 1.682 \mathrm{mmol})$ in benzene $(20 \mathrm{~mL})$ was stirred at $40{ }^{\circ} \mathrm{C}$ for $2 \mathrm{~h}$, and then the solvent was evaporated in vacuo. The residue was azeotropically dehydrated with benzene $(6 \times 10 \mathrm{~mL})$ and then stored for $1 \mathrm{~h}$ under high vacuum. The resulting crude imine was dissolved in THF $(20 \mathrm{~mL})$ and treated at room temperature with a $0.5 \mathrm{M}$ solution of KHMDS in toluene $(21.20 \mathrm{~mL}, 10.59 \mathrm{mmol})$. The reaction mixture was stirred for additional $20 \mathrm{~min}$, then quenched with saturated aqueous $\mathrm{NH}_{4} \mathrm{Cl}(5 \mathrm{~mL})$ and diluted with EtOAc $(50 \mathrm{~mL})$. The organic layer was separated, washed with $10 \%$ aqueous $\mathrm{NaHSO}_{4}, 10 \%$ aqueous $\mathrm{NaHCO}_{3}$, and brine $(20 \mathrm{~mL}$ each), dried over $\mathrm{Na}_{2} \mathrm{SO}_{4}$, and concentrated in vacuo. The crude product was purified by flash chromatography using ethyl acetate-hexanes (gradient from 1:1 to 4:1) as eluant to afford trispyrrolinone (-)-9 as a colorless oil (210 mg, 19\% yield). [ $\alpha]_{\mathrm{D}}^{23}-79.7\left(\mathrm{c} 0.36, \mathrm{CHCl}_{3}\right)$; IR (neat) $3291(\mathrm{~s}), 3064(\mathrm{w}), 2930(\mathrm{~s}), 2872(\mathrm{w}), 2094(\mathrm{~m}), 1636(\mathrm{~s})$, 1569 (s), $1453(\mathrm{~m}), 1159(\mathrm{~m}) \mathrm{cm}^{-1} ;{ }^{1} \mathrm{H}$ NMR $\left(500 \mathrm{MHz}, \mathrm{CDCl}_{3}\right) \delta 8.38(\mathrm{~d}, J=4.0 \mathrm{~Hz}, 1 \mathrm{H}), 7.86(\mathrm{~d}, J=4.0 \mathrm{~Hz}, 1$ H), $7.59(\mathrm{~d}, J=3.7 \mathrm{~Hz}, 1 \mathrm{H}), 7.10-7.30(11 \mathrm{H}), 7.01(\mathrm{~d}, J=4.0 \mathrm{~Hz}, 1 \mathrm{H}), 5.99(\mathrm{~d}, J=4.0 \mathrm{~Hz}, 1 \mathrm{H}), 4.40(\mathrm{dd}, J=$ 7.6, 3.8 Hz, $1 \mathrm{H}$ ), 3.44 (d, J=15.7 Hz, $1 \mathrm{H}$ ), $3.32(\mathrm{~d}, J=15.7 \mathrm{~Hz}, 1 \mathrm{H}), 3.26(\mathrm{~s}, 3 \mathrm{H}), 3.21(\mathrm{~s}, 3 \mathrm{H}), 3.13$ (app t, $J$ = 7.1 Hz, $2 \mathrm{H}), 2.94(\mathrm{~d}, J=13.3 \mathrm{~Hz}, 1 \mathrm{H}), 2.89(\mathrm{~d}, J=13.3 \mathrm{~Hz}, 1 \mathrm{H}), 1.95-2.05(2 \mathrm{H}), 1.82(\mathrm{dd}, J=14.5,7.6 \mathrm{~Hz}$, $1 \mathrm{H}), 1.45-1.35(3 \mathrm{H}), 1.22(\mathrm{~m}, 1 \mathrm{H}), 1.08(\mathrm{~m}, 1 \mathrm{H}), 0.95(\mathrm{~m}, 1 \mathrm{H}), 0.89(\mathrm{~d}, J=6.9 \mathrm{~Hz}, 3 \mathrm{H}), 0.75(\mathrm{~d}, J=6.7 \mathrm{~Hz}, 3$ $\mathrm{H}) ;{ }^{13} \mathrm{C}$ NMR $\left(125 \mathrm{MHz}, \mathrm{CDCl}_{3}\right) \delta 203.6,202.2,201.9,163.2,162.6,159.8,140.8,134.7,130.2,128.5,128.3$, 128.0, 127.0, 125.9, 113.5, 109.6, 108.3, 102.1, 70.8, 68.8, 67.8, 64.7, 53.1, 51.1, 40.9, 38.7, 38.0, 37.5, 28.7, 28.5, 20.4, 17.4, 16.4; high resolution mass spectrum (ESI positive ion) $\mathrm{m} / z 675.3289\left[(\mathrm{M}+\mathrm{Na})^{+}\right.$; calcd for $\left.\mathrm{C}_{37} \mathrm{H}_{44} \mathrm{O}_{5} \mathrm{~N}_{6} \mathrm{Na:} 675.3270\right]$. 


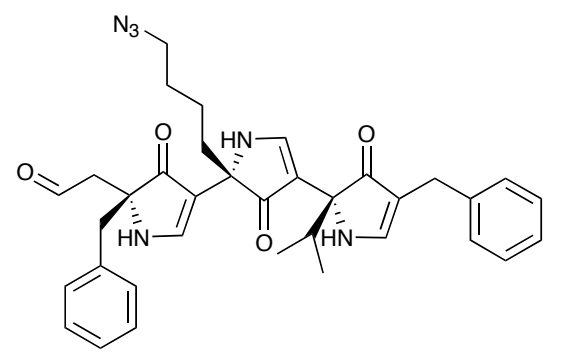

$(-)-S 4$

Trispyrrolinone (-)-S4. To a solution of dimethyl acetal (-)-9 (200 mg, $0.307 \mathrm{mmol})$ in THF (23 mL) was added aqueous $4 \mathrm{~N} \mathrm{HCl}(7 \mathrm{~mL})$, and the reaction mixture was stirred at room temperature for $8 \mathrm{~h}$. EtOAc $(40 \mathrm{~mL})$ was added, followed by solid $\mathrm{NaHCO}_{3}(2.5 \mathrm{~g})$. The organic layer was separated and the aqueous phase was further extracted with EtOAc $(2 \times 20 \mathrm{~mL})$. The combined organic extracts were washed with $10 \%$ aqueous $\mathrm{NaHCO}_{3}$ and brine (10 $\mathrm{mL}$ each), dried over $\mathrm{Na}_{2} \mathrm{SO}_{4}$, and concentrated in vacuo. The crude product was purified by flash chromatography using $2 \%$ methanol in dichloromethane as eluant to afford trispyrrolinone (-)-S4 as a colorless oil (166 mg, 89\% yield). [ $\alpha]_{\mathrm{D}}^{23}-69.8\left(c 0.48, \mathrm{CHCl}_{3}\right)$; IR (neat) $3298(\mathrm{~s}), 3028(\mathrm{w}), 2926(\mathrm{~s}), 2854(\mathrm{~m}), 2095(\mathrm{~s})$, 1723 (s), 1644 (s), 1568 (s), 1495 (w), 1455 (m), 1160 (s) cm "-1 ; H NMR (500 MHz, CDCl $) \delta 9.66$ (d, J=1.5 Hz, $1 \mathrm{H}), 8.39(\mathrm{~d}, J=4.1 \mathrm{~Hz}, 1 \mathrm{H}), 7.85(\mathrm{~d}, J=4.1 \mathrm{~Hz}, 1 \mathrm{H}), 7.61(\mathrm{~d}, J=3.7 \mathrm{~Hz}, 1 \mathrm{H}), 7.26-7.10(11 \mathrm{H}), 6.98(\mathrm{~d}, J=$ $3.6 \mathrm{~Hz}, 1 \mathrm{H}), 6.31(\mathrm{~d}, J=4.0 \mathrm{~Hz}, 1 \mathrm{H}), 3.46(\mathrm{~d}, J=15.7 \mathrm{~Hz}, 1 \mathrm{H}), 3.36(\mathrm{~d}, J=15.7 \mathrm{~Hz}, 1 \mathrm{H}), 3.14(\mathrm{~d}, J=7.0 \mathrm{~Hz}$, $2 \mathrm{H}$ ), $3.10(\mathrm{~d}, J=13.4 \mathrm{~Hz}, 1 \mathrm{H}), 2.96(\mathrm{~d}, J=13.4 \mathrm{~Hz}, 1 \mathrm{H}), 2.96(\mathrm{dd}, J=18.0,1.5 \mathrm{~Hz}, 1 \mathrm{H}), 2.54(\mathrm{~d}, J=18.0 \mathrm{~Hz}$, $1 \mathrm{H}$ ), 1.99 (app sept, $J=6.7 \mathrm{~Hz}, 1 \mathrm{H}$ ), 1.48 (td, $J=13.0,4.1 \mathrm{~Hz}, 1 \mathrm{H}$ ), 1.42 (quintet, $J=7.3 \mathrm{~Hz}, 2 \mathrm{H}$ ), 1.25 (td, $J$ $=13.3,4.7 \mathrm{~Hz}, 1 \mathrm{H}), 1.23(\mathrm{~m}, 1 \mathrm{H}), 0.94(\mathrm{~m}, 1 \mathrm{H}), 0.90(\mathrm{~d}, J=6.9 \mathrm{~Hz}, 3 \mathrm{H}), 0.75(\mathrm{~d}, J=6.7 \mathrm{~Hz}, 3 \mathrm{H}) ;{ }^{13} \mathrm{C} \mathrm{NMR}$ $\left(125 \mathrm{MHz}, \mathrm{CDCl}_{3}\right) \delta$ 203.6, 201.7, 201.1, 199.7, 163.3, 162.5, 160.9, 140.9, 134.1, 130.1, 128.5, 128.3, 128.2, 127.3, 125.9, 113.4, 108.9, 108.2, 70.7, 68.0, 67.5, 51.1, 48.1, 40.9, 38.0, 37.6, 28.7, 28.4, 20.4, 17.3, 16.4; high resolution mass spectrum (ESI positive ion) $\mathrm{m} / \mathrm{z} 629.2858\left[(\mathrm{M}+\mathrm{Na})^{+}\right.$; calcd for $\mathrm{C}_{33} \mathrm{H}_{38} \mathrm{O}_{4} \mathrm{~N}_{6} \mathrm{Na:}$ 629.2852].

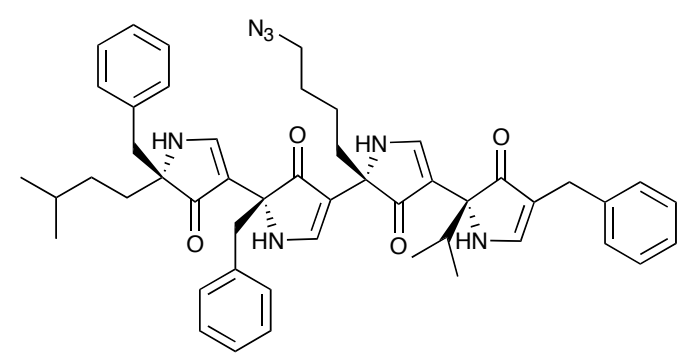

(+)-S5

Tetrapyrrolinone (+)-S5. A solution of aldehyde (-)-S4 $(83 \mathrm{mg}, 0.137 \mathrm{mmol})$ and aminoester (+)-10 (31 mg, $0.124 \mathrm{mmol}$ ) in benzene $(5 \mathrm{~mL})$ was stirred at $40^{\circ} \mathrm{C}$ for $2 \mathrm{~h}$. The solvent was evaporated in vacuo. The residue was azeotropically dehydrated with benzene $(7 \times 1 \mathrm{~mL})$ and then stored for $1 \mathrm{~h}$ under high vacuum. The resulting crude imine was dissolved in THF $(10 \mathrm{~mL})$ and treated at room temperature with a $0.5 \mathrm{M}$ solution of 
KHMDS in toluene $(1.74 \mathrm{~mL}, 0.870 \mathrm{mmol})$. The reaction mixture was stirred for additional 15 min, then quenched with saturated aqueous $\mathrm{NH}_{4} \mathrm{Cl}(1 \mathrm{~mL})$ and diluted with EtOAc $(20 \mathrm{~mL})$. The organic layer was separated, washed with $10 \%$ aqueous $\mathrm{NaHSO}_{4}, 10 \%$ aqueous $\mathrm{NaHCO}_{3}$, and brine $(5 \mathrm{~mL}$ each), dried over $\mathrm{Na}_{2} \mathrm{SO}_{4}$, and concentrated in vacuo. The crude product was purified by flash chromatography using $2 \%$ methanol in dichloromethane as eluant to afford tetrapyrrolinone (+)-S5 as a white solid (38 $\mathrm{mg}, 38 \%$ yield). m.p. 204-205 ${ }^{\circ} \mathrm{C},[\alpha]^{23} \mathrm{D}+10.6\left(c 0.44, \mathrm{CHCl}_{3}\right)$; IR (neat) 3296 (s), $3062(w), 3028(w), 2955(\mathrm{~m}), 2870(w), 2095$ (s), 1638 (s), 1568 (s), 1495 (w), 1454 (m), 1435 (m), 1158 (s) cm ; ; H NMR (500 MHz, MeOH-d 4 ) 88.07 (s, 1 H), $7.78(\mathrm{~s}, 1 \mathrm{H}), 7.77(\mathrm{~s}, 1 \mathrm{H}), 7.56(\mathrm{~s}, 1 \mathrm{H}), 7.10-6.90(15 \mathrm{H}), 3.31(\mathrm{~d}, J=15.7 \mathrm{~Hz}, 1 \mathrm{H}), 3.22(\mathrm{~d}, J=15.7 \mathrm{~Hz}, 1$ H), $3.06(\mathrm{t}, J=7.6 \mathrm{~Hz}, 2 \mathrm{H}), 2.97(\mathrm{~d}, J=13.4 \mathrm{~Hz}, 1 \mathrm{H}), 2.89(\mathrm{~d}, J=13.3 \mathrm{~Hz}, 1 \mathrm{H}), 2.78(\mathrm{~d}, J=13.3 \mathrm{~Hz}, 1 \mathrm{H})$, $2.28(\mathrm{~d}, J=13.4 \mathrm{~Hz}, 1 \mathrm{H}$ ), 2.07 (app sept, $J=6.9 \mathrm{~Hz}, 1 \mathrm{H}$ ), 1.70-1.50 (3 H), 1.35-1.20 (3 H), 1.05-0.80 (5 H), $0.78(\mathrm{~d}, J=6.9 \mathrm{~Hz}, 3 \mathrm{H}), 0.70(\mathrm{~d}, J=7.0 \mathrm{~Hz}, 3 \mathrm{H}), 0.68(\mathrm{~d}, J=7.0 \mathrm{~Hz}, 3 \mathrm{H}), 0.63(\mathrm{~d}, J=6.7 \mathrm{~Hz}, 3 \mathrm{H}) ;{ }^{13} \mathrm{C} \mathrm{NMR}$ $\left(125 \mathrm{MHz}, \mathrm{CDCl}_{3}\right) \delta 204.1,203.1,201.8,200.9,163.8,162.3,160.1,160.1,140.5,134.9,134.8,130.6,130.4$, 130.0, 128.5, 128.3, 128.1, 127.7, 127.1, 125.9, 113.2, 108.8, 108.5, 108.0, 71.2, 71.0, 67.9, 67.7, 51.0, 44.0, 42.2, 38.3, 37.7, 33.8, 32.0, 28.7, 28.5, 28.1, 22.5, 22.3, 20.3, 17.3, 16.3; high resolution mass spectrum (ESI positive ion) $\mathrm{m} / \mathrm{z} 828.4225\left[(\mathrm{M}+\mathrm{Na})^{+}\right.$; calcd for $\mathrm{C}_{49} \mathrm{H}_{55} \mathrm{O}_{4} \mathrm{~N}_{7} \mathrm{Na}$ : 828.4213].

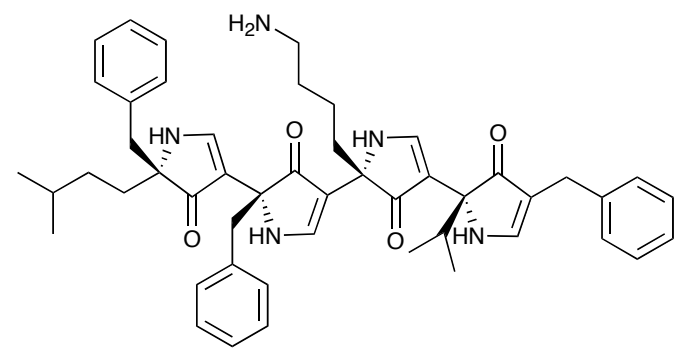

$(+)-3$

Tetrapyrrolinone (+)-3. To a solution of azide (+)-S5 (38 mg, $0.047 \mathrm{mmol})$ in methanol $(5 \mathrm{~mL})$ was added $10 \%$ wt Pd on carbon (13 mg). The mixtured was briefly evacuated and opened to argon three times, then evacuated again and opened to hydrogen (1atm). After stirring at room temperature for $5 \mathrm{~h}$, the reaction mixture was filtered through Celite, and concentrated in vacuo. The crude residue was subjected to preparative TLC (30\% methanol in dichloromethane) to provide pure tetrapyrrolinone (+)-3 as a white solid (21 $\mathrm{mg}, 57 \%$ yield). m.p. 173-174 ${ }^{\circ} \mathrm{C},[\alpha]_{\mathrm{D}}^{23}+28.5(\mathrm{c} 0.26, \mathrm{MeOH})$; IR (neat) 3290 (s), 2956 (s), $2666(\mathrm{~m}), 1635$ (s), $1568(\mathrm{~s}), 1455(\mathrm{~m})$, $1162(\mathrm{~m}) \mathrm{cm}^{-1} ;{ }^{1} \mathrm{H}$ NMR $\left(500 \mathrm{MHz}, \mathrm{MeOH}-\mathrm{d}_{4}\right) \delta 7.99(\mathrm{~s}, 1 \mathrm{H}), 7.81(\mathrm{~s}, 1 \mathrm{H}), 7.77(\mathrm{~s}, 1 \mathrm{H}), 7.56(\mathrm{~s}, 1 \mathrm{H}), 7.10-6.90$ (15 H), $3.31(\mathrm{~d}, J=15.7 \mathrm{~Hz}, 1 \mathrm{H}), 3.23(\mathrm{~d}, J=15.7 \mathrm{~Hz}, 1 \mathrm{H}), 3.00(\mathrm{~d}, J=13.4 \mathrm{~Hz}, 1 \mathrm{H}), 2.89(\mathrm{~d}, J=13.3 \mathrm{~Hz}, 1$ H), $2.78(\mathrm{~d}, J=13.3 \mathrm{~Hz}, 1 \mathrm{H}), 2.57(\mathrm{~m}, 2 \mathrm{H}), 2.28(\mathrm{~d}, J=13.4 \mathrm{~Hz}, 1 \mathrm{H}), 2.23$ (app sept, $J=6.8 \mathrm{~Hz}, 1 \mathrm{H}$ ), 1.70$1.50(3 \mathrm{H}), 1.25-1.35(3 \mathrm{H}), 1.05(\mathrm{~m}, 1 \mathrm{H}), 1.00-0.65(4 \mathrm{H}), 0.77(\mathrm{~d}, J=6.8 \mathrm{~Hz}, 3 \mathrm{H}), 0.70(\mathrm{~d}, J=6.7 \mathrm{~Hz}, 3 \mathrm{H})$, $0.69(\mathrm{~d}, J=6.7 \mathrm{~Hz}, 3 \mathrm{H}), 0.62(\mathrm{~d}, J=6.8 \mathrm{~Hz}, 3 \mathrm{H}) ;{ }^{13} \mathrm{C} \mathrm{NMR}\left(125 \mathrm{MHz}, \mathrm{CDCl}_{3}\right) \delta$ 204.9, 204.4, 202.2, 201.5, $166.7,164.1$, 163.0, 162.1, 142.4, 136.5, 136.4, 131.5, 131.2, 129.3, 129.2, 128.8, 128.6, 127.8, 127.7, 126.9, 
111.8, 109.3, 109.0, 108.0, 73.3, 72.8, 69.6, 69.3, 43.7, 42.9, 40.6, 36.4, 35.7, 35.5, 33.0, 29.4, 29.3, 29.0, 23.0, $22.8,21.1,18.1,16.5$; high resolution mass spectrum (ESI positive ion) $\mathrm{m} / \mathrm{z} 7804488\left[(\mathrm{M}+\mathrm{H})^{+}\right.$; calcd for $\mathrm{C}_{49} \mathrm{H}_{58} \mathrm{O}_{4} \mathrm{~N}_{5} \mathrm{Na:} 780.4470$ ]. 


\section{Synthesis of Building Blocks}

\section{Amino Ester Building Block (+)-A.}
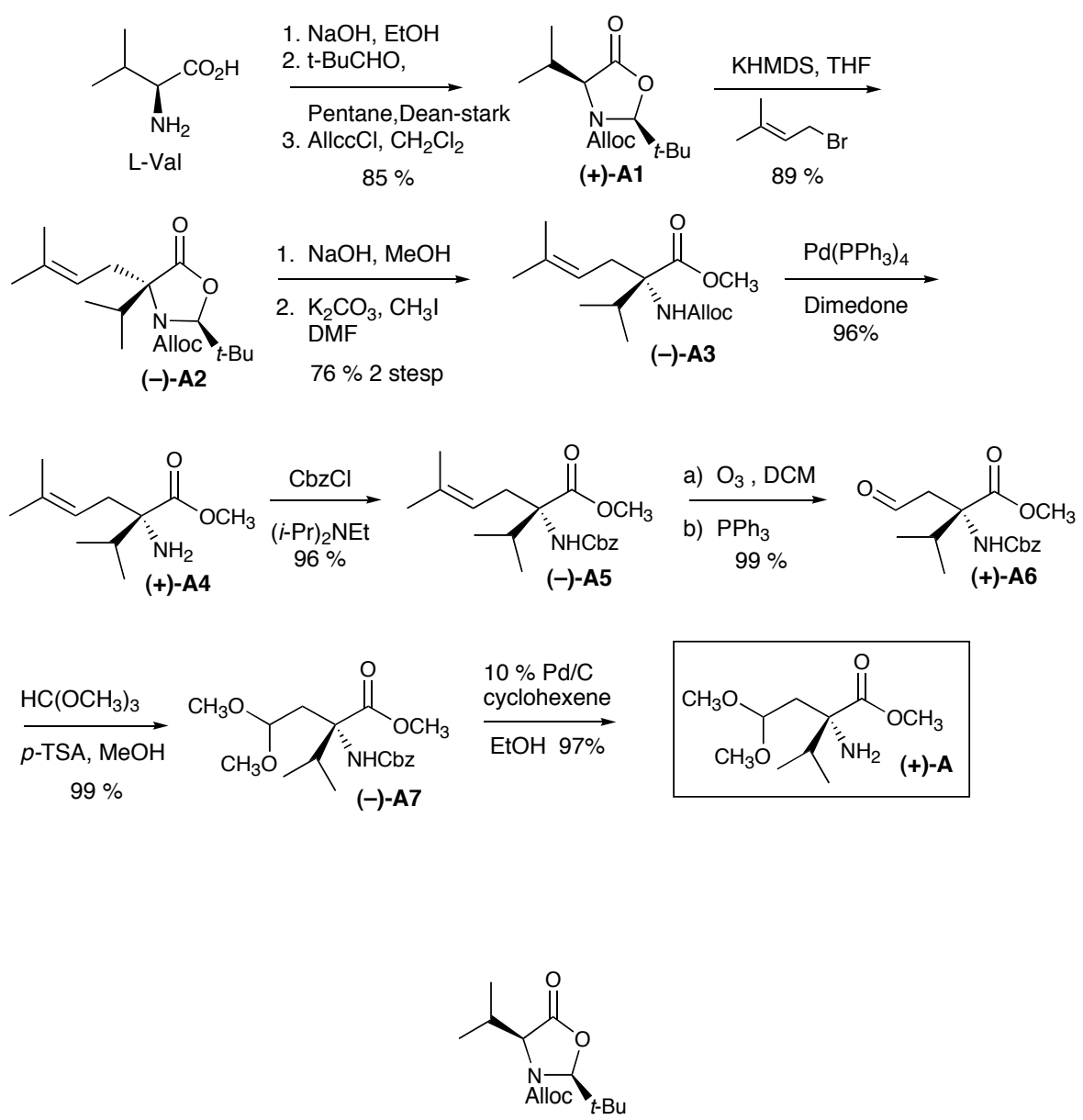

$(+)-\mathbf{A} 1$

Oxazolidinone (+)-A1. To a mixture of L-valine $(50.0 \mathrm{~g}, 427.0 \mathrm{mmol})$ in absolute ethanol $(800 \mathrm{~mL})$ was added a solution of $\mathrm{NaOH}(17.1 \mathrm{~g}, 380.0 \mathrm{mmol})$ in water $(60 \mathrm{~mL})$. The mixture was stirred at room temperature for $2 \mathrm{~h}$ over which time it became homogenous. The solution was concentrated in vacuo to give a solid mass, and $n$-pentane $(1.2 \mathrm{~L})$ was added followed by pivalaldehyde $(69.5 \mathrm{~mL}, 640 \mathrm{mmol})$. The flask was fitted with a Dean-Stark trap, and the mixture was heated to gentle reflux at $45^{\circ} \mathrm{C}$ for $72 \mathrm{~h}$. The heat was then removed and the mixture was concentrated in vacuo to provide a white solid that was azeotropically dried with toluene (800 $\mathrm{mL}$ ) and stored under high vacuum for $16 \mathrm{~h}$.

A suspension of the dried salt in $\mathrm{CH}_{2} \mathrm{Cl}_{2}(1 \mathrm{~L})$ was cooled to $0{ }^{\circ} \mathrm{C}$, allyl chloroformate $(67.9 \mathrm{~mL}, 640.0$ $\mathrm{mmol}$ ) was added, and the slurry mixture was stirred at $5{ }^{\circ} \mathrm{C}$ for 16 days. Water $(600 \mathrm{~mL})$ and a catalytic quantity of dimethylaminopyridine (DMAP) were then added to catalyze the hydrolysis of the excess chloroformate while the mixture was still cold. The biphasic system that resulted was warmed to room temperature and stirred for $16 \mathrm{~h}$. The mixture was then extracted with EtOAc $(2 \times 600 \mathrm{~mL})$, and the combined 
organic phases were washed with $10 \%$ aqueous $\mathrm{NaHSO}_{4}$, saturated aqueous $\mathrm{NaHCO}_{3}$, and brine ( $1 \mathrm{~L}$ each). The organic phase was then dried over anhydrous $\mathrm{MgSO}_{4}$ and concentrated in vacuo. The residue was purified by flash chromatography using ethyl acetate-hexanes (10:90) as eluant to afford (+)-A1 (98.1g, 85\% yield) as a colorless oil: $[\alpha]_{\mathrm{D}}^{23}+17.8^{\circ}\left(c 1.34, \mathrm{CHCl}_{3}\right)$; IR $\left(\mathrm{CHCl}_{3}\right) 3000(\mathrm{~s}), 2960(\mathrm{~m}), 2380(\mathrm{~m}), 1780(\mathrm{~m}), 1710(\mathrm{~s}), 1370$

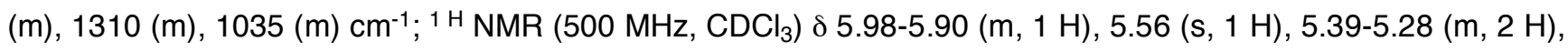
$4.66(\mathrm{~d}, J=5.9 \mathrm{~Hz}, 2 \mathrm{H}), 3.99(\mathrm{~d}, J=10.9 \mathrm{~Hz}, 1 \mathrm{H}), 2.06-1.98(\mathrm{~m}, 1 \mathrm{H}), 1.27(\mathrm{~d}, J=6.6 \mathrm{~Hz}, 3 \mathrm{H}), 1.09(\mathrm{~d}, J=$ $6.6 \mathrm{~Hz}, 3 \mathrm{H}), 1.00$ (s, $9 \mathrm{H}) ;{ }^{13} \mathrm{C}$ NMR $\left(125 \mathrm{MHz}, \mathrm{CDCl}_{3}\right) \delta 172.2,156.5,131.7,119.0,96.2,67.2,62.0,36.6$, 32.0, 25.0, 19.8, 19.5; high-resolution mass spectrum $\left(\mathrm{Cl}, \mathrm{CH}_{4}\right) \mathrm{m} / \mathrm{z} 270.1709\left[(\mathrm{M}+\mathrm{H})^{+}\right.$; calcd for $\mathrm{C}_{14} \mathrm{H}_{24} \mathrm{NO}_{4}$ : 270.1705]. Anal. Calcd for $\mathrm{C}_{14} \mathrm{H}_{23} \mathrm{NO}_{4}$ : C, 62.46; $\mathrm{H}, 8.61 ; \mathrm{N}, 5.20$. Found: $\mathrm{C}, 62.46 ; \mathrm{H}, 8.94 ; \mathrm{N}, 5.18$.

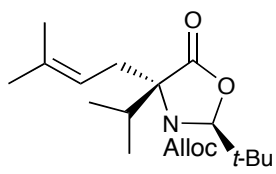

$(-)-\mathbf{A 2}$

Prenyloxazolidinone (-)-A2. A solution of (+)-A1 $(46.5 \mathrm{~g}, 173.3 \mathrm{mmol})$ in THF (866 mL) was cooled to -78 ${ }^{\circ} \mathrm{C}$, and $0.5 \mathrm{M}$ KHMDS in toluene $(416.0 \mathrm{~mL}, 208.0 \mathrm{mmol})$ was added via a dropping funnel at a rate that maintained an internal temperature no higher than $-70^{\circ} \mathrm{C}$. The resulting yellow solution was stirred for $15 \mathrm{~min}$, and then freshly distilled 1-bromo-3-methyl-2-butene $(40.0 \mathrm{~mL}, 346.6 \mathrm{mmol})$ was added dropwise via syringe, again maintaining an internal temperature less than $-70{ }^{\circ} \mathrm{C}$. The solution was stirred for $45 \mathrm{~min}$ at $-78{ }^{\circ} \mathrm{C}$ and was then quenched at $-78{ }^{\circ} \mathrm{C}$ by pouring into $10 \%$ aqueous $\mathrm{NaHSO}_{4}(500 \mathrm{~mL})$. The resulting biphasic mixture was extracted with EtOAc $(500 \mathrm{~mL})$, and the organic phase was washed with saturated aqueous $\mathrm{NaHCO}_{3}$ and brine (500 $\mathrm{mL}$ each), dried over anhydrous $\mathrm{MgSO}_{4}$, and concentrated in vacuo. The resulting yellow oil was purified by flash chromatography using ethyl acetate-hexanes (3:97) as eluant to afford (-)-A2 (52.0 g, 89\% yield) as a colorless oil: $[\alpha]_{D}^{23}-22.25^{\circ}\left(c\right.$ 1.29, $\left.\mathrm{CHCl}_{3}\right)$; IR $\left(\mathrm{CHCl}_{3}\right) 3000(\mathrm{~s}), 2980(\mathrm{~m}), 2380(\mathrm{~m}), 1770(\mathrm{~m})$, $1700(\mathrm{~m}), 1420(\mathrm{~m}), 1340(\mathrm{~m}) \mathrm{cm}^{-1} ;{ }^{1} \mathrm{H}$ NMR $\left(500 \mathrm{MHz}, \mathrm{CDCl}_{3}\right)$ 8 5.93-5.87 (m, $\left.1 \mathrm{H}\right), 5.47(\mathrm{~s}, 1 \mathrm{H})$, 5.35-5.24 (m, $2 \mathrm{H}), 4.75-4.71(\mathrm{~m}, 1 \mathrm{H}), 4,68-4.64(\mathrm{~m}, 1 \mathrm{H}), 4.47-4.43(\mathrm{~m}, 1 \mathrm{H}), 3.06(\mathrm{dd}, J=6.0,14.7 \mathrm{~Hz}, 1 \mathrm{H}), 2.54(\mathrm{dd}, J=$ 6.0, $14.7 \mathrm{~Hz}, 1 \mathrm{H}), 2.38-2.32(\mathrm{~m}, 1 \mathrm{H}), 1.67(\mathrm{~s}, 3 \mathrm{H}), 1.59(\mathrm{~s}, 3 \mathrm{H}), 1.17(\mathrm{~d}, J=3.8 \mathrm{~Hz}, 3 \mathrm{H}), 1.16(\mathrm{~d}, J=3.8 \mathrm{~Hz}$, $3 \mathrm{H}), 1.00$ (s, $9 \mathrm{H}) ;{ }^{13} \mathrm{C}$ NMR $\left(125 \mathrm{MHz}, \mathrm{CDCl}_{3}\right) \delta 174.2,155.1,137.7,131.9,118.9,116.3,95.1,70.1,66.6$, 37.7, 35.5, 30.0, 26.1, 25.9, 18.8, 18.5, 18.2; high-resolution mass spectrum $\left(\mathrm{Cl}, \mathrm{CH}_{4}\right) \mathrm{m} / \mathrm{z} 338.2335\left[(\mathrm{M}+\mathrm{H})^{+}\right.$; calcd for $\mathrm{C}_{19} \mathrm{H}_{32} \mathrm{NO}_{4}: 338.2331$ ]. Anal. Calcd for $\mathrm{C}_{19} \mathrm{H}_{31} \mathrm{NO}_{4}$ : C, 67.69; $\mathrm{H}, 9.27 ; \mathrm{N}, 4.16$. Found: C, 67.50; $\mathrm{H}$, $9.58 ; \mathrm{N}, 4.16$. 


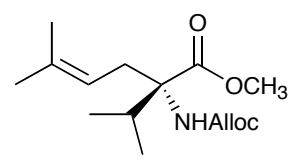

$(-)$-A3

Alloc-protected Amino Ester (-)-A3. A heterogeneous mixture of oxazolidinone (-)-A2 (29.5 g, $87.6 \mathrm{mmol})$ in $\mathrm{MeOH}$ and $3 \mathrm{~N}$ aqueous $\mathrm{KOH}(300 \mathrm{~mL}$ each) was heated at reflux for $16 \mathrm{~h}$. The resulting homogenous solution was cooled to room temperature and was then concentrated in vacuo. The resultant mixture was acidified to $\mathrm{pH} 1$ with $10 \%$ aqueous $\mathrm{NaHSO}_{4}$ and then extracted with EtOAc $(3 \times 300 \mathrm{~mL})$. The combined organic phases were washed with $\mathrm{H}_{2} \mathrm{O}$ and brine $\left(500 \mathrm{~mL}\right.$ each), dried over anhydrous $\mathrm{MgSO}_{4}$, concentrated in vacuo, and placed under high vacuum for $8 \mathrm{~h}$.

A solution of the crude residue in anhydrous DMF $(120 \mathrm{~mL})$ was treated with anhydrous $\mathrm{K}_{2} \mathrm{CO}_{3}(30 \mathrm{~g})$, and cooled to $0{ }^{\circ} \mathrm{C}$. lodomethane $(10.9 \mathrm{~mL}, 175.2 \mathrm{mmol})$ was added, and the mixture was stirred for $30 \mathrm{~min}$ and warmed to room temperature. The mixture was then diluted with $\mathrm{Et}_{2} \mathrm{O}(800 \mathrm{~mL})$ and was washed with water $(4 \mathrm{x}$ $100 \mathrm{~mL})$, followed by brine $(200 \mathrm{~mL})$. The organic phase was then dried over anhydrous $\mathrm{MgSO}_{4}$ and concentrated in vacuo. Flash chromatography using EtOAc-Hexanes (10:90) as eluant gave (-)-A3 (18.0 g, $76 \%$ yield) as a colorless oil: $[\alpha]_{\mathrm{D}}^{23}-30.78^{\circ}\left(c\right.$ 1.03, $\left.\mathrm{CHCl}_{3}\right)$; IR $\left(\mathrm{CHCl}_{3}\right) 3000(\mathrm{~s}), 2990(\mathrm{~m}), 2390(\mathrm{~m}), 1710$

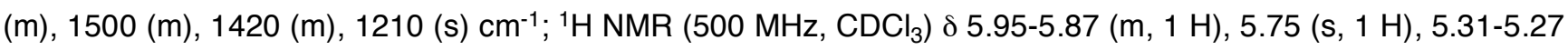
$(\mathrm{m}, 1 \mathrm{H}), 5.21-5.18(\mathrm{~m}, 1 \mathrm{H}), 4.92-4.89(\mathrm{~m}, 1 \mathrm{H}), 4.56-4.52(\mathrm{~m} 2 \mathrm{H}), 3.74(\mathrm{~s}, 3 \mathrm{H}), 3.11(\mathrm{dd}, J=7.4,14.6 \mathrm{~Hz}, 1$ H), $2.65(\mathrm{dd}, J=7.4,14.6 \mathrm{~Hz}, 1 \mathrm{H}), 2.49-2.47(\mathrm{~m}, 1 \mathrm{H}), 1.66(\mathrm{~s}, 3 \mathrm{H}), 1.59(\mathrm{~s}, 3 \mathrm{H}), 0.98(\mathrm{~d}, J=6.9 \mathrm{~Hz}, 3 \mathrm{H})$, $0.90(\mathrm{~d}, J=6.9 \mathrm{~Hz}, 3 \mathrm{H}) ;{ }^{13} \mathrm{C} \mathrm{NMR}\left(125 \mathrm{MHz}, \mathrm{CDCl}_{3}\right) \delta 173.4,154.1,135.1,133.1,118.4,117.2,67.4,65.0$, 52.2, 33.8, 31.0, 26.0, 17.9, 17.8, 17.8; high-resolution mass spectrum $\left(\mathrm{Cl}, \mathrm{CH}_{4}\right) \mathrm{m} / z 284.1862\left[(\mathrm{M}+\mathrm{H})^{+}\right.$; calcd for $\mathrm{C}_{15} \mathrm{H}_{26} \mathrm{NO}_{4}$ : 284.1862]. Anal. Calcd for $\mathrm{C}_{15} \mathrm{H}_{25} \mathrm{NO}_{4}$ : C, 63.62; $\mathrm{H}, 8.90 ; \mathrm{N}, 4.95$. Found: $\mathrm{C}, 63.42 ; \mathrm{H}, 8.73 ; \mathrm{N}$, 4.92 .

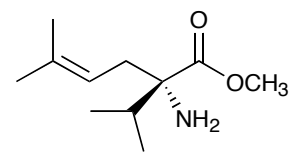

$(+)-\mathbf{A} 4$

Amine (+)-A4. $\quad$ To a solution of (-)-A3 (33.7 g, $119.1 \mathrm{mmol})$ in THF (1.2 L) was added dimedone (83.50 $\mathrm{g}, 595.6 \mathrm{mmol})$ and $\mathrm{Pd}\left(\mathrm{Ph}_{3} \mathrm{P}\right)_{4}(1.4 \mathrm{~g}, 1.2 \mathrm{mmol})$. The flask was wrapped with aluminum foil to exclude light, and the mixture was stirred for $16 \mathrm{~h}$. The mixture was then diluted with ether $(500 \mathrm{~mL})$, and extracted with $1 \mathrm{~N}$ $\mathrm{HCl}(5 \times 250 \mathrm{~mL})$. The combined aqueous layers were made basic by addition of solid $\mathrm{K}_{2} \mathrm{CO}_{3}$, and additional 
base was added to facilitate extraction of the product. The resultant mixture was extracted with EtOAc $(3 \times 250$ $\mathrm{mL}$ ), and the combined organic layers were washed with saturated aqueous $\mathrm{NaHCO}_{3}$ and brine (500 $\mathrm{mL}$ each). The organic phase was then dried over anhydrous $\mathrm{MgSO}_{4}$, concentrated in vacuo, Kugelrohr distillation provided (+)-A4 (20.8 g, 93\% yield) as a colorless oil: $[\alpha]_{\mathrm{D}}^{23}+13.52^{\circ}\left(c \mathrm{1.58}, \mathrm{CHCl}_{3}\right)$; IR $\left(\mathrm{CHCl}_{3}\right) 3650(\mathrm{w}), 3600(\mathrm{w})$, 3000 (s), 2950 (m), $2380(\mathrm{~m}), 1720(\mathrm{~m}), 1510(\mathrm{~m}), 1420(\mathrm{~m}), 1200(\mathrm{~s}) \mathrm{cm}^{-1} ;{ }^{1} \mathrm{H}$ NMR $\left(500 \mathrm{MHz}, \mathrm{CDCl}_{3}\right) \delta$ 4.99$4.95(\mathrm{~m}, 1 \mathrm{H}), 3.68(\mathrm{~s}, 3 \mathrm{H}), 2.36$ (dd, $J=8.4,14.1 \mathrm{~Hz}, 1 \mathrm{H}), 2.29$ (dd, $J=8.4,14.1 \mathrm{~Hz}, 1 \mathrm{H}), 1.99$ (app sept., J $=6.9 \mathrm{~Hz}, 1 \mathrm{H}), 1.68(\mathrm{~s}, 3 \mathrm{H}), 1.60(\mathrm{~s}, 3 \mathrm{H}), 1.46(\mathrm{~s}, 2 \mathrm{H}), 0.93(\mathrm{~d}, J=6.8 \mathrm{~Hz}, 3 \mathrm{H}), 0.82(\mathrm{~d}, J=6.8 \mathrm{~Hz}, 3 \mathrm{H}) ;{ }^{13} \mathrm{C}$ NMR $\left(125 \mathrm{MHz}, \mathrm{CDCl}_{3}\right) \delta 178.7,136.8,119.6,65.5,52.7,37.1,36.3,26.9,18.9,18.8,17.1$; high-resolution mass spectrum $\left(\mathrm{Cl}, \mathrm{CH}_{4}\right) \mathrm{m} / \mathrm{z} 198.1486\left[(\mathrm{M}-\mathrm{H})^{+}\right.$; calcd for $\left.\mathrm{C}_{11} \mathrm{H}_{20} \mathrm{NO}_{2}: 198.1494\right]$.

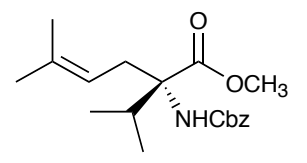

$(-)$-A5

Cbz Protected Amine (-)-A5. To a solution of (+)-A4 $(20.80 \mathrm{~g}, 104.3 \mathrm{mmol})$ in THF $(522 \mathrm{~mL})$ at $0{ }^{\circ} \mathrm{C}$ was added diisopropylethylamine $(21.82 \mathrm{~mL}, 125.2 \mathrm{mmol})$ via a syringe. After $10 \mathrm{~min}$, benzyl chloroformate (16.4 $\mathrm{mL}, 114.7 \mathrm{mmol}$ ) was added dropwise and the mixture was allowed to stir and warm to room temperature. The reaction mixture with diluted with ethyl acetate $(100 \mathrm{~mL})$ after $6 \mathrm{~h}$ and washed with $1 \mathrm{~N} \mathrm{HCl}(500 \mathrm{~mL})$, followed by saturated aqueous $\mathrm{NaHCO}_{3}$ and brine $(500 \mathrm{~mL}$ each). The organic phase was then dried over anhydrous $\mathrm{MgSO}_{4}$, concentrated in vacuo, and purified by flash chromatography using ethyl acetate-hexanes (8:92) as eluant to give (-)-A5 $\left(33.40 \mathrm{~g}, 96 \%\right.$ yield) as a colorless oil: $[\alpha]^{23}-19.89^{\circ}\left(c 3.480, \mathrm{CHCl}_{3}\right)$; IR $\left(\mathrm{CHCl}_{3}\right) 3010$ (s), $2400(\mathrm{~m}), 1730(\mathrm{~m}), 1510(\mathrm{~m}), 1420(\mathrm{~m}), 1220(\mathrm{~s}) \mathrm{cm}^{-1} ;{ }^{1} \mathrm{H}$ NMR $\left(500 \mathrm{MHz}, \mathrm{CDCl}_{3}\right) \delta$ 7.36-7.30 (m, $\left.5 \mathrm{H}\right)$, $5.97(\mathrm{~s}, 1 \mathrm{H}), 5.09(\mathrm{~d}, J=12.4 \mathrm{~Hz}, 1 \mathrm{H}), 5.03(\mathrm{~d}, J=12.4 \mathrm{~Hz}, 1 \mathrm{H}), 4.90-4.87(\mathrm{~m}, 1 \mathrm{H}), 3.73(\mathrm{~s}, 3 \mathrm{H}), 3.13(\mathrm{dd}, J$ $=7.3,14.6 \mathrm{~Hz}, 1 \mathrm{H}), 2.66(\mathrm{dd}, J=7.3,14.6 \mathrm{~Hz}, 1 \mathrm{H}), 2.50-2.48(\mathrm{~m}, 1 \mathrm{H}), 1.64(\mathrm{~s}, 3 \mathrm{H}), 1.55(\mathrm{~s}, 3 \mathrm{H}), 0.98(\mathrm{~d}, J$ $=6.9 \mathrm{~Hz}, 3 \mathrm{H}), 0.91(\mathrm{~d}, \mathrm{~J}=6.9 \mathrm{~Hz}, 3 \mathrm{H}) ;{ }^{13} \mathrm{C} \mathrm{NMR}\left(125 \mathrm{MHz}, \mathrm{CDCl}_{3}\right) \delta 173.6,154.5,135.4,128.7,128.2,128.1$, 118.6, 67.7, 66.4, 52.5, 34.1, 31.3, 26.2, 18.1, 18.0; high-resolution mass spectrum (ES, Na) $\mathrm{m} / \mathrm{z} 356.1822$ [(M $+\mathrm{Na})^{+}$; calcd for $\mathrm{C}_{19} \mathrm{H}_{27} \mathrm{NO}_{4} \mathrm{Na}: 356.1838$ ]. Anal. Calcd for $\mathrm{C}_{19} \mathrm{H}_{27} \mathrm{NO}_{4}: \mathrm{C}, 68.44 ; \mathrm{H}, 8.16 ; \mathrm{N}, 4.20$. Found: C, $68.25 ; \mathrm{H}, 8.42 ; \mathrm{N}, 4.13$.

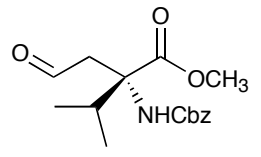

(+)-A6

Aldehyde (+)-A6. A solution of (-)-A5 (1.66 g, $4.98 \mathrm{mmol})$ in $\mathrm{CH}_{2} \mathrm{Cl}_{2}(50 \mathrm{~mL})$ was cooled to $-78{ }^{\circ} \mathrm{C}$ and ozone was bubbled into the solution until a light blue color persisted. The solution was then purged with argon until the blue color dissipated. $\mathrm{Ph}_{3} \mathrm{P}(1.44 \mathrm{~g}, 5.48 \mathrm{mmol})$ was then added. The resulting solution was stirred and warmed to room temperature under argon for $4 \mathrm{~h}$. The solution was then concentrated in vacuo and purified by 
flash chromatography using ethyl acetate-hexanes (10:90) to ethyl acetate-hexanes $(20: 80)$ as eluants to yield (+)-A6 (1.51 g, 99\% yield) as a colorless oil: $[\alpha]^{23}+1.74^{\circ}\left(c 4.71, \mathrm{CHCl}_{3}\right)$; IR $\left(\mathrm{CHCl}_{3}\right) 3010(\mathrm{~s}), 2400(\mathrm{~m}), 1730$ (s), $1510(\mathrm{~m}), 1210(\mathrm{~s}) \mathrm{cm}^{-1}$; ${ }^{1} \mathrm{H}$ NMR $\left(500 \mathrm{MHz}, \mathrm{CDCl}_{3}\right) \delta 9.67(\mathrm{~s}, 1 \mathrm{H}), 7.36-7.30(\mathrm{~m}, 5 \mathrm{H}), 5.91(\mathrm{~s}, 1 \mathrm{H}), 5.07-$ $5.00(\mathrm{~m}, 2 \mathrm{H}), 3.80(\mathrm{~d}, J=17.7 \mathrm{~Hz}, 1 \mathrm{H}), 3.76(\mathrm{~s}, 3 \mathrm{H}), 3.07$ (d, J = 17.7 Hz, $1 \mathrm{H}), 2.37-2.33(\mathrm{~m}, 1 \mathrm{H}), 0.92(\mathrm{~d}, J$ $=6.6 \mathrm{~Hz}, 3 \mathrm{H}), 0.91(\mathrm{~d}, \mathrm{~J}=6.6 \mathrm{~Hz}, 3 \mathrm{H}) ;{ }^{13} \mathrm{C} \mathrm{NMR}\left(125 \mathrm{MHz}, \mathrm{CDCl}_{3}\right) \delta 199.1,171.8,154.7,136.3,128.5,128.0$, 127.8, 66.5, 63.2, 52.6, 46.2, 34.5, 17.4, 17.2; high-resolution mass spectrum $\left(\mathrm{Cl}_{1} \mathrm{CH}_{4}\right) \mathrm{m} / \mathrm{z} 308.1486\left[(\mathrm{M}+\mathrm{H})^{+}\right.$; calcd for $\mathrm{C}_{16} \mathrm{H}_{22} \mathrm{NO}_{5}$ : 308.1498]. Anal. Calcd for $\mathrm{C}_{16} \mathrm{H}_{21} \mathrm{NO}_{5}$ : C, 71.09; $\mathrm{H}, 6.71 ; \mathrm{N}, 10.36$. Found: C, 70.99; $\mathrm{H}$, $6.59 ; \mathrm{N}, 10.32$.

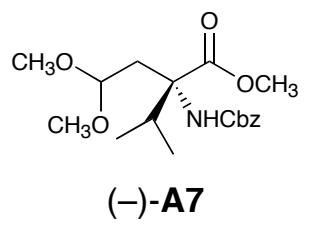

Dimethyl acetal (-)-A7. To a solution of (+)-A6 (16.7 g, $54.34 \mathrm{mmol})$ in $\mathrm{MeOH}(543 \mathrm{~mL})$ was added trimethyl orthoformate $(237.8 \mathrm{~mL}, 2.17 \mathrm{~mol})$ and a catalytic quantity of $p$ - TsOH. The solution was heated at reflux with stirring for $1.5 \mathrm{~h}$, and was then diluted with $\mathrm{Et}_{2} \mathrm{O}(500 \mathrm{~mL})$. The mixture was washed with saturated aqueous $\mathrm{NaHCO}_{3}$ and brine (300 $\mathrm{mL}$ each), and the organic phase was dried over anhydrous $\mathrm{MgSO}_{4}$ and concentrated in vacuo. Flash chromatography using ethyl acetate-hexanes (20:80) as eluant then afforded (-)-A7 (19.00 g, 99\% yield) as a colorless oil: $[\alpha]_{\mathrm{D}}^{23}-13.24^{\circ}\left(\mathrm{c} 1.465, \mathrm{CHCl}_{3}\right)$; IR $\left(\mathrm{CHCl}_{3}\right) 3408(\mathrm{~m}), 3018(\mathrm{~s}), 2954(\mathrm{~m}), 1716$ (s), 1499 (s), 1438 (m), 1357 (m), 1217 (s), 1248 (s), $1193(\mathrm{~m}), 1065$ (s) cm ${ }^{-1} ;{ }^{1} \mathrm{H}$ NMR (500 MHz, CDCl $) \delta$ 7.37-7.25 (m, 5 H), $6.10(\mathrm{~s}, 1 \mathrm{H}), 5.12(\mathrm{~d}, J=12.4 \mathrm{~Hz}, 1 \mathrm{H}), 5.03(\mathrm{~d}, J=12.4 \mathrm{~Hz}, 1 \mathrm{H}), 4.15$ (dd, $J=2.5,8.5$ Hz, 1 H), $3.72(\mathrm{~s}, 3 \mathrm{H}$ ), $3.25(\mathrm{~s}, 3 \mathrm{H}), 3.23(\mathrm{~s}, 3 \mathrm{H}), 2.80(\mathrm{dd}, J=2.5,14.0 \mathrm{~Hz}, 1 \mathrm{H}$ ), 2.50 (app sept. $J=6.9 \mathrm{~Hz}$, $1 \mathrm{H}$ ), 2.27 (dd, $J=8.5,14.0 \mathrm{~Hz}, 1 \mathrm{H}), 0.95(\mathrm{~d}, J=6.9 \mathrm{~Hz}, 3 \mathrm{H}), 0.85(\mathrm{~d}, J=6.9 \mathrm{~Hz}, 3 \mathrm{H}) ;{ }^{13} \mathrm{C} \mathrm{NMR}(125 \mathrm{MHz}$, $\left.\mathrm{CDCl}_{3}\right) \delta 173.3,154.2,136.9,128.5,128.1,128.0,103.8,66.3,64.6,55.7,54.2,52.3$, 36.3, 34.3, 17.6, 17.5; high-resolution mass spectrum (ES, Na) $\mathrm{m} / z 376.1739\left[(\mathrm{M}+\mathrm{Na})^{+}\right.$; calcd for $\mathrm{C}_{18} \mathrm{H}_{27} \mathrm{NO}_{6} \mathrm{Na}$ : 376.1736]. Anal. Calcd for $\mathrm{C}_{18} \mathrm{H}_{27} \mathrm{NO}_{6}: \mathrm{C}, 61.71 ; \mathrm{H}, 7.70 ; \mathrm{N}, 3.96$. Found: $\mathrm{C}, 61.81 ; \mathrm{H}, 7.75 ; \mathrm{N}, 3.93$.

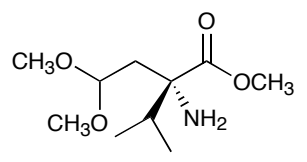

$(+)-\mathbf{A}$

Amino Ester Building Block (+)-A. A mixture of (-)-A7 (20.5 g, $58.0 \mathrm{mmol}), 10 \% \mathrm{Pd} / \mathrm{C}(4.1 \mathrm{~g})$, and freshly distilled cyclohexene $(58.75 \mathrm{~mL}, 580 \mathrm{mmol})$ in absolute $\mathrm{EtOH}(232 \mathrm{~mL})$ was heated at reflux for $2.5 \mathrm{~h}$. The mixture was then filtered and concentrated in vacuo, purified by flash chromatography using methanoldichloromathane $(2: 98)$ as eluant to give $(+)$-A $\left(12.33 \mathrm{~g}, 97 \%\right.$ yield) as a colorless oil: $[\alpha]^{23}+13.79^{\circ}(c 1.16$, $\left.\mathrm{CHCl}_{3}\right)$; IR $\left(\mathrm{CHCl}_{3}\right) 3660$ (w), 3600 (w), 3000 (s), 2980 (m), 2900 (w), 2380 (m), 1750 (m), 1530 (m), 1440 (m), 1220 (s), $1050(\mathrm{~m}) \mathrm{cm}^{-1} ;{ }^{1} \mathrm{H} \mathrm{NMR}\left(500 \mathrm{MHz}, \mathrm{CDCl}_{3}\right) \delta 4.42$ (app t, J=5.6 Hz, $\left.1 \mathrm{H}\right), 3.70(\mathrm{~s}, 3 \mathrm{H}), 3.32(\mathrm{~s}, 3 \mathrm{H})$, 3.29 (s, 3 H), 2.05 (dd, $J=5.6,14.0 \mathrm{~Hz}, 1 \mathrm{H}$ ), 1.96 (app sept., $J=5.6 \mathrm{~Hz}, 1 \mathrm{H}$ ), 1.90 (dd, $J=5.6,14.0 \mathrm{~Hz}, 1$ 
H), 1.88 (br s, $2 \mathrm{H}), 0.92(\mathrm{~d}, J=6.8 \mathrm{~Hz}, 3 \mathrm{H}), 0.80(\mathrm{~d}, J=6.8 \mathrm{~Hz}, 3 \mathrm{H}) ;{ }^{13} \mathrm{C}$ NMR $\left(125 \mathrm{MHz}, \mathrm{CDCl}_{3}\right) \delta 177.4$, 103.0, 62.1, 53.6, 53.4, 51.9, 40.3, 36.2, 17.3, 16.1; high-resolution mass spectrum $\left(\mathrm{Cl}_{1} \mathrm{CH}_{4}\right) \mathrm{m} / \mathrm{z} 220.1549[(\mathrm{M}$ $+\mathrm{H})^{+}$; calcd for $\left.\mathrm{C}_{10} \mathrm{H}_{22} \mathrm{NO}_{4}: 220.1549\right]$.

\section{Amino Ester Building Block (-)-B.}
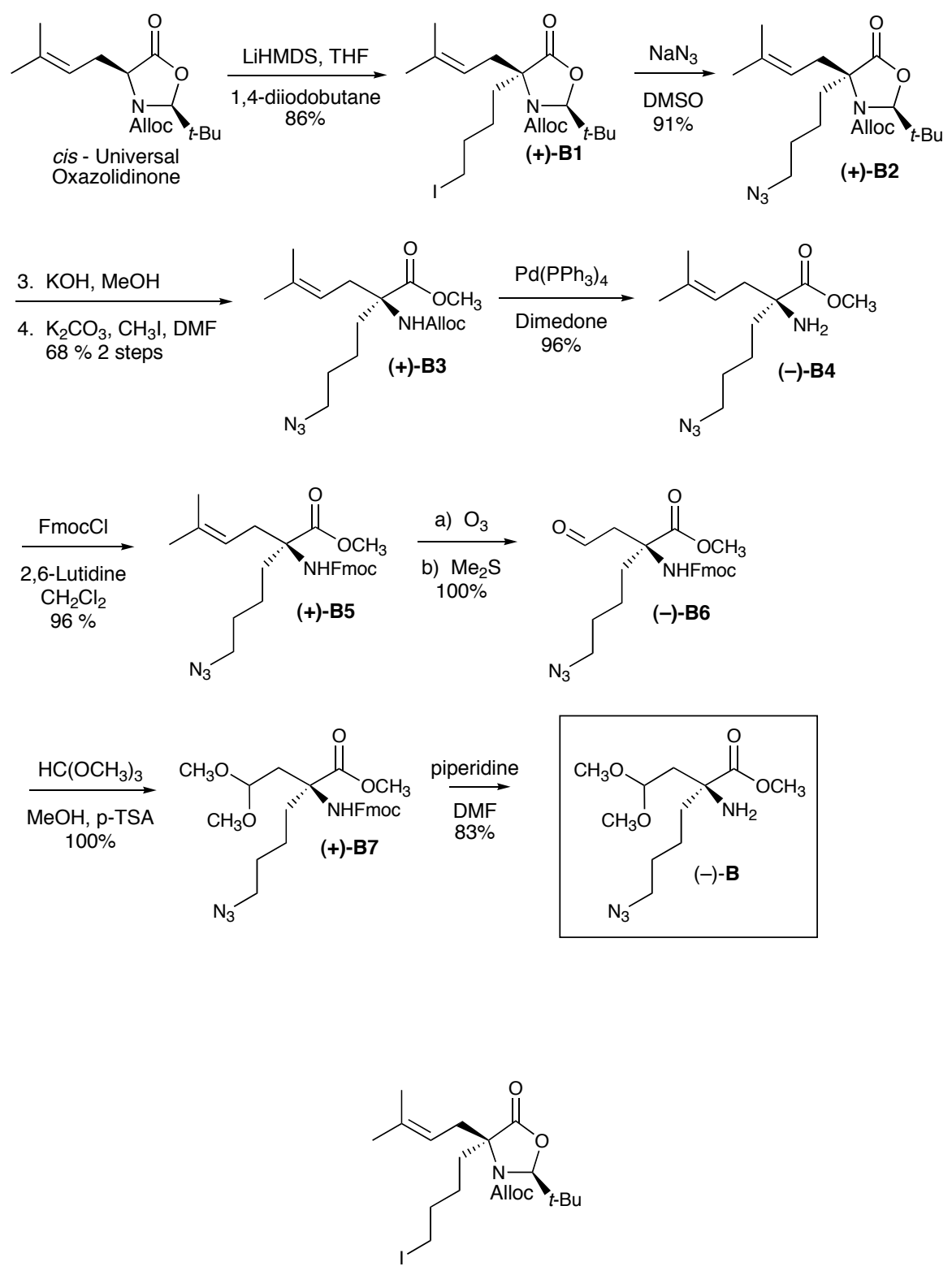

$(+)-B 1$

lodide (+)-B1. To a $-78{ }^{\circ} \mathrm{C}$ solution of cis-Universal Oxazolidinone $(22.0 \mathrm{~g}, 67.8 \mathrm{mmol})$ in THF $(400 \mathrm{~mL})$ was added 1.0 M LiHMDS in THF $(74.6 \mathrm{~mL}, 74.6 \mathrm{mmol})$ followed by addition of 1,4-diiodobutane (34.7 $\mathrm{g}, 111.9$ $\mathrm{mmol}$ ) rapidly and in one portion. The resulting solution was stirred and warmed to $0{ }^{\circ} \mathrm{C}$ over $2 \mathrm{~h}$, and was then 
quenched at $0{ }^{\circ} \mathrm{C}$ by addition of $10 \%$ aqueous $\mathrm{NaHSO}_{4}(200 \mathrm{~mL})$. The mixture was diluted with EtOAc $(100$ $\mathrm{mL}$ ), washed with $10 \%$ aqueous $\mathrm{NaHSO}_{4}(100 \mathrm{~mL})$, then saturated aqueous $\mathrm{NaHCO}_{4}$ and brine $(100 \mathrm{~mL}$ each) The organic phase was then dried over anhydrous $\mathrm{MgSO}_{4}$, concentrated in vacuo, and purified by flash chromatography using ethyl acetate-hexanes (1:19) as eluant to provide (+)-B1 (27.7 g, 86\% yield) as a colorless oil: $[\alpha]_{D}^{23}+10.8^{\circ}\left(c 2.655, \mathrm{CHCl}_{3}\right)$; IR $\left(\mathrm{CHCl}_{3}\right) 3005(\mathrm{w}), 2970(\mathrm{w}), 1790(\mathrm{~s}), 1710(\mathrm{~s}), 1390(\mathrm{~m}), 1315$ (m), $1190(\mathrm{~m}), 1035(\mathrm{~m}) \mathrm{cm}^{-1} ;{ }^{1} \mathrm{H}$ NMR $\left(500 \mathrm{MHz}, \mathrm{CDCl}_{3}\right) \delta 5.92(\mathrm{~m}, 1 \mathrm{H}), 5.50(\mathrm{~s}, 1 \mathrm{H}), 5.35(\mathrm{~d}, J=17.2 \mathrm{~Hz}, 1$ H), $5.28(\mathrm{~m}, 2 \mathrm{H}), 4.65(\mathrm{dd}, J=6.1,12.6 \mathrm{~Hz}, 1 \mathrm{H}), 4.60(\mathrm{~m}, 1 \mathrm{H}), 3.08(\mathrm{~m}, 2 \mathrm{H}), 2.75(\mathrm{dd}, J=8.0,14.3,1 \mathrm{H})$, 2.64 (dd, $J=7.3,14.6 \mathrm{~Hz}, 1 \mathrm{H}), 2.30$ (br s, $1 \mathrm{H}), 1.74(\mathrm{~m}, 3 \mathrm{H}), 1.68(\mathrm{~s}, 3 \mathrm{H}), 1.60(\mathrm{~s}, 3 \mathrm{H}), 1.12(\mathrm{~m}, 2 \mathrm{H}), 0.96$ (s, $9 \mathrm{H}) ;{ }^{13} \mathrm{C}$ NMR $\left(125 \mathrm{MHz}, \mathrm{CDCl}_{3}\right) \delta 174.2,135.4,131.7,119.6,118.1,95.2,67.0,66.7,38.1,36.1,33.0,25.9$, 25.6, 24.5, 17.8, 5.5; high-resolution mass spectrum $\left(\mathrm{Cl}, \mathrm{NH}_{3}\right) \mathrm{m} / z 495.1729\left[\left(\mathrm{M}+\mathrm{NH}_{4}\right)^{+}\right.$, calcd for $\mathrm{C}_{20} \mathrm{H}_{36} \mathrm{IN}_{2} \mathrm{O}_{4}$ : 495.1720]. Anal. Calcd for $\mathrm{C}_{20} \mathrm{H}_{32} \mathrm{INO}_{4}$ : C, 50.32; $\mathrm{H}, 6.76 ; \mathrm{N}, 2.93$. Found: $\mathrm{C}, 50.60 ; \mathrm{H}, 6.84 ; \mathrm{N}, 2.89$.

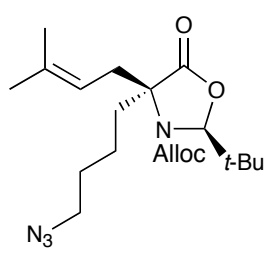

(+)-B2

Azide (+)-B2. To a solution of (+)-B1 $(27.7 \mathrm{~g}, 58.2 \mathrm{mmol})$ in DMSO (150 mL) was added $\mathrm{NaN}_{3}(11.4 \mathrm{~g}, 174.6$ $\mathrm{mmol})$. The mixture was stirred for $1 \mathrm{~h}$, and was then diluted with $\mathrm{Et}_{2} \mathrm{O}(200 \mathrm{~mL})$ and washed with water $(2 \mathrm{x}$ $100 \mathrm{~mL}$ ), and brine $(100 \mathrm{~mL})$. The organic phase was dried over anhydrous $\mathrm{MgSO}_{4}$, concentrated in vacuo, and purified by flash chromatography using ethyl acetate-hexanes (1:9) as eluant to yield (+)-B2 (21.2 g, 91\% yield) as a colorless oil: $[\alpha]_{\mathrm{D}}^{23}+14.6\left(c\right.$ 2.145, $\left.\mathrm{CHCl}_{3}\right)$; IR $\left(\mathrm{CHCl}_{3}\right) 3020(\mathrm{w}), 2980$ (w), 2100 (s), 1790 (s), 1715 (s), $1390(\mathrm{~m}), 1315(\mathrm{~m}), 1190(\mathrm{~m}), 1040(\mathrm{~m}) \mathrm{cm}^{-1}$; ${ }^{1} \mathrm{H}$ NMR (500 MHz, CDCl $) \delta 5.92(\mathrm{~m}, 1 \mathrm{H}), 5.49(\mathrm{~s}, 1 \mathrm{H}), 5.35(\mathrm{~d}$, $J=17.2 \mathrm{~Hz}, 1 \mathrm{H}), 5.28(\mathrm{~m}, 2 \mathrm{H}), 4.64(\mathrm{dd}, J=6.0,12.7 \mathrm{~Hz}, 1 \mathrm{H}), 4.58(\mathrm{~m}, 1 \mathrm{H}), 3.19(\mathrm{~m}, 2 \mathrm{H}), 2.76(\mathrm{dd}, J=8.4$, 14.4 Hz, $1 \mathrm{H}$ ), 2.64 (dd, J = 7.4, 14.6 Hz, $1 \mathrm{H}$ ), 2.32 (br s, $1 \mathrm{H}), 1.73$ (ddd, J= 4.8, 12.2, $13.9 \mathrm{~Hz}, 1 \mathrm{H}$ ), 1.69 (s, 3 $\mathrm{H}), 1.61(\mathrm{~s}, 3 \mathrm{H}), 1.51(\mathrm{~m}, 2 \mathrm{H}), 1.11(\mathrm{~m}, 2 \mathrm{H}), 0.96(\mathrm{~s}, 9 \mathrm{H}) ;{ }^{13} \mathrm{C} \mathrm{NMR}\left(125 \mathrm{MHz}, \mathrm{CDCl}_{3}\right) \delta 174.2,135.4,131.7$, 119.5, 118.1, 95.2, 67.0, 66.7, 50.8, 38.1, 36.1, 28.4, 25.9, 25.6, 20.9, 17.8; high-resolution mass spectrum $(\mathrm{Cl}$, $\left.\mathrm{NH}_{3}\right) \mathrm{m} / \mathrm{z} 410.2763\left[\left(\mathrm{M}+\mathrm{NH}_{4}\right)^{+}\right.$, calcd for $\left.\mathrm{C}_{20} \mathrm{H}_{36} \mathrm{~N}_{5} \mathrm{O}_{4}: 410.2767\right]$. Anal. Calcd for $\mathrm{C}_{20} \mathrm{H}_{32} \mathrm{~N}_{4} \mathrm{O}_{4}: \mathrm{C}, 61.20 ; \mathrm{H}, 8.22$; N, 14.27. Found: C, $61.37 ; \mathrm{H}, 8.30 ; \mathrm{N}, 13.97$. 


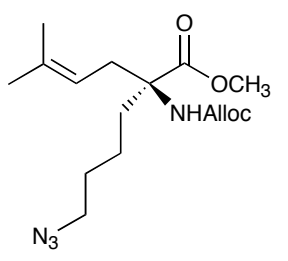

(+)-B3

Ester (+)-B3. A solution of (+)-B2 $(21.2 \mathrm{~g}, 52.9 \mathrm{mmol})$ in $\mathrm{MeOH}(200 \mathrm{~mL})$ was treated with an aqueous solution of $3 \mathrm{~N} \mathrm{KOH}(200 \mathrm{~mL})$ and the resulting mixture was heated at reflux for $2 \mathrm{~h}$. The resultant homogenous solution was then cooled to room temperature and concentrated in vacuo to remove most of the $\mathrm{MeOH}$. The resultant mixture was acidified with $10 \% \mathrm{NaHSO}_{4}$ to $\mathrm{pH} 1$ and extracted with ethyl acetate $(2 \times 200 \mathrm{~mL})$. The combined organic phases were washed with brine $(100 \mathrm{~mL})$, dried over $\mathrm{MgSO}_{4}$, and concentrated in vacuo. The crude acid was then used without further purification. A $0{ }^{\circ} \mathrm{C}$ solution of the residue in DMF (100 $\left.\mathrm{mL}\right)$ was treated with $\mathrm{K}_{2} \mathrm{CO}_{3}(20 \mathrm{~g})$ and iodomethane $(6.6 \mathrm{~mL}, 106 \mathrm{mmol})$ followed by warming to room temp. After $1 \mathrm{~h}$ the reaction was quenched with water $(50 \mathrm{~mL})$ and extracted with ether $(2 \times 100 \mathrm{~mL})$. The combined extracts were washed with water $(70 \mathrm{~mL})$, brine $(70 \mathrm{~mL})$, dried over $\mathrm{MgSO}_{4}$, and concentrated in vacuo. Purification via flash chromatography (5-20\% ethyl acetate:hexanes) then provided (+)-B3 (12.0 g, 68\% yield) as a colorless oil that was used without further purification: $[\alpha]_{\mathrm{D}}^{23}+26.8^{\circ}\left(c\right.$ 1.17, $\left.\mathrm{CHCl}_{3}\right)$; IR $\left(\mathrm{CHCl}_{3}\right) 3420(\mathrm{~m}), 3005(\mathrm{w}), 2940(\mathrm{~m})$,

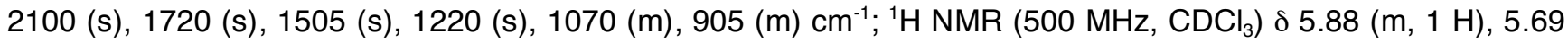
(s, $1 \mathrm{H}), 5.28(\mathrm{dq}, J=1.5,17.2 \mathrm{~Hz}, 1 \mathrm{H}), 5.18(\mathrm{~m}, 1 \mathrm{H}), 4.88$ (apparent t, J=7.5 Hz, $1 \mathrm{H}$ ), $4.51(\mathrm{~m}, 2 \mathrm{H}), 3.72(\mathrm{~s}$, 3 H), 3.21 (m, 2 H), 2.94 (dd, J= 7.2, $13.6 \mathrm{~Hz}, 1 \mathrm{H}), 2.41$ (dd, J=7.5, $14.6 \mathrm{~Hz}, 1 \mathrm{H}), 2.35(\mathrm{~m}, 1 \mathrm{H}), 1.80$ (ddd, J $=4.8,11.9,13.6 \mathrm{~Hz}, 1 \mathrm{H}), 1.64(\mathrm{~s}, 3 \mathrm{H}), 1.54(\mathrm{~s}, 3 \mathrm{H}), 1.53(\mathrm{~m}, 2 \mathrm{H}), 1.34(\mathrm{~m}, 1 \mathrm{H}), 1.07(\mathrm{~m}, 1 \mathrm{H}) ;{ }^{13} \mathrm{C} \mathrm{NMR}(125$ $\left.\mathrm{MHz}, \mathrm{CDCl}_{3}\right) \delta 173.9,153.9,135.9,132.9,117.5,65.1,64.1,52.7,51.1,34.5,28.6,25.9,21.3,17.8$; highresolution mass spectrum $\left(\mathrm{Cl}, \mathrm{NH}_{3}\right) m / z 339.2033\left[(\mathrm{M}+\mathrm{H})^{+}\right.$, calcd for $\left.\mathrm{C}_{16} \mathrm{H}_{27} \mathrm{~N}_{4} \mathrm{O}_{4}: 339.2032\right]$.

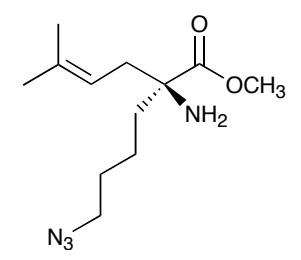

$(-)-B 4$

Amine (-)-B4 To a solution of (+)-B3 $(11.8 \mathrm{~g}, 35.1 \mathrm{mmol})$ in dried THF (200 mL) was added dimedone $(19.7 \mathrm{~g}$, $140.4 \mathrm{mmol})$ and $\mathrm{Pd}\left(\mathrm{Ph}_{3} \mathrm{P}\right)_{4}(100 \mathrm{mg}, 0.087 \mathrm{mmol})$. The flask was wrapped in foil to exclude light and the reaction was stirred at room temp for $16 \mathrm{~h}$ before diluting with ether $(200 \mathrm{~mL})$, and extracting with $1 \mathrm{~N} \mathrm{aq}$. $\mathrm{HCl}(5$ $x 100 \mathrm{~mL})$. The combined aqueous layers were basified by addition of $3 \mathrm{~N}$ aq. $\mathrm{KOH}(500 \mathrm{~mL})$ and extracted with ethyl acetate $(3 \times 200 \mathrm{~mL})$, dried over $\mathrm{MgSO}_{4}$, concentrated in vacuo and purified via flash chromatography 
using ethyl acetate-hexanes (1:4 then 2:3) as eluant to provide (-)-B4 (8.6 g, 96\% yield) as a yellow oil: $[\alpha]^{23}{ }^{23}$ $11.8^{\circ}$ ( c 0.96, $\mathrm{CHCl}_{3}$ ); IR $\left(\mathrm{CHCl}_{3}\right) 3370$ (w), 2960 (m), 2100 (s), 1730 (s), $1220(\mathrm{~m}) \mathrm{cm}^{-1} ;{ }^{1} \mathrm{H} \mathrm{NMR}(500 \mathrm{MHz}$,

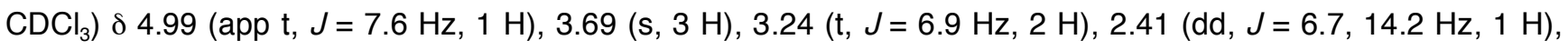
2.27 (dd, $J=8.6,14.1 \mathrm{~Hz}, 1 \mathrm{H}$ ), 1.76 (ddd, $J=4.6,12.4,13.4 \mathrm{~Hz}, 1 \mathrm{H}), 1.69$ (s, $3 \mathrm{H}), 1.66$ (m, $2 \mathrm{H}), 1.61$ (s, 3 $\mathrm{H}), 1.55(\mathrm{~m}, 3 \mathrm{H}), 1.42(\mathrm{~m}, 1 \mathrm{H}), 1.18(\mathrm{~m}, 1 \mathrm{H}) ;{ }^{13} \mathrm{C} \mathrm{NMR}\left(125 \mathrm{MHz}, \mathrm{CDCl}_{3}\right) \delta 177.3,136.4,117.9,61.4,52.1$, 51.2, 39.4, 38.4, 29.1, 26.0, 21.3, 18.0; high-resolution mass spectrum $\left(\mathrm{Cl}, \mathrm{NH}_{3}\right) \mathrm{m} / \mathrm{z} 255.1827\left[(\mathrm{M}+\mathrm{H})^{+}\right.$, calcd for $\mathrm{C}_{12} \mathrm{H}_{23} \mathrm{~N}_{4} \mathrm{O}_{2}$ : 255.1821]. Anal. Calcd for $\mathrm{C}_{12} \mathrm{H}_{22} \mathrm{~N}_{4} \mathrm{O}_{2}$ : C, 56.67; $\mathrm{H}, 8.72 ; \mathrm{N}, 22.03$. Found: C, 56.66; $\mathrm{H}, 8.74$; $\mathrm{N}, 21.81$.

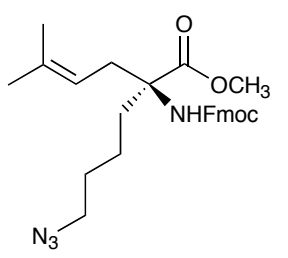

(+)-B5

Carbamate (+)-B5. To a solution of (-)-B4 $(5.48 \mathrm{~g}, 21.528 \mathrm{mmol})$ in $\mathrm{CH}_{2} \mathrm{Cl}_{2}(215 \mathrm{~mL})$ was added 2,6lutidine $(3.54 \mathrm{~mL}, 30.4 \mathrm{mmol})$ and 9-fluorenylmethyl chloroformate $(\mathrm{FmocCl}, 6.68 \mathrm{~g}, 25.8 \mathrm{mmol})$. The solution was stirred for $16 \mathrm{~h}$ and was then washed with aqueous $1 \mathrm{~N} \mathrm{HCl}$ and brine (200 mL each). The organic phase was then dried over anhydrous $\mathrm{MgSO}_{4}$, concentrated in vacuo, and purified by flash chromatography using ethyl acetate-hexanes (3:17) as eluant to give (+)-B5 $\left(9.85 \mathrm{~g}, 96 \%\right.$ yield) as a colorless oil: $[\alpha]_{\mathrm{D}}^{23}+5.1(c) 1.11$, $\left.\mathrm{CHCl}_{3}\right)$; IR $\left(\mathrm{CHCl}_{3}\right) 3410$ (m), 3010 (s), 2940 (s), 2090 (s), 1715 (s), 1495 (s), 1450 (s), 1330 (s), 1210 (s), 1080 (s) $\mathrm{cm}^{-1} ;{ }^{1} \mathrm{H}$ NMR $\left(500 \mathrm{MHz}, \mathrm{CDCl}_{3}\right) \delta 7.75(\mathrm{~d}, J=7.6 \mathrm{~Hz}, 2 \mathrm{H}), 7.58(\mathrm{~m}, 2 \mathrm{H}), 7.38(\mathrm{t}, J=7.4 \mathrm{~Hz}, 2 \mathrm{H}), 7.30$ (td, J = 0.9, $7.4 \mathrm{~Hz}, 2 \mathrm{H}), 5.77(\mathrm{~s}, 1 \mathrm{H}), 4.88(\mathrm{~m}, 1 \mathrm{H}), 4.38(\mathrm{~m}, 1 \mathrm{H}), 4.31(\mathrm{~m}, 1 \mathrm{H}), 4.21(\operatorname{app~t}, J=6.9 \mathrm{~Hz}, 1 \mathrm{H}), 3.76$ (s, 3 H), 3.22 (m, 2 H), 3.00 (dd, J = 7.3, 13.9 Hz, 1 H), 2.42 (m, 2 H), 1.65 (s, 3 H), 1.54 (br s, 5 H), 1.34 (m, 1 $\mathrm{H}), 1.08(\mathrm{~m}, 1 \mathrm{H}) ;{ }^{13} \mathrm{C}$ NMR $\left(125 \mathrm{MHz}, \mathrm{CDCl}_{3}\right) \delta 174.0,154.0,144.0,143.9,141.4,134.0,127.6,127.0,125.0$, 120.0, 117.5, 66.2, 64.2, 52.7, 51.1, 47.3, 34.6, 34.5, 28.6, 23.9, 21.3, 17.8; high-resolution mass spectrum (ESI, positive ion) $\mathrm{m} / \mathrm{z} 499.2324\left[(\mathrm{M}+\mathrm{Na})^{+}\right.$; calcd for $\left.\mathrm{C}_{27} \mathrm{H}_{32} \mathrm{~N}_{4} \mathrm{O}_{4} \mathrm{Na}: 499.2321\right]$. Anal. Calcd for $\mathrm{C}_{27} \mathrm{H}_{32} \mathrm{~N}_{4} \mathrm{O}_{4}: \mathrm{C}$, $68.05 ; \mathrm{H}, 6.77$; N, 11.76. Found: C, 68.20; H, 6.94; N, 11.59 .

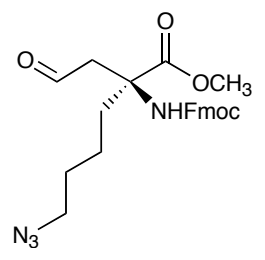

$(-)-\mathbf{B 6}$ 
Aldehyde (-)-B6. $\quad$ A - $78{ }^{\circ} \mathrm{C}$ solution of (+)-B5 $(9.78 \mathrm{~g}, 20.52 \mathrm{mmol})$ in $\mathrm{CH}_{2} \mathrm{Cl}_{2}(200 \mathrm{~mL})$ was saturated with ozone until a blue color persisted. The solution was then purged with argon until the blue color dissipated, and $\mathrm{Me}_{2} \mathrm{~S}(3.0 \mathrm{~mL}, 40.8 \mathrm{mmol}$ ) was added. The solution was stirred and warmed to room temperature under an argon atmosphere for $16 \mathrm{~h}$. The solution was then concentrated in vacuo and the residue was purified by flash chromatography using ethyl acetate-hexanes (3:7) as eluant to yield (-)-B6 (9.381 $2 \mathrm{~g}, 100 \%$ yield) as a colorless oil: $[\alpha]_{\mathrm{D}}^{23}-3.6\left(c 1.39, \mathrm{CHCl}_{3}\right)$; IR $\left(\mathrm{CHCl}_{3}\right) 3410(\mathrm{w}), 3010(\mathrm{~m}), 2940(\mathrm{~m}), 2090(\mathrm{~s}), 1720(\mathrm{~s}), 1495(\mathrm{~m})$, $1440(\mathrm{~m}), 1215(\mathrm{~s}), 1080(\mathrm{~m}), 705(\mathrm{~m}) \mathrm{cm}^{-1} ;{ }^{1} \mathrm{H} \mathrm{NMR}\left(500 \mathrm{MHz}, \mathrm{CDCl}_{3}\right) \delta 9.58(\mathrm{~s}, 1 \mathrm{H}), 7.74(\mathrm{~d}, J=7.5 \mathrm{~Hz}, 2 \mathrm{H})$, $7.55(\mathrm{~m}, 2 \mathrm{H}), 7.38(\mathrm{t}, J=7.4 \mathrm{~Hz}, 2 \mathrm{H}), 7.29(\mathrm{~m}, 2 \mathrm{H}), 5.99(\mathrm{~s}, 1 \mathrm{H}), 4.35(\mathrm{~d}, J=4.0 \mathrm{~Hz}, 2 \mathrm{H}), 4.18(\operatorname{app~t}, J=6.5$ $\mathrm{Hz}, 1 \mathrm{H}), 3.77(\mathrm{~s}, 3 \mathrm{H}), 3.73(\mathrm{~m}, 1 \mathrm{H}), 3.20(\mathrm{~s}, 2 \mathrm{H}), 2.95(\mathrm{~d}, J=17.9 \mathrm{~Hz}, 1 \mathrm{H}), 2.36(\mathrm{~m}, 1 \mathrm{H}), 1.63(\mathrm{~m}, 1 \mathrm{H}), 1.52$ $(\mathrm{m}, 2 \mathrm{H}), 1.30(\mathrm{~m}, 1 \mathrm{H}), 1.10(\mathrm{~m}, 1 \mathrm{H}) ;{ }^{13} \mathrm{C} \mathrm{NMR}\left(125 \mathrm{MHz}, \mathrm{CDCl}_{3}\right) \delta 198.7,172.7,154.2,143.7,141.3,127.7$, 127.0, 125.0, 120.0, 66.4, 59.6, 53.1, 50.9, 49.0, 47.2, 35.1, 28.4, 20.6; high-resolution mass spectrum (ESI, positive ion) $\mathrm{m} / \mathrm{z} 473.1811\left[(\mathrm{M}+\mathrm{Na})^{+}\right.$; calcd for $\mathrm{C}_{24} \mathrm{H}_{26} \mathrm{~N}_{4} \mathrm{O}_{5} \mathrm{Na}$ : 473.1801].

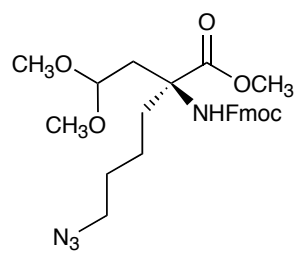

$(+)-B 7$

Acetal (+)-B7. To a solution of (-)-B6 $(9.2460 \mathrm{~g}, 20.523 \mathrm{mmol})$ in $\mathrm{MeOH}(100 \mathrm{~mL})$ was added trimethyl orthoformate $(100 \mathrm{~mL})$ and $p-\mathrm{TsOH}(500 \mathrm{mg}, 2.63 \mathrm{mmol})$. The solution was stirred for $2 \mathrm{~h}$, and was then concentrated in vacuo. The residue was next diluted with ethyl acetate $(300 \mathrm{~mL})$, and washed with saturated aqueous $\mathrm{NaHCO}_{3}$ and brine (200 mL each). The organic phase was next dried over anhydrous $\mathrm{MgSO}_{4}$, and concentrated in vacuo to afford (+)-B7 (10.15 g, 100\% yield) as a pale yellow oil that was used without further purification: $[\alpha]_{\mathrm{D}}^{23}+2.0\left(\mathrm{c} \mathrm{1.60}, \mathrm{CHCl}_{3}\right)$; IR $\left(\mathrm{CHCl}_{3}\right) 3400(\mathrm{w}), 3010$ (s), 2950 (m), 2090 (s), 1715 (s), 1495 (s), 1445 (s), 1205 (s), 1080 (s), 720 (s) cm ${ }^{-1} ;{ }^{1} \mathrm{H}$ NMR (500 MHz, $\mathrm{CDCl}_{3}$ ) $\delta 7.75$ (d J=7.5 Hz, $2 \mathrm{H}$ ), 7.59 (d J=6.8 $\mathrm{Hz}, 2 \mathrm{H}$ ), 7.38 (t, J=7.4 Hz, $2 \mathrm{H}$ ), 7.30 (td, J=0.5, 7.4 Hz, $2 \mathrm{H}), 6.01$ (s, $1 \mathrm{H}), 4.40(\mathrm{~m}, 2 \mathrm{H}), 4.25$ (dd, $J=2.3$, $7.6 \mathrm{~Hz}, 1 \mathrm{H}), 4.21(\mathrm{t}, J=6.8 \mathrm{~Hz}, 1 \mathrm{H}), 3.74(\mathrm{~s}, 3 \mathrm{H}), 3.26(\mathrm{~s}, 3 \mathrm{H}), 3.24(\mathrm{~s}, 3 \mathrm{H}), 3.20(\mathrm{~m}, 2 \mathrm{H}), 2.65(\mathrm{dd}, J=2.4$, 14.1 Hz, $1 \mathrm{H}), 2.33(\mathrm{~m}, 1 \mathrm{H}), 2.11(\mathrm{dd}, J=8.1,14.1 \mathrm{~Hz}, 1 \mathrm{H}), 1.76(\mathrm{~m}, 1 \mathrm{H}), 1.52(\mathrm{~m}, 2 \mathrm{H}), 1.27(\mathrm{~m}, 1 \mathrm{H}), 1.03$ $(\mathrm{m}, 1 \mathrm{H}) ;{ }^{13} \mathrm{C}$ NMR $\left(125 \mathrm{MHz}, \mathrm{CDCl}_{3}\right) \delta 173.8,154.0,143.9,141.4,127.7,127.0,125.0,120.0,102.5,66.1,61.2$, $55.0,53.4,52.7,51.0,47.3,39.0,34.9,28.5,20.8$; high-resolution mass spectrum (ESI, positive ion) $\mathrm{m} / \mathrm{z} 51$ $9.2214\left[(\mathrm{M}+\mathrm{Na})^{+}\right.$; calcd for $\left.\mathrm{C}_{26} \mathrm{H}_{32} \mathrm{~N}_{4} \mathrm{NaO}_{6}: 519.2220\right]$. 


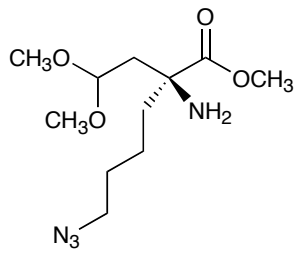

$(-)-\mathbf{B}$

Amino Ester Building Block (-)-B. To a solution of (+)-B7 (10.11 g, $20.4 \mathrm{mmol})$ in DMF (200 mL) was added piperidine $(4.03 \mathrm{~mL}, 40.7 \mathrm{mmol})$. The solution was stirred for $30 \mathrm{~min}$, and was then diluted with $\mathrm{Et}_{2} \mathrm{O}(300$ $\mathrm{mL}$ ) and washed with water $(2 \times 300 \mathrm{~mL})$. The organic phase was next dried over anhydrous $\mathrm{MgSO}_{4}$, concentrated in vacuo, and purified by gradient flash chromatography using ethyl acetate-hexanes $(1: 1)$ then methanol-methylene chloride (1:19) as the eluant to provide (-)-B (4.64 g, 83\% yield) as a pale yellow oil: $[\alpha]_{D}^{23}$ -9.6 (c 0.72, $\mathrm{CHCl}_{3}$ ); IR ( $\left.\mathrm{CHCl}_{3}\right) 3680$ (w), 3380 (w), 3020 (s), 2960 (s), 2100 (s), 1730 (s), 1200 (s), 1120 (s), 1050 (s), 710 (s) cm ${ }^{-1}$; ${ }^{1} \mathrm{H} \mathrm{NMR}\left(500 \mathrm{MHz}, \mathrm{CDCl}_{3}\right.$ ) $\delta 4.43$ (t, $J=5.5 \mathrm{~Hz}, 1 \mathrm{H}$ ), $3.69(\mathrm{~s}, 3 \mathrm{H}), 3.29$ (s, $3 \mathrm{H}$ ), 3.27 (s, $3 \mathrm{H}), 3.23(\mathrm{t}, J=6.9 \mathrm{~Hz}, 2 \mathrm{H}), 2.09(\mathrm{dd}, J=5.6,14.1 \mathrm{~Hz}, 1 \mathrm{H}), 1.89(\mathrm{~s}, 2 \mathrm{H}), 1.84(\mathrm{dd}, J=5.4,14.1 \mathrm{~Hz}, 1 \mathrm{H})$, 1.71 (ddd, $J=4.6,12.4,13.3 \mathrm{~Hz}, 1 \mathrm{H}), 1.54(\mathrm{~m}, 3 \mathrm{H}), 1.42(\mathrm{~m}, 1 \mathrm{H}), 1.18(\mathrm{~m}, 1 \mathrm{H}) ;{ }^{13} \mathrm{C} \mathrm{NMR}\left(125 \mathrm{MHz}, \mathrm{CDCl}_{3}\right)$ $\delta 177.00,102.5,59.1,53.5,53.4,52.1,51.1,42.2,40.6,28.9,20.8$; high-resolution mass spectrum (ESI, positive ion) $\mathrm{m} / \mathrm{z} 275.1716\left[(\mathrm{M}+\mathrm{H})^{+}\right.$; calcd for $\mathrm{C}_{11} \mathrm{H}_{23} \mathrm{~N}_{4} \mathrm{O}_{4}$ : 275.1719]. Anal. Calcd for $\mathrm{C}_{11} \mathrm{H}_{22} \mathrm{~N}_{4} \mathrm{O}_{4}: \mathrm{C}, 48.16 ; \mathrm{H}, 8.08 ; \mathrm{N}$, 20.42. Found: C, 47.80; H, 8.15; N, 20.23. 


\section{Amino Ester Building Block (-)-C $\alpha$}
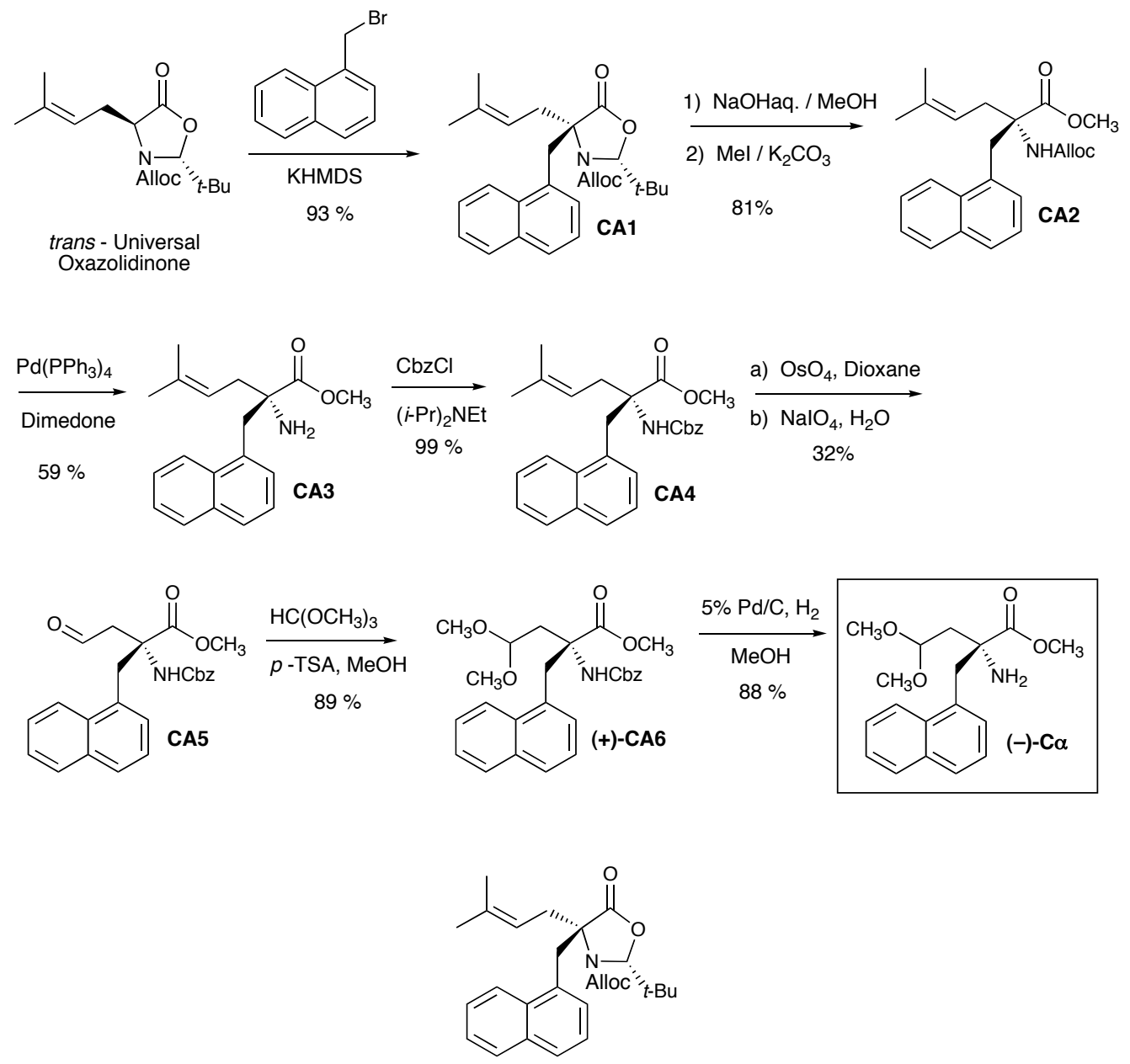

CA1

Oxazolidinone CA1. To a $-78{ }^{\circ} \mathrm{C}$ solution of trans-Universal Oxazolidinone $(20.0 \mathrm{~g}, 67.7 \mathrm{mmol})$ in THF (400 $\mathrm{mL}$ ) was added LiHMDS $1.0 \mathrm{M}$ THF solution $(80 \mathrm{~mL}, 80 \mathrm{mmol}$ ) dropwise over $30 \mathrm{~min}$. The resulting orangebrown suspension was stirred for $30 \mathrm{~min}$ and then 2-bromomethylnaphthalene (24.6 g, $111 \mathrm{mmol})$ was added. The mixture was stirred for $1 \mathrm{~h}$ at $-78{ }^{\circ} \mathrm{C}$ and was gradually warmed to room temperature. The resulting suspension was poured into $10 \%$ aqueous $\mathrm{NaHSO}_{4}(200 \mathrm{~mL})$. The mixture was extracted with Hexane-ethyl acetate 1:1 mixture $(300 \mathrm{~mL}, 100 \mathrm{~mL} \times 2)$, and the combined extract was washed with brine, dried over $\mathrm{Na}_{2} \mathrm{SO}_{4}$, and concentrated in vacuo. Flash chromatography, using hexane-ethyl acetate (95:5) as eluant, gave $27.3 \mathrm{~g}$ (93\% yield) of CA1 as a slightly yellow oil: ${ }^{1} \mathrm{H} \mathrm{NMR}\left(500 \mathrm{MHz}, \mathrm{CDCl}_{3}\right) \delta 8.12(\mathrm{br}, 1 \mathrm{H}) ; 7.82(\mathrm{~d}, \mathrm{~J}=8.0 \mathrm{~Hz}, 1 \mathrm{H})$, $7.76(\mathrm{~d}, J=8.3 \mathrm{~Hz}, 1 \mathrm{H}), 7.53-7.44(\mathrm{~m}, 2 \mathrm{H}), 7.38(\mathrm{~d}, J=7.5 \mathrm{~Hz}, 1 \mathrm{H}), 7.26(\mathrm{br}, 1 \mathrm{H}), 5.83(\mathrm{br}, 1 \mathrm{H}), 5.46(\mathrm{br}, 1$ H), $5.26(\mathrm{br}, 2 \mathrm{H}), 4.54(\mathrm{br}, 3 \mathrm{H}), 3.97(\mathrm{br}, 1 \mathrm{H}), 3.64(\mathrm{br}, 1 \mathrm{H}), 3.13(\mathrm{br}, 1 \mathrm{H}), 2.99 \sim 3.03(\mathrm{~m}, 1 \mathrm{H}), 1.77(\mathrm{~s}, 6 \mathrm{H})$, 0.83 (s, $9 \mathrm{H}) ;{ }^{13} \mathrm{C}$ NMR $\left(125 \mathrm{MHz}, \mathrm{CDCl}_{3}\right) \delta 173.7,135.9,133.9,132.4,131.6,128.5,128.2,127.8,125.8,125.7$, $125.0,124.2,119.4,118.7,94.9,66.4,38.2,36.3,31.6,26.0,26.0,25.9,25.7,22.6,18.0$. 


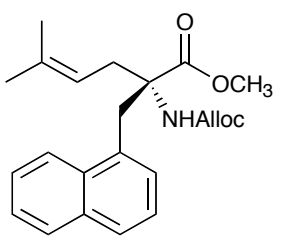

\section{CA2}

Alloc-Amino Ester CA2. To a solution of CA1 $(25.9 \mathrm{~g}, 59.6 \mathrm{mmol})$ in THF $(125 \mathrm{~mL})$ and $\mathrm{MeOH}(250 \mathrm{~mL})$ was added $6 \mathrm{M}$ aqueous $\mathrm{KOH}(125 \mathrm{~mL})$. The resulting mixture was heated to reflux and stirred for $4 \mathrm{~h}$. After cooling down the mixture was evaporated to remove most of the solvent. The resulting residue was acidified with conc. hydrochloric acid (ca. $60 \mathrm{~mL}$ ) under ice bath, extracted with EtOAc (200 mL x 3), and the combined extract was washed with brine, dried over $\mathrm{Na}_{2} \mathrm{SO}_{4}$, and concentrated in vacuo. The residue was dissolved in DMF (200 mL). To this solution was added $\mathrm{K}_{2} \mathrm{CO}_{3}(17 \mathrm{~g}, 122 \mathrm{mmol})$, followed by Mel $(8 \mathrm{~mL}, 129 \mathrm{mmol})$ under ice bath. The mixture was stirred overnight, and then diluted with ether $(300 \mathrm{~mL})$, and washed with water $(300 \mathrm{~mL})$ The water layer was extracted with ether $(100 \mathrm{~mL} \times 2)$. The combined organic layer was washed with brine, dried over $\mathrm{Na}_{2} \mathrm{SO}_{4}$, and concentrated in vacuo. Flash chromatography, using hexane-ethyl acetate (95:5) as eluant, gave $17.6 \mathrm{~g}$ (81\% yield) of CA2 as a slightly yellow oil: ${ }^{1} \mathrm{H} N \mathrm{NR}\left(500 \mathrm{MHz}, \mathrm{CDCl}_{3}\right) \delta 8.11$ (d, $J=7.8$ $\mathrm{Hz}, 1 \mathrm{H}), 7.83(\mathrm{~d}, J=7.1 \mathrm{~Hz}, 1 \mathrm{H}), 7.74(\mathrm{dm} J=8.1 \mathrm{~Hz}, 1 \mathrm{H}), 7.47-7.41(\mathrm{~m}, 2 \mathrm{H}), 7.38(\mathrm{t}, J=7.6 \mathrm{~Hz}, 1 \mathrm{H}), 7.27$ $(\mathrm{d}, J=7.1 \mathrm{~Hz}, 1 \mathrm{H}), 5.92(\mathrm{~m}, 1 \mathrm{H}), 5.60(\mathrm{~s}, 1 \mathrm{H}), 5.30(\mathrm{~d}, J=17.4 \mathrm{~Hz}, 1 \mathrm{H}), 5.22(\mathrm{~d}, J=10.4 \mathrm{~Hz}, 1 \mathrm{H}), 4.99(\mathrm{t}, J=$ $7.0 \mathrm{~Hz}, 1 \mathrm{H}), 4.60(\mathrm{~m}, 2 \mathrm{H}), 4.07$ (d, J=14.4 Hz, $1 \mathrm{H}$ ), 3.68 (d, J=14.4 Hz, $1 \mathrm{H}$ ), 3.58 (s, 3 H), 3.37 (dd, $J=6.9$ $14.3 \mathrm{~Hz}, 1 \mathrm{H}), 2.78(\mathrm{dd}, J=7.2,14.5 \mathrm{~Hz}, 1 \mathrm{H}), 1.70(\mathrm{~s}, 3 \mathrm{H}), 1.64(\mathrm{~s}, 3 \mathrm{H}) ;{ }^{13} \mathrm{C} \mathrm{NMR}\left(125 \mathrm{MHz}, \mathrm{CDCl}_{3}\right) \delta 173.1$, 154.4 , 135.8, 133.8, 133.0, 132.8, 132.7, 128.6, 128.1 127.6, 125.6, 125.3, 125.1, 123.9, 117.7, 117.4, 65.2, $65.1,52.3,37.0,34.4,26.0,17.9$.

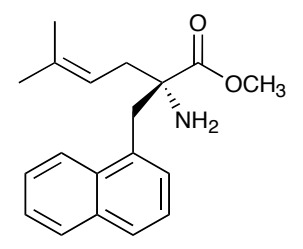

CA3

Amine CA3. To a solution of CA2 $(17.0 \mathrm{~g}, 46.4 \mathrm{mmol})$ in THF $(350 \mathrm{~mL})$ was added dimedone $(26 \mathrm{~g}, 185$ $\mathrm{mmol})$, followed by $\mathrm{Pd}\left(\mathrm{PPh}_{3}\right)_{4}(500 \mathrm{mg}, 0.43 \mathrm{mmol})$. The resulting mixture was stirred overnight, then evaporated to remove most of THF. The residue was diluted with ether and filtered. The filtrate was extracted with $1 \mathrm{~N}$ hydrochloric acid $(100 \mathrm{~mL} \times 10)$. The combined water layer was cooled by ice bath and basified with $6 \mathrm{~N}$ aqueous $\mathrm{NaOH}$. The mixture was extracted with EtOAc (200 $\mathrm{mL} \times 3)$, washed with brine, and dried over $\mathrm{Na}_{2} \mathrm{SO}_{4}$. Concentration in vacuo gave $8.1 \mathrm{~g}$ (59 \% yield) of CA3 as a yellow oil.; ${ }^{1} \mathrm{H} \mathrm{NMR}\left(500 \mathrm{MHz}, \mathrm{CDCl}_{3}\right) \delta$ $8.18(\mathrm{~d}, J=8.4 \mathrm{~Hz}, 1 \mathrm{H}), 7.83(\mathrm{~d}, J=8.0 \mathrm{~Hz}, 1 \mathrm{H}), 7.75(\mathrm{~d}, J=8.0 \mathrm{~Hz}, 1 \mathrm{H}), 7.50(\mathrm{t}, J=8.2 \mathrm{~Hz}, 1 \mathrm{H}), 7.45(\mathrm{t}, J=$ $8.1 \mathrm{~Hz}, 1 \mathrm{H}), 7.39$ (t, $J=8.0 \mathrm{~Hz}, 1 \mathrm{H}), 7.35(\mathrm{~d}, J=8.2 \mathrm{~Hz}, 1 \mathrm{H}), 5.10(\mathrm{dd}, J=6.8,8.4 \mathrm{~Hz}, 1 \mathrm{H}), 3.58(\mathrm{~d}, J=13.9$ $\mathrm{Hz}, 1 \mathrm{H}), 3.56(\mathrm{~s}, 3 \mathrm{H}), 3.41(\mathrm{~d}, J=13.8 \mathrm{~Hz}, 1 \mathrm{H}), 2.75$ (dd, $J=6.7,14.1 \mathrm{~Hz}, 1 \mathrm{H}), 2.49$ (dd, $J=8.4,14.0 \mathrm{~Hz}, 1$ 
H), $1.74(\mathrm{~s}, 3 \mathrm{H}), 1.69(\mathrm{~s}, 3 \mathrm{H}), 1.58(\mathrm{br}, 2 \mathrm{H}) ;{ }^{13} \mathrm{C}$ NMR $\left(125 \mathrm{MHz}, \mathrm{CDCl}_{3}\right) \delta$ 177.0, 136.4, 133.9, 133.0, 132.9, $128.6,128.2,127.6,125.7,125.4,125.1,124.5,118.1,63.1,51.8,41.7,39.0,16.0,18.1$.

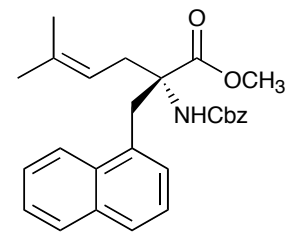

CA4

Cbz-Amino Ester CA4. To a solution of CA3 $(7.0 \mathrm{~g}, 23.5 \mathrm{mmol})$ in THF $(140 \mathrm{~mL})$ was added diisopropylethyl amine $(15 \mathrm{~mL}, 86.1 \mathrm{mmol})$, followed by $\mathrm{CbzCl}(10 \mathrm{~mL}, 70.6 \mathrm{mmol})$. The resulting mixture was stirred overnight, then filtered to remove precipitation. The filtrate was diluted with ether, washed with $1 \mathrm{~N}$ hydrochloric acid, sat. aqueous $\mathrm{NaHCO}_{3}$, and brine. The organic layer was washed with brine, dried over $\mathrm{Na}_{2} \mathrm{SO}_{4}$, and concentrated in vacuo. Flash chromatography, using hexane-ethyl acetate $(95: 5)$ as eluant, gave $10.1 \mathrm{~g}\left(99 \%\right.$ yield) of CA4 as a colorless oil: ${ }^{1} \mathrm{H}$ NMR $\left(500 \mathrm{MHz}, \mathrm{CDCl}_{3}\right) \delta 9.11(\mathrm{~d}, J=8.3 \mathrm{~Hz}, 1 \mathrm{H}), 7.82(\mathrm{~d}, J=$ $7.6 \mathrm{~Hz}, 1 \mathrm{H}), 7.73(\mathrm{~d}, J=8.2 \mathrm{~Hz}, 1 \mathrm{H}), 7.45-7.26(\mathrm{~m}, 8 \mathrm{H}), 7.20(\mathrm{~d}, J=7.0 \mathrm{~Hz}, 1 \mathrm{H}), 5.63(\mathrm{~s}, 1 \mathrm{H}), 5.19 \sim 5.11$ (m, $2 \mathrm{H}), 4.98$ (t, $J=7.1 \mathrm{~Hz}, 1 \mathrm{H}), 4.07$ (d, J=14.3 Hz, $1 \mathrm{H}$ ), 3.69 (d, J=14.3 Hz, 1 H), 3.59 (s, $3 \mathrm{H}), 3.39$ (dd, $J$ $=7.1,14.4 \mathrm{~Hz}, 1 \mathrm{H}), 2.79(\mathrm{dd}, J=7.2,14.5 \mathrm{~Hz}, 1 \mathrm{H}), 1.69(\mathrm{~s}, 3 \mathrm{H}), 1.62(\mathrm{~s}, 3 \mathrm{H}) ;{ }^{13} \mathrm{C} \mathrm{NMR}\left(125 \mathrm{MHz}, \mathrm{CDCl}_{3}\right) \delta$ 173.0, 154.5, 135.8, 133.8, 132.8, 132.6, 128.6, 128.4, 128.4, 128.1, 128.1, 127.7, 127.6, 125.6, 125.3, 125.1, $123.8,117.6,66.2,65.3,52.3,37.0,34.5,25.9,17.9$.

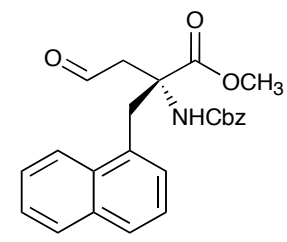

\section{CA5}

Aldehyde CA5. To a solution of CA4 $(26.5 \mathrm{~g}, 58.5 \mathrm{mmol})$ in 1,4-dioxane $(400 \mathrm{~mL})$ was added $\mathrm{OsO}_{4} 4 \mathrm{wt}$ $\%$ aqueous solution $(2 \mathrm{~mL}, 0.31 \mathrm{mmol})$. The resulting mixture was stirred for $30 \mathrm{~min}$. To this solution was added $\mathrm{NaIO}_{4}(20.0 \mathrm{~g}, 93.5 \mathrm{mmol})$ aqueous solution $(100 \mathrm{~mL})$ portionwise. The mixture was stirred overnight and extracted with ether ( $300 \mathrm{~mL}, 100 \mathrm{~mL} \times 2)$, and the combined extract was washed with brine, dried over $\mathrm{Na}_{2} \mathrm{SO}_{4}$, and concentrated in vacuo. Flash chromatography, using hexane-ethyl acetate (85:15) as eluant, gave $7.53 \mathrm{~g}$ (32\% yield) of CA5 as a colorless oil: ${ }^{1} \mathrm{H}$ NMR $\left(500 \mathrm{MHz}, \mathrm{CDCl}_{3}\right) \delta 9.67$ (s, $\left.1 \mathrm{H}\right) ; 7.96$ (d, J= $8.2 \mathrm{~Hz}, 1$ H), $7.82(\mathrm{~d}, J=7.5 \mathrm{~Hz}, 1 \mathrm{H}), 7.74(\mathrm{~d}, J=8.2 \mathrm{~Hz}, 1 \mathrm{H}), 7.45-7.27(\mathrm{~m}, 8 \mathrm{H}), 7.12(\mathrm{~d}, J=7.0 \mathrm{~Hz}, 1 \mathrm{H}), 5.86(\mathrm{~s}, 1 \mathrm{H})$, $5.18(\mathrm{~d}, J=12.3 \mathrm{~Hz}, 1 \mathrm{H}), 5.02(\mathrm{~d}, J=12.3 \mathrm{~Hz}, 1 \mathrm{H}), 4.13(\mathrm{~d}, J=17.6 \mathrm{~Hz}, 1 \mathrm{H}), 3.90(\mathrm{~d}, J=14.2 \mathrm{~Hz}, 1 \mathrm{H}), 3.62$ $(\mathrm{d}, J=14.1 \mathrm{~Hz}, 1 \mathrm{H}), 3.50$ (s, $3 \mathrm{H}), 3.23(\mathrm{~d}, J=18.2 \mathrm{~Hz}, 1 \mathrm{H}) ;{ }^{13} \mathrm{C} \mathrm{NMR}\left(125 \mathrm{MHz}, \mathrm{CDCl}_{3}\right) \delta$ 198.5, 171.9, 154.7, 136.1, 133.8, 132.7, 131.1, 128.8, 128.6, 128.5, 128.2, 128.1, 126.0, 125.5, 125.1, 123.4, 66.6, 61.1, 52.7, 48.5, $37.9,14.1$. 


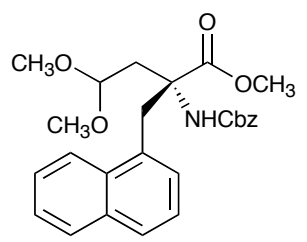

(+)-CA6

Acetal (+)-CA6. To a solution of CA5 $(0.82 \mathrm{~g}, 2.02 \mathrm{mmol})$ in $\mathrm{MeOH}(10 \mathrm{~mL})$ and trimethyl orthoformate $(3.0 \mathrm{~mL})$ was added $p-\mathrm{TsOH} \cdot \mathrm{H}_{2} \mathrm{O}(0.1 \mathrm{~g}, 0.58 \mathrm{mmol})$. The mixture was heated to reflux and stirred for $5 \mathrm{~h}$. After cooling down the reaction mixture was poured into sat. aqueous $\mathrm{NaHCO}_{3}$ and extracted with EtOAc (50 $\mathrm{mL} \times 3$ ), washed with brine, and dried over $\mathrm{Na}_{2} \mathrm{SO}_{4}$. Concentration in vacuo gave $0.81 \mathrm{~g}$ (89\%) of 79 as a colorless oil: $[\alpha]_{\mathrm{D}}^{23}=+84.5^{\circ}\left(\mathrm{c} \mathrm{1.09}, \mathrm{CHCl}_{3}\right) ; \mathrm{IR}\left(\mathrm{CHCl}_{3}\right) 3414(\mathrm{w}), 2951(\mathrm{~m}), 2832(\mathrm{w}), 1720(\mathrm{~s}), 1497(\mathrm{~s}), 1454(\mathrm{~m}), 1339$ (m), $1306(\mathrm{~m}), 1223(\mathrm{~m}), 1126(\mathrm{~m}), 1059(\mathrm{~s}), 786(\mathrm{~m}), 698(\mathrm{~m}) ;{ }^{1} \mathrm{H}$ NMR $\left(500 \mathrm{MHz}, \mathrm{CDCl}_{3}\right) \delta 8.01(\mathrm{~d}, J=8.4 \mathrm{~Hz}$, $1 \mathrm{H}), 7.82(\mathrm{~d}, J=8.4 \mathrm{~Hz}, 1 \mathrm{H}), 7.73(\mathrm{~d}, J=8.2 \mathrm{~Hz}, 1 \mathrm{H}), 7.44-7.30(\mathrm{~m}, 7 \mathrm{H}), 7.28(\mathrm{~d}, J=7.9 \mathrm{~Hz}, 1 \mathrm{H}), 7.16(\mathrm{~d}, J$ $=7.1 \mathrm{~Hz}, 1 \mathrm{H}), 5.88(\mathrm{~s}, 1 \mathrm{H}), 5.18(\mathrm{~d}, J=18.0 \mathrm{~Hz}, 1 \mathrm{H}), 5.16(\mathrm{~d}, J=18.0 \mathrm{~Hz}, 1 \mathrm{H}), 4.30(\mathrm{dd}, J=3.3,8.0 \mathrm{~Hz}, 1$ H), 4.03 (d, J=14.2 Hz, 1 H), $3.62(\mathrm{~d}, J=14.2 \mathrm{~Hz}, 1 \mathrm{H}), 3.59$ (s, $3 \mathrm{H}), 3.24(\mathrm{~s}, 3 \mathrm{H}), 3.32(\mathrm{~s}, 3 \mathrm{H}), 3.02$ (dd, $J=$ 3.3, $14.1 \mathrm{~Hz}, 1 \mathrm{H}), 2.48(\mathrm{dd}, J=8.0,14.1 \mathrm{~Hz}, 1 \mathrm{H}) ;{ }^{13} \mathrm{C} \mathrm{NMR}\left(125 \mathrm{MHz}, \mathrm{CDCl}_{3}\right) \delta 172.7,154.5,136.6,133.7$, 132.8, 132.0, 128.6, 128.4, 128.3, 128.2, 128.1, 127.7, 125.5, 125.3, 125.0, 123.8, 102.9, 66.3, 62.6, 55.1, 53.8, 52.2, 39.0, 37.2; high-resolution mass spectrum (ESI positive ion) $\mathrm{m} / \mathrm{z} 474.1881\left[(\mathrm{M}+\mathrm{Na})^{+}\right.$, calcd for $\mathrm{C}_{26} \mathrm{H}_{29} \mathrm{~N}_{1} \mathrm{O}_{6} \mathrm{Na}$ 474.1893].

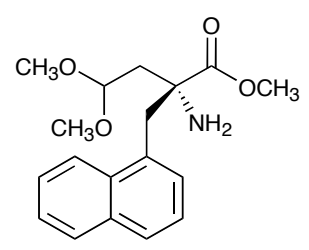

$(-)-C_{\alpha}$

Amino Ester Building Block (-)-C $\alpha$. To a solution of (+)-CA6 (0.79 g, $1.75 \mathrm{mmol})$ in $\mathrm{MeOH}(5 \mathrm{~mL}) \mathrm{was}$ added $5 \% \mathrm{Pd}$ on Carbon $(80 \mathrm{mg}$ ) suspended in $t$ - $\mathrm{BuOH}(5 \mathrm{~mL})$. The mixture was stirred under hydrogen atmosphere for $3 \mathrm{~h}$, and filtered through celite bed. Concentration of filtrate in vacuo gave $0.49 \mathrm{~g}$ ( $88 \%$ yield) of building block (-)-C $\alpha$ as brown oil: $[\alpha]_{\mathrm{D}}^{23}=-7.58\left(c 1.13, \mathrm{CH}_{2} \mathrm{Cl}_{2}\right)$; IR (neat) $3386(\mathrm{w}, \mathrm{br}), 3321(\mathrm{w}), 2943(\mathrm{~m})$, 2839 (w), 1732 (s), 1597 (m), 1446 (m), 1377 (w), 1196 (s), 1068 (s), 791 (m); $\left.{ }^{1} \mathrm{H} \mathrm{NMR} \mathrm{(500} \mathrm{MHz,} \mathrm{CDCl}\right)_{3} \delta$ $8.16(\mathrm{~d}, J=8.5 \mathrm{~Hz}, 1 \mathrm{H}), 7.83(\mathrm{~d}, J=7.7 \mathrm{~Hz}, 1 \mathrm{H}), 7.75(\mathrm{~d}, J=8.3 \mathrm{~Hz}, 1 \mathrm{H}), 7.50(\mathrm{t}, J=8.4 \mathrm{~Hz}, 1 \mathrm{H}), 7.45(\mathrm{t}, J=$ $7.0 \mathrm{~Hz}, 1 \mathrm{H}), 7.39$ (t , J=7.3 Hz, $1 \mathrm{H}), 7.32(\mathrm{~d}, J=6.8 \mathrm{~Hz}, 1 \mathrm{H}), 4.52(\mathrm{t}, J=5.6 \mathrm{~Hz}, 1 \mathrm{H}), 3.58(\mathrm{~s}, 3 \mathrm{H}), 3.51(\mathrm{~d}, J$ $=13.9 \mathrm{~Hz}, 1 \mathrm{H}), 3.43(\mathrm{~d}, J=13.9 \mathrm{~Hz}, 1 \mathrm{H}), 3.33(\mathrm{~s}, 3 \mathrm{H}), 3.31(\mathrm{~s}, 3 \mathrm{H}), 2.45(\mathrm{dd}, J=5.7,14.0 \mathrm{~Hz} 1 \mathrm{H}), 2.07$ (dd, $J=5.614 .0 \mathrm{~Hz}, 1 \mathrm{H}), 1.99$ (s, $2 \mathrm{H}) ;{ }^{13} \mathrm{C}$ NMR $\left(125 \mathrm{MHz}, \mathrm{CDCl}_{3}\right) \delta 176.7,134.0,133.0,132.3,128.6,128.4$, 127.8, 125.8, 125.5, 125.2, 124.4, 102.6, 60.9, 53.6, 53.3, 51.9, 42.6, 42.5; high resolution mass spectrum (ESI positive ion) $\mathrm{m} / \mathrm{z} 340.1532$, [( $\mathrm{M}+\mathrm{Na})^{+}$; calcd for $\left.\mathrm{C}_{18} \mathrm{H}_{23} \mathrm{NO}_{4} \mathrm{Na} 340.1525\right]$. 


\section{Amino Ester Building Block (-)-C $\beta$}<smiles>CC(C)=CCC1N=[13C]([18OH])OC1=O</smiles>

trans - Universal Oxazolidinone

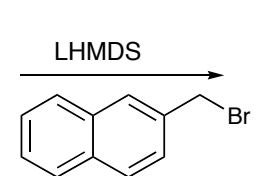

$90 \%$<smiles>CC(C)=CC[C@@]12Cc3cc4ccccc4cc3[C@@H](C(Br)(Br)Br)N1OC2=O</smiles>

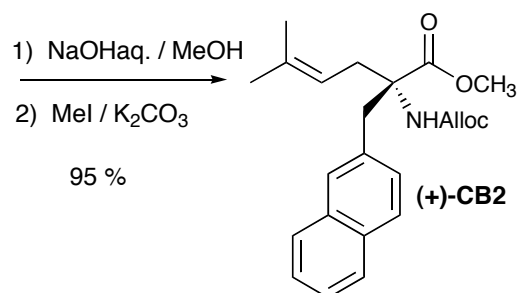

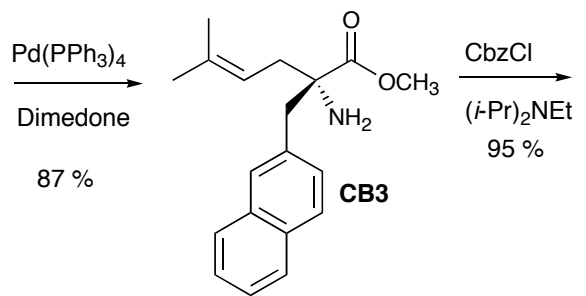<smiles>CC(C)=CCC(CC=C(C)C)(NO[N+](=O)[O-])C(=O)O[Na]</smiles>

$(+)-C B 4$<smiles>[c]1ccccc1</smiles><smiles>COC(=O)[C@](CC=O)(Cc1ccc2ccccc2c1)NOC(=O)O</smiles><smiles>COC(=O)[C@](Cc1cc(C(C)(C)C)cc2ccccc12)(CC(O)OC)C(=O)O</smiles><smiles>COC(=O)[C@](N)(Cc1ccc2ccccc2c1)CC(C)O</smiles><smiles>CC(C)=CC[C@]12C[N@+]1(Cc1ccc3ccccc3c1)[C@H]([13CH3])OC2=O</smiles>

(+)-CB1

Oxazolidinone (+)-CB1. To a $-78^{\circ} \mathrm{C}$ solution of trans-Universal Oxazolidinone $(20.0 \mathrm{~g}, 67.7 \mathrm{mmol})$ in THF (400 mL) was added LiHMDS 1.0 M THF solution ( $80 \mathrm{~mL}, 80 \mathrm{mmol})$ dropwise over $30 \mathrm{~min}$. The resulting orange-brown suspension was stirred for $30 \mathrm{~min}$ and then 2-bromomethylnaphthalene $(20 \mathrm{~g}, 90.5 \mathrm{mmol})$ was added. The mixture was stirred for $1 \mathrm{~h}$ at $-78{ }^{\circ} \mathrm{C}$ and was gradually warmed to room temperature. The resulting suspension was poured into $10 \%$ aqueous $\mathrm{NaHSO}_{4}(200 \mathrm{~mL})$. The mixture was extracted with hexane-ethyl acetate $1: 1$ mixture $(300 \mathrm{~mL}, 100 \mathrm{~mL} \times 2)$, and the combined extract was washed with brine (100 $\mathrm{mL}$ ), dried over $\mathrm{Na}_{2} \mathrm{SO}_{4}$, and concentrated in vacuo. Flash chromatography, using hexane-ethyl acetate (95:5) as eluant, gave $26.4 \mathrm{~g}\left(90 \%\right.$ yield) of $(+)$-CB1 as a colorless oil.: $[\alpha]^{23}=+44.5^{\circ}\left(c 1.28, \mathrm{CHCl}_{3}\right) ;{ }^{1} \mathrm{H}$ NMR $(500$ $\left.\mathrm{MHz}, \mathrm{CDCl}_{3}\right) \delta$ 7.80-7.74 (m, 3 H); $7.55(\mathrm{br}, 1 \mathrm{H}), 7.47(\mathrm{~m}, 2 \mathrm{H})$, 7.44-7.23 (br, $\left.1 \mathrm{H}\right), 6.09(\mathrm{br}, 1 \mathrm{H}), 5.91(\mathrm{br}, 1 \mathrm{H})$, 5.48 (br, 1 H), 5.32 (br, 1 H), 4.72, (br, 2 H), 4.61 (br, 1 H), 3.81 (br, 1 H), 3.25 (d, J=14.0 Hz, 1 H), 2.71, (br, 1 $\mathrm{H}), 2.87(\mathrm{dd}, J=7.2,17.2 \mathrm{~Hz}, 1 \mathrm{H}), 1.78(\mathrm{~s}, 3 \mathrm{H}), 1.74(\mathrm{~s}, 3 \mathrm{H}), 0.84(\mathrm{~s}, 9 \mathrm{H}) ;{ }^{13} \mathrm{C} \mathrm{NMR}\left(125 \mathrm{MHz}, \mathrm{CDCl}_{3}\right) \delta$ 
174.0; 154.0, 135.8, 133.3, 132.6, 131.7, 129.2, 128.2, 127.8, 127.6, 126.0, 125.8, 119.6, 118.4, 94.7, 68.7, $66.5,39.9,38.0,36.2,26.0,25.7,18.0$.

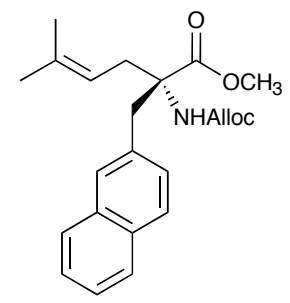

(+)-CB2

Alloc-Amino Ester (+)-CB2. To a solution of (+)-CB1 $(26.4 \mathrm{~g}, 60.6 \mathrm{mmol})$ in THF (125 mL) and MeOH (250 $\mathrm{mL}$ ) was added $6 \mathrm{M}$ aqueous $\mathrm{KOH}(125 \mathrm{~mL})$. The resulting mixture was heated to reflux and stirred for $2.5 \mathrm{~h}$. After cooling down the mixture was evaporated to remove most of the solvent. The resulting residue was acidified with conc. hydrochloric acid (ca. $60 \mathrm{~mL})$ under ice bath, extracted with EtOAc (200 $\mathrm{mL} \times 3)$, and the combined extract was washed with brine, dried over $\mathrm{Na}_{2} \mathrm{SO}_{4}$, and concentrated in vacuo. The residue was dissolved in DMF (200 mL). To this solution was added $\mathrm{K}_{2} \mathrm{CO}_{3}(17 \mathrm{~g}, 122 \mathrm{mmol})$, followed by Mel $(8 \mathrm{~mL}, 129$ $\mathrm{mmol})$ under ice bath. The mixture was stirred overnight, and then dillued with ether $(300 \mathrm{~mL})$, and washed with water $(300 \mathrm{~mL})$ The water layer was extracted with ether $(100 \mathrm{~mL} \times 2)$. The combined organic layer was washed with brine, dried over $\mathrm{Na}_{2} \mathrm{SO}_{4}$, and concentrated in vacuo. Flash chromatography, using hexane-ethyl acetate (95:5) as eluant, gave $22.0 \mathrm{~g}\left(95 \%\right.$ yield) of (+)-CB2 as a pale yellow oil: $[\alpha]^{23}=+45.8^{\circ}(c 1.56$, $\left.\mathrm{CHCl}_{3}\right) ;{ }^{1} \mathrm{H}$ NMR $\left(500 \mathrm{MHz}, \mathrm{CDCl}_{3}\right) \delta$ 7.81-7.72 (m, 3 H); $7.45(\mathrm{~m}, 2 \mathrm{H}), 7.53(\mathrm{~s}, 1 \mathrm{H}), 7.18$ (dd, J= 1.6, 8.3 Hz, 1 H), $5.60(\mathrm{~s}, 1 \mathrm{H}), 5.98(\mathrm{~m}, 1 \mathrm{H}), 5.35(\mathrm{~d}, J=17.2 \mathrm{~Hz}, 1 \mathrm{H}), 5.26(\mathrm{~d}, J=10.4 \mathrm{~Hz}, 1 \mathrm{H}), 5.01$ (t, $J=7.3 \mathrm{~Hz}, 1 \mathrm{H})$, $4.68(\mathrm{dd}, J=5.5,13.4 \mathrm{~Hz}, 1 \mathrm{H}), 4.60(\mathrm{dd}, J=5.2,13.4 \mathrm{~Hz}, 1 \mathrm{H}), 3.85$ (d, J=13.6 Hz, $1 \mathrm{H}$ ), 3.77 (s, $3 \mathrm{H}), 3.34$ (d, $J=13.6 \mathrm{~Hz}, 1 \mathrm{H}$ ), $3.21(\mathrm{dd}, J=7.4,14.4 \mathrm{~Hz}, 1 \mathrm{H}), 2.66$ (dd, $J=7.5,14.5 \mathrm{~Hz}, 1 \mathrm{H}), 1.72(\mathrm{~s}, 3 \mathrm{H}), 1.64(\mathrm{~s}, 3 \mathrm{H})$; ${ }^{13} \mathrm{C}$ NMR $\left(125 \mathrm{MHz}, \mathrm{CDCl}_{3}\right) \delta$ 173.0, 154.3, 135.9, 133.9, 133.3, 133.0, 132.4, 128.5, 127.8, 127.7, 127.6, 127.5, $127.5,125.9,125.5,117.5,65.3,65.0,52.4,40.7,34.6,25.9,17.9$.

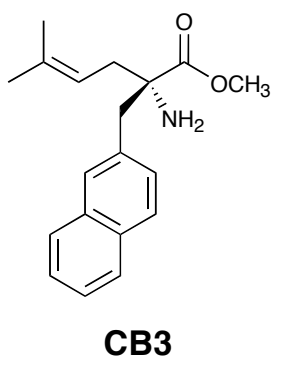

Amine CB3. To a solution of (+)-CB2 $(22.0 \mathrm{~g}, 57.7 \mathrm{mmol})$ in THF (350 mL) was added dimedone $(20 \mathrm{~g}, 143$ $\mathrm{mmol})$, followed by $\mathrm{Pd}\left(\mathrm{PPh}_{3}\right)_{4}(600 \mathrm{mg}, 0.52 \mathrm{mmol})$. The resulting mixture was stirred overnight, then evaporated to remove most of the THF. The residue was diluted with ether and filtered. The filtrate was extracted with $1 \mathrm{~N}$ hydrochloric acid $(100 \mathrm{~mL} \times 20)$ until the trace of product in organic layer disappeared. The combined water layer was cooled by ice bath and basified with $10 \mathrm{~N}$ aqueous $\mathrm{NaOH}$. The mixture was 
extracted with EtOAc (200 mL x 3), washed with brine $(100 \mathrm{~mL})$, and dried over $\mathrm{Na}_{2} \mathrm{SO}_{4}$. Concentration in vacuo gave $15 \mathrm{~g}$ (87\% yield) of CB3 as a white pink solid: ${ }^{1} \mathrm{H}$ NMR $\left(500 \mathrm{MHz}, \mathrm{CDCl}_{3}\right) \delta$ 7.81-7.75 (m, $\left.3 \mathrm{H}\right), 7.45(\mathrm{~m}, 2$ H), $7.66(\mathrm{~s}, 1 \mathrm{H}), 7.28(\mathrm{dd}, J=1.4,8.3 \mathrm{~Hz}, 1 \mathrm{H}), 5.11(\mathrm{t}, J=8.0 \mathrm{~Hz}, 1 \mathrm{H}), 3.70(\mathrm{~s}, 3 \mathrm{H}), 3.37(\mathrm{~d}, J=13.1 \mathrm{~Hz}, 1$ H), $2.97(\mathrm{~d}, J=13.1 \mathrm{~Hz}, 1 \mathrm{H}), 2.65$ (dd, $J=7.5,13.7 \mathrm{~Hz}, 1 \mathrm{H}), 2.45(\mathrm{dd}, J=8.6,14.0 \mathrm{~Hz}, 1 \mathrm{H}), 1.75(\mathrm{~s}, 3 \mathrm{H})$, 1.69 (s, $3 \mathrm{H}), 1.62(\mathrm{br}, 2 \mathrm{H}) ;{ }^{13} \mathrm{C}$ NMR $\left(125 \mathrm{MHz}, \mathrm{CDCl}_{3}\right) \delta$ 176.8, 136.3, 134.0, 133.3, 132.3, 128.6, 127.9, $127.8,127.5,127.5,125.9,125.5,117.9,62.6,51.8,46.0,38.7,26.0,18.0$.

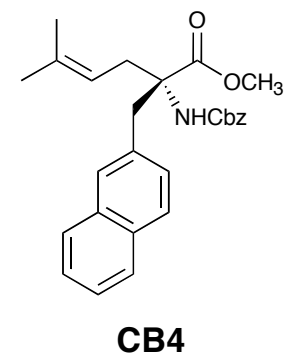

Cbz-Amino Ester CB4. To a solution of CB3 $(7.7 \mathrm{~g}, 25.9 \mathrm{mmol})$ in THF (150 mL) was added diisopropylethyl amine $(11 \mathrm{~mL}, 63 \mathrm{mmol})$, followed by $\mathrm{CbzCl}(8 \mathrm{~mL}, 56.5 \mathrm{mmol})$. The resulting mixture was stirred for $2 \mathrm{~h}$ and then filtered. The filtrate was diluted with ether $(100 \mathrm{~mL})$, washed with $1 \mathrm{~N} \mathrm{aq.} \mathrm{HCl}(50 \mathrm{~mL})$, sat. aqueous $\mathrm{NaHCO}_{3}(50 \mathrm{~mL})$, and brine $(50 \mathrm{~mL})$. The organic layer was then dried over $\mathrm{Na}_{2} \mathrm{SO}_{4}$, and concentrated in vacuo. Flash chromatography, using hexane-ethyl acetate (95:5) as eluant, gave $11.0 \mathrm{~g}(95 \%$ yield) of CB4 as a colorless oil.: ${ }^{1} \mathrm{H}$ NMR $\left(500 \mathrm{MHz}, \mathrm{CDCl}_{3}\right) \delta 7.78(\mathrm{~m}, 1 \mathrm{H})$, 7.66-7.61 $(\mathrm{m}, 2 \mathrm{H})$, 7.46-7.35 $(\mathrm{m}, 8$ H), $7.09(\mathrm{dd}, J=1.6,6.7 \mathrm{~Hz}, 1 \mathrm{H}), 5.60(\mathrm{~s}, 1 \mathrm{H}), 5.24(\mathrm{~d}, J=12.3 \mathrm{~Hz}, 1 \mathrm{H}), 5.11(\mathrm{~d}, J=12.3 \mathrm{~Hz}, 1 \mathrm{H}), 4.98(\mathrm{t}, J=$ $7.0 \mathrm{~Hz}, 1 \mathrm{H}), 3.83(\mathrm{~d}, J=13.6 \mathrm{~Hz}, 1 \mathrm{H}), 3.76(\mathrm{~s}, 3 \mathrm{H}), 3.32(\mathrm{~d}, J=13.6 \mathrm{~Hz}, 1 \mathrm{H}), 3.21(\mathrm{dd}, J=7.0,14.2 \mathrm{~Hz}, 1 \mathrm{H})$, $2.64(\mathrm{dd}, J=7.4,14.4 \mathrm{~Hz}, 1 \mathrm{H}), 1.69$ (s, $3 \mathrm{H}), 1.60$ (s, 3 H); ${ }^{13} \mathrm{C} \mathrm{NMR}\left(125 \mathrm{MHz}, \mathrm{CDCl}_{3}\right) \delta$ 173.0, 154.4, 136.3, 136.0, 133.9, 133.3, 132.4, 128.5, 128.4, 128.1, 128.1, 127.9, 127.8, 127.7, 127.5, 125.8, 125.5, 117.5, 66.2, $65.4,52.5,40.7,34.6,26.0,17.9$.

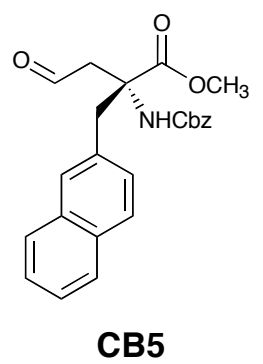

Aldehyde CB5. To a solution of CB4 $(10.0 \mathrm{~g}, 23.2 \mathrm{mmol})$ in 1,4-dioxane $(150 \mathrm{~mL})$ was added $\mathrm{OsO}_{4} 4 \mathrm{wt}$ $\%$ aqueous solution $(2 \mathrm{~mL}, 0.31 \mathrm{mmol})$. The resulting mixture was stirred for $30 \mathrm{~min}$. To this solution was added $\mathrm{NalO}_{4}(10.5 \mathrm{~g}, 49.1 \mathrm{mmol})$ aqueous solution $(60 \mathrm{~mL})$ portionwise. The mixture was stirred overnight and extracted with ether (300 mL, $100 \mathrm{~mL} \times 2)$, and the combined extract was washed with brine (100 mL), dried over $\mathrm{Na}_{2} \mathrm{SO}_{4}$, and concentrated in vacuo. Flash chromatography, using hexane-ethyl acetate (85:15) as eluant, gave $6.14 \mathrm{~g}$ (65\% yield) of CB5 as a pale yellow oil: ${ }^{1} \mathrm{H}$ NMR $\left(500 \mathrm{MHz}, \mathrm{CDCl}_{3}\right) \delta 9.69(\mathrm{~s}, 1 \mathrm{H}), 7.80-7.78(\mathrm{~m}, 1$ 
H), $7.67(\mathrm{~d}, J=8.4 \mathrm{~Hz}, 1 \mathrm{H}), 7.63-7.61(\mathrm{~m}, 1 \mathrm{H}), 7.46-7.26(\mathrm{~m}, 8 \mathrm{H}), 7.03(\mathrm{dd}, J=1.7,8.4 \mathrm{~Hz}, 1 \mathrm{H}), 5.86(\mathrm{~s}, 1 \mathrm{H})$, $5.26(\mathrm{~d}, J=12.3 \mathrm{~Hz}, 1 \mathrm{H}), 5.02(\mathrm{~d}, J=12.3 \mathrm{~Hz}, 1 \mathrm{H}), 3.97(\mathrm{~d}, J=18.0 \mathrm{~Hz}, 1 \mathrm{H}), 3.78(\mathrm{~d}, J=13.4 \mathrm{~Hz}, 1 \mathrm{H}), 3.74$ (s, $3 \mathrm{H}), 3.16(\mathrm{~d}, J=13.5 \mathrm{~Hz}, 1 \mathrm{H}), 3.15(\mathrm{~d}, J=13.5 \mathrm{~Hz}, 1 \mathrm{H}) ;{ }^{13} \mathrm{C} \mathrm{NMR}\left(125 \mathrm{MHz}, \mathrm{CDCl}_{3}\right) \delta$ 198.6, 171.9, 154.6, 136.3, 133.3, 132.5, 132.1, 128.7, 128.6, 128.2, 128.1, 127.9, 127.6, 127.6, 127.6, 126.0, 125.8, 66.5, 61.2, $52.9,48.8,41.6$.

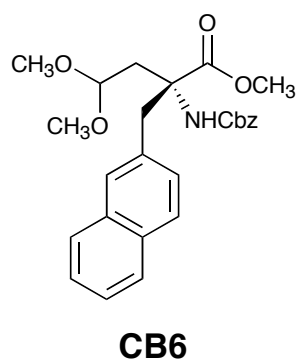

Acetal CB6. To a solution of CB5 $(6.14 \mathrm{~g}, 15.1 \mathrm{mmol})$ in $\mathrm{MeOH}(50 \mathrm{~mL})$ and methyl orthoformate $(10 \mathrm{~mL})$ was added $p-\mathrm{TsOH} \cdot \mathrm{H}_{2} \mathrm{O}(0.5 \mathrm{~g}, 2.9 \mathrm{mmol})$. The mixture was heated to reflux and stirred for $3 \mathrm{~h}$. After cooling down the reaction mixture was evaporated to remove most of solvent and diluted with ether. The resulting mixture was washed with sat. aqueous $\mathrm{NaHCO}_{3}$ and dried over $\mathrm{Na}_{2} \mathrm{SO}_{4}$. Concentration in vacuo gave $6.64 \mathrm{~g}(97$ \%) of CB6 as a colorless oil: ${ }^{1} \mathrm{H}$ NMR $\left(500 \mathrm{MHz}, \mathrm{CDCl}_{3}\right) \delta$ 7.79-7.76 $(\mathrm{m}, 1 \mathrm{H}), 7.64(\mathrm{~d}, \mathrm{~J}=8.4 \mathrm{~Hz}, 1 \mathrm{H}), 7.62-$ $7.59(\mathrm{~m}, 1 \mathrm{H}), 7.44-7.26(\mathrm{~m}, 8 \mathrm{H}), 7.06(\mathrm{dd}, J=1.6,8.4 \mathrm{~Hz}, 1 \mathrm{H}), 5.86(\mathrm{~s}, 1 \mathrm{H}), 5.29(\mathrm{~d}, J=12.3 \mathrm{~Hz}, 1 \mathrm{H}), 5.12$ (d, $J=12.3 \mathrm{~Hz}, 1 \mathrm{H}$ ), 4.35 (dd, $J=3.0,8.1 \mathrm{~Hz}, 1 \mathrm{H}$ ), 3.77 (d, $J=13.8 \mathrm{~Hz}, 1 \mathrm{H}$ ), $3.76(\mathrm{~s}, 3 \mathrm{H}), 3.32(\mathrm{~s}, 3 \mathrm{H}), 3.27$ (d, $J=13.5 \mathrm{~Hz}, 1 \mathrm{H}$ ), 3.26 (s, $3 \mathrm{H}), 2.89$ (dd, $J=3.0,14.2 \mathrm{~Hz}, 1 \mathrm{H}), 2.36$ (dd, $J=8.2,14.2 \mathrm{~Hz}, 1 \mathrm{H}$ ); ${ }^{13} \mathrm{C}$ NMR $\left(125 \mathrm{MHz}, \mathrm{CDCl}_{3}\right) \delta 172.8,154.4,136.8,133.3,133.2,132.4,128.7,128.5,128.2,128.1,127.9,125.7,127.5$, $125.8,124.5,102.6,66.4,62.6,55.1,53.6,52.4,41.2,39.2,31.5$.

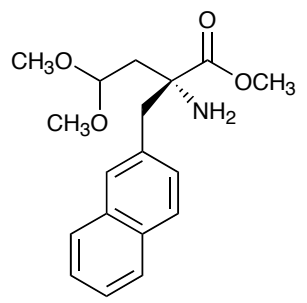

$(-)-\mathbf{C} \beta$

Amino Ester Building Block (-)-C $\beta$. To a solution of CB6 $(6.64 \mathrm{~g}, 14.7 \mathrm{mmol})$ in $\mathrm{MeOH}(120 \mathrm{~mL})$ was added $5 \% \mathrm{Pd}$ on Carbon $(200 \mathrm{mg}$ ) suspended in $t-\mathrm{BuOH}(5 \mathrm{~mL})$. The mixture was stirred under hydrogen atmosphere for $3 \mathrm{~h}$, and filtered through celite bed. Concentration of filtrate in vacuo gave $4.50 \mathrm{~g}$ (96\% yield) of building block (-)-C $\beta$ as white-yellow solid: $[\alpha]_{D}^{23}-23.94\left(c 0.85, \mathrm{CH}_{2} \mathrm{Cl}_{2}\right)$; IR (neat) $3386(\mathrm{w}, \mathrm{br}), 3321(\mathrm{w}), 3051(\mathrm{w})$, $2943(\mathrm{~m}), 2835$ (w), 1736 (s), 1600 (m), $1442(\mathrm{~m}), 1373$ (w), 1196 (s), 1122 (s), 1061 (s), 964 9w), 902 (w), 860 (w), $821(\mathrm{~m}), 748(\mathrm{~m}) ;{ }^{1} \mathrm{H}$ NMR $\left(500 \mathrm{MHz}, \mathrm{CDCl}_{3}\right) \delta$ 7.81-7.78 (m, $\left.2 \mathrm{H}\right), 7.63(\mathrm{~s}, 1 \mathrm{H}), 7.76(\mathrm{~d}, \mathrm{~J}=8.8 \mathrm{~Hz}, 1 \mathrm{H})$, $7.46(\mathrm{~m}, 2 \mathrm{H}), 7.25(\mathrm{~d}, \mathrm{~J}=8.4 \mathrm{~Hz}, 1 \mathrm{H}), 4.51(\mathrm{t}, \mathrm{J}=5.5 \mathrm{~Hz}, 1 \mathrm{H}), 3.71(\mathrm{~s}, 3 \mathrm{H}), 3.34(\mathrm{~s}, 3 \mathrm{H}), 3.31(\mathrm{~s}, 3 \mathrm{H}), 3.30$ 
$(\mathrm{d}, \mathrm{J}=13.0 \mathrm{~Hz}, 1 \mathrm{H}), 2.96(\mathrm{~d}, \mathrm{~J}=13.1 \mathrm{~Hz}, 1 \mathrm{H}), 2.36(\mathrm{dd}, \mathrm{J}=5.6,14.2 \mathrm{~Hz}, 1 \mathrm{H}), 2.00(\mathrm{dd}, \mathrm{J}=5.4,14.2 \mathrm{~Hz}, 1 \mathrm{H})$, 1.87 (br, $2 \mathrm{H}), ;{ }^{13} \mathrm{C}$ NMR $\left(125 \mathrm{MHz}, \mathrm{CDCl}_{3}\right) \delta 176.5,133.3,132.5,128.9,128.2,127.9,127.6,127.6,127.5$, 126.0, 125.6, 102.4, 60.2, 53.5, 53.4, 51.9, 47.1, 42.5; high resolution mass spectrum (ESI positive ion) $\mathrm{m} / \mathrm{z}$ 340.1532, $\left[(\mathrm{M}+\mathrm{Na})^{+}\right.$; calcd for $\left.\mathrm{C}_{18} \mathrm{H}_{23} \mathrm{NO}_{4} \mathrm{Na} 340.1525\right]$. 


\section{Building Block C (Phe)}
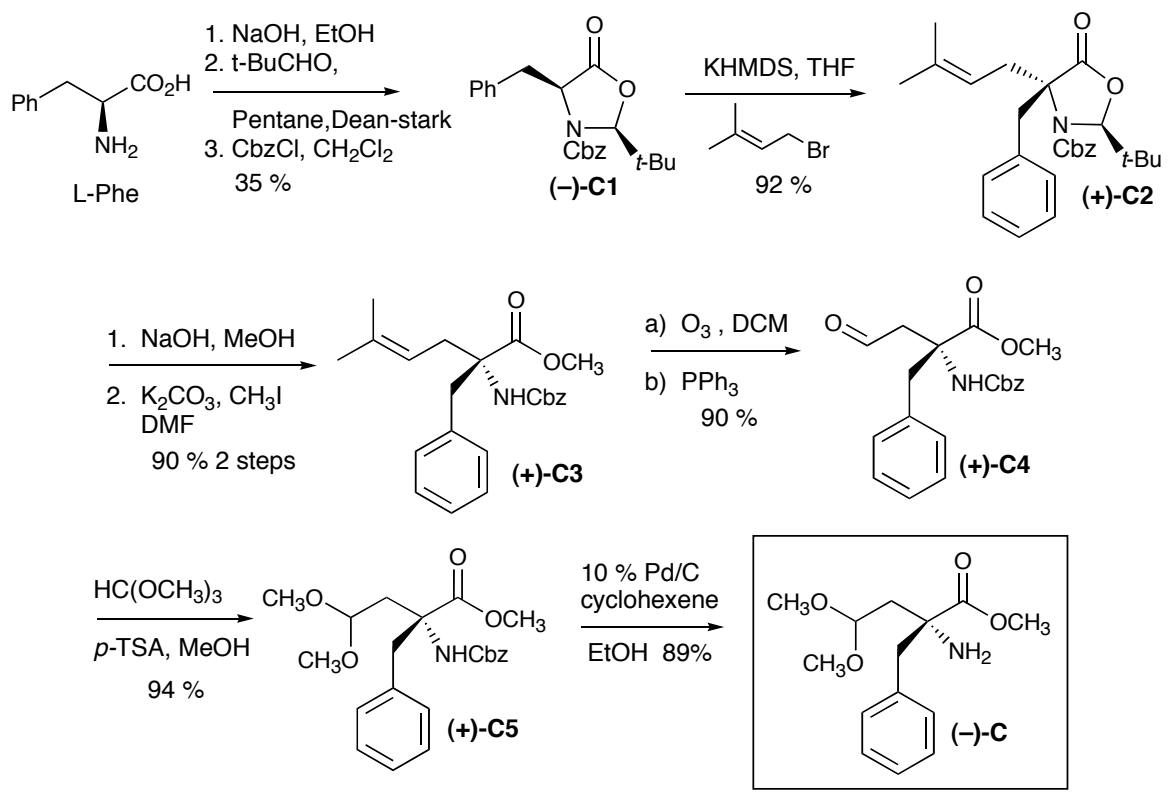

Oxazolidinone (-)-C1. A solution of $\mathrm{NaOH}(4.4 \mathrm{~g}, 110 \mathrm{mmol})$ in water $(22 \mathrm{~mL})$ was added to a mixture of Lphenylalanine $(17.2 \mathrm{~g}, 104 \mathrm{mmol})$ in $\mathrm{EtOH}(230 \mathrm{~mL})$. The mixture was stirred at room temperature for $1 \mathrm{~h}$, and then it was concentrated in vacuo to provide a white solid. Pentane was added $(300 \mathrm{~mL})$, followed by pivalaldehyde (17 mL, $156 \mathrm{mmol})$. The flask was equipped with a Dean-Stark trap, and the reaction mixture was stirred at reflux for $72 \mathrm{~h}$, when the collection of water had ceased. After cooling, the mixture was concentrated in vacuo to provide a white solid that was azeotropically dried with toluene $(200 \mathrm{~mL})$ and then stored under high vacuum overnight. The resulting dry imine was suspended in methylene chloride $(270 \mathrm{~mL})$ and treated with benzyl chloroformate at $0{ }^{\circ} \mathrm{C}$. The reaction mixture was maintained at this temperature for 16 days, when water $(100 \mathrm{~mL})$ and DMAP $(25 \mathrm{mg})$ were added and the resulting biphasic system was warmed to room temperature and stirred overnight. The mixture was extracted with EtOAc $(500 \mathrm{~mL})$ and the organic layer was washed with $10 \%$ aqueous $\mathrm{NaHSO}_{4}$, saturated aqueous $\mathrm{NaHCO}_{3}$, and brine (200 mL each), dried over $\mathrm{Na}_{2} \mathrm{SO}_{4}$, and concentrated in vacuo. The residue was purified by flash chromatography using ethyl acetate-hexanes (1:9) as eluant to afford a mixture of (-)-C1 and its trans isomer (19 g, 50\% yield) in a 2.5:1 diastereomeric ratio. Separation of the two isomers by preparative HPLC (Waters LC500), using 7\% ethyl acetate in hexanes as eluant, provided the cis isomer (-)-C1 as a colorless oil (13.3 g, 35\%, d.r. > 20:1). 


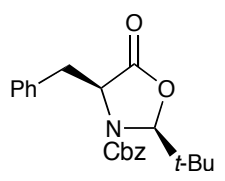

$(-)-C_{1}$

Cis isomer (-)-C1. [ $[\alpha]_{\mathrm{D}}^{23}-10.7\left(\mathrm{c} 0.98, \mathrm{CHCl}_{3}\right)$; IR (neat) $2961(\mathrm{~m}), 1793(\mathrm{~s}), 1722(\mathrm{~s}), 1455(\mathrm{w}), 1392(\mathrm{~m})$,

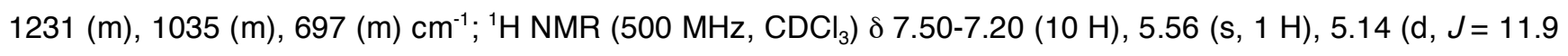
$\mathrm{Hz}, 1 \mathrm{H}), 4.93(\mathrm{~d}, J=11.8 \mathrm{~Hz}, 1 \mathrm{H}), 4.48(\mathrm{dd}, J=7.6,5.6 \mathrm{~Hz}, 1 \mathrm{H}), 3.21(\mathrm{dd}, J=13.9 .7 .6 \mathrm{~Hz}, 1 \mathrm{H}), 3.12(\mathrm{dd}, J=$ 13.9, $5.5 \mathrm{~Hz}, 1 \mathrm{H}), 1.00$ (s, $9 \mathrm{H}) ;{ }^{13} \mathrm{C}$ NMR $\left(125 \mathrm{MHz}, \mathrm{CDCl}_{3}\right) \delta 171.9,155.9,136.8,135.2,129.5,128.7,128.6$, $128.5,128.4,126.9,96.3,68.3,58.9,39.3,37.1,24.9$; high resolution mass spectrum (ESI positive ion) $\mathrm{m} / \mathrm{z}$ $390.1684\left[(\mathrm{M}+\mathrm{Na})^{+}\right.$; calcd for $\left.\mathrm{C}_{22} \mathrm{H}_{25} \mathrm{O}_{4} \mathrm{NNa}: 390.1681\right]$.

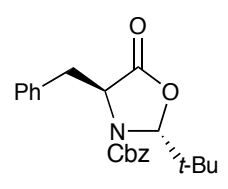

Trans isomer. m.p. $66-68^{\circ} \mathrm{C},[\alpha]_{\mathrm{D}}^{23}+117.7\left(\mathrm{c} 1.02, \mathrm{CHCl}_{3}\right)$; IR (neat) $2968(\mathrm{~m}), 1796(\mathrm{~s}), 1713(\mathrm{~s}), 1455(\mathrm{w})$, $1407(\mathrm{~s}), 1357(\mathrm{~m}), 1327(\mathrm{~m}), 1228(\mathrm{~m}), 1165(\mathrm{~m}), 1123(\mathrm{~m}), 1006(\mathrm{~m}), 755(\mathrm{~m}), 700(\mathrm{~m}) \mathrm{cm}^{-1} ;{ }^{1} \mathrm{H}$ NMR $(500$ $\mathrm{MHz}, \mathrm{CDCl}_{3}$ ) $\delta$ 7.45-7.35 (5 H), 7.25-7.10 (3 H), 7.01 (broad s, $\left.2 \mathrm{H}\right), 5.30(\mathrm{~d}, J=11.9 \mathrm{~Hz}, 1 \mathrm{H}), 5.14$ (broad s, 1 H), 5.06 (broad s, $1 \mathrm{H}), 4.45(\mathrm{~m}, 1 \mathrm{H}), 3.80$ (broad s, $1 \mathrm{H}), 3.15(\mathrm{dd}, J=14.2,2.4 \mathrm{~Hz}, 1 \mathrm{H}), 0.88(\mathrm{~s}, 9 \mathrm{H}) ;{ }^{13} \mathrm{C}$ $\operatorname{NMR}\left(125 \mathrm{MHz}, \mathrm{CDCl}_{3}\right) \delta 172.3,152.9,135.2,134.2,129.8,128.9,128.7,128.5,128.1,127.3,95.0,67.7,58.4$, 39.6, 34.4, 24.8; high resolution mass spectrum (ESI positive ion) $\mathrm{m} / \mathrm{z} 390.1681\left[(\mathrm{M}+\mathrm{Na})^{+}\right.$; calcd for $\mathrm{C}_{22} \mathrm{H}_{25} \mathrm{O}_{4} \mathrm{NNa}$ : 390.1681].

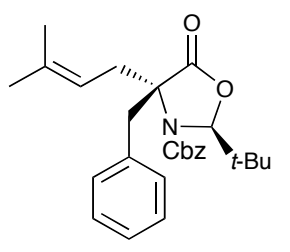

(+)-C2

Oxazolidinone (+)-C2. A solution of oxazolidinone (-)-C1 (12.3 g, $33.4 \mathrm{mmol})$ in THF (125 mL) was treated dropwise with a $0.5 \mathrm{M}$ solution of KHMDS in toluene $(83.5 \mathrm{~mL}, 41.7 \mathrm{mmol})$ at $-78{ }^{\circ} \mathrm{C}$. After $20 \mathrm{~min} 1$-bromo-3methyl-butene $(7.9 \mathrm{~mL}, 66.7 \mathrm{mmol})$ was added dropwise to the reaction mixture and stirring was continued at the same temperature for additional $45 \mathrm{~min}$. The reaction was quenched with $10 \%$ aqueous $\mathrm{NaHSO}_{4}(240 \mathrm{~mL})$, followed by extraction with EtOAc $(2 \times 200 \mathrm{~mL})$. The combined organic extracts were washed with $10 \%$ aqueous $\mathrm{NaHSO}_{4}$, saturated aqueous $\mathrm{NaHCO}_{3}$, and brine (170 mL each), dried over $\mathrm{Na}_{2} \mathrm{SO}_{4}$, and concentrated in vacuo. The product was purified by flash chromatography using $5 \%$ ethyl acetate in hexanes as eluant to afford 
oxazolidinone (+)-C2 as a colorless oil (13.3 g, 92\% yield). $[\alpha]_{\mathrm{D}}^{23}+30.8\left(\mathrm{c} 0.74, \mathrm{CHCl}_{3}\right)$; IR (neat) $3064(\mathrm{w})$, $3032(\mathrm{w}), 2963(\mathrm{~m}), 2932(\mathrm{~m}), 1790$ (s), 1716 (s), $1603(\mathrm{w}), 1496(\mathrm{~m}), 1481(\mathrm{~m}), 1455$ (s), 1392 (s), 1324 (s), $1277(\mathrm{~s}), 1213(\mathrm{~m}), 1190(\mathrm{~s}), 1129(\mathrm{~m}), 1080(\mathrm{w}), 1043(\mathrm{~s}), 1014(\mathrm{~s}), 916(\mathrm{w}), 848(\mathrm{w}), 804(\mathrm{w}), 751(\mathrm{~m}), 700(\mathrm{~s})$ $\mathrm{cm}^{-1}$; ${ }^{1} \mathrm{H}$ NMR (500 MHz, $\mathrm{CDCl}_{3}$ ) 8 7.50-7.30 (5 H), 7.19 (broad s, $\left.5 \mathrm{H}\right), 5.31$ (d, J=11.9 Hz, $1 \mathrm{H}$ ), 5.30 (broad s, $1 \mathrm{H}), 5.11$ (broad s, $1 \mathrm{H}$ ), $4.82($ broad t, $J=7.1 \mathrm{~Hz}, 1 \mathrm{H}), 3.29$ (broad s, $1 \mathrm{H}$ ), 3.28 (broad d, $J=0.7 \mathrm{~Hz}, 1 \mathrm{H}$ ), 2.93 (broad s, $1 \mathrm{H}), 2.44(\mathrm{~m}, 1 \mathrm{H}), 1.65(\mathrm{~s}, 3 \mathrm{H}), 1.54(\mathrm{~s}, 3 \mathrm{H}), 0.53(\mathrm{~s}, 9 \mathrm{H}) ;{ }^{13} \mathrm{C} \mathrm{NMR}\left(125 \mathrm{MHz}, \mathrm{CDCl}_{3}\right) \delta$ 173.7, 156.0, 138.2, 135.9, 135.2, 131.0, 128.7, 128.6, 128.5, 128.2, 127.1, 115.5, 95.5, 69.3, 67.9, 42.1, 37.6, $36.9,26.0,25.0,17.9$; high resolution mass spectrum (ESI positive ion) $\mathrm{m} / \mathrm{z} 458.2318\left[(\mathrm{M}+\mathrm{Na})^{+}\right.$; calcd for $\left.\mathrm{C}_{27} \mathrm{H}_{33} \mathrm{NO}_{4} \mathrm{Na}: 458.2307\right]$.

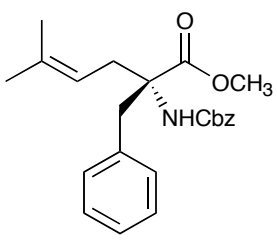

$(+)-\mathrm{C} 3$

Aminoester (+)-C3. A solution of oxazolidinone (+)-C2 $(13.5 \mathrm{~g}, 31 \mathrm{mmol})$ in methanol $(150 \mathrm{~mL})$ and aqueous $1 \mathrm{~N} \mathrm{NaOH}(150 \mathrm{~mL})$ was stirred at reflux for $8 \mathrm{~h}$. After cooling to room temperature the reaction mixture was concentrated in vacuo and the residue was acidified to $\mathrm{pH} 1$ with aqueous $10 \%$ solution of $\mathrm{NaHSO}_{4}$. The mixture was extracted with EtOAc $(3 \times 300 \mathrm{~mL})$ and the combined organic extracts were washed with water and brine (250 L each), dried over $\mathrm{Na}_{2} \mathrm{SO}_{4}$, and concentrated in vacuo. The crude product was stored under high vacuum for $2 \mathrm{~h}$, then dissolved in DMF $(20 \mathrm{~mL})$ and treated with iodomethane $(4 \mathrm{~mL}, 62 \mathrm{mmol})$ at $0{ }^{\circ} \mathrm{C}$. The reaction mixture was stirred at this temperature for $30 \mathrm{~min}$, then at room temperature for additional $30 \mathrm{~min}$. Water (30 $\mathrm{mL}$ ) was added to the reaction followed by extraction with diethyl ether $(2 \times 300 \mathrm{~mL})$. The combined organic extracts were washed with water $(4 \times 150 \mathrm{~mL})$, saturated aqueous $\mathrm{NaHCO}_{3}$, and brine (150 mL each), dried over $\mathrm{MgSO}_{4}$, and concentrated in vacuo. The crude product was purified by flash chromatography using $8 \%$ ethyl acetate in hexanes as eluant to afford aminoester $(+)-\mathbf{C} 3$ as a colorless oil $(10.7 \mathrm{~g}, 90 \%$ yield $)$. $[\alpha]_{\mathrm{D}}^{23}+34.6(c$ 1.47, $\mathrm{CHCl}_{3}$ ); IR (neat) $3422(\mathrm{~m}), 2951$ (m), 1722 (s), $1498(\mathrm{~s}), 1455(\mathrm{~m}), 1343(\mathrm{w}), 1237(\mathrm{~m}), 1075(\mathrm{~m}), 1041$ (m), $744(\mathrm{w}), 701(\mathrm{~m}) \mathrm{cm}^{-1}$; ${ }^{1} \mathrm{H}$ NMR $\left(500 \mathrm{MHz}, \mathrm{CDCl}_{3}\right) \delta$ 7.50-7.30 (5 H), 7.20-7.10 (3 H), 7.00-6.90 (2 H), 5.60 (broad s, $1 \mathrm{H}$ ), $5.20(\mathrm{~d}, J=12.7 \mathrm{~Hz}, 1 \mathrm{H}), 5.09(\mathrm{~d}, J=12.7 \mathrm{~Hz}, 1 \mathrm{H}), 4.96(\mathrm{t}, J=7.4 \mathrm{~Hz}, 1 \mathrm{H}), 3.74(\mathrm{~s}, 3 \mathrm{H}), 3.66$ (d, $J=13.6 \mathrm{~Hz}, 1 \mathrm{H}$ ), 3.17 (dd, $J=14.4,7.4 \mathrm{~Hz}, 1 \mathrm{H}$ ), 3.14 (d, $J=13.6 \mathrm{~Hz}, 1 \mathrm{H}), 2.59$ (dd, $J=14.4,7.4 \mathrm{~Hz}, 1 \mathrm{H}$ ), 1.68 (s, $3 \mathrm{H}), 1.59$ (s, $3 \mathrm{H}) ;{ }^{13} \mathrm{C}$ NMR (125 MHz, $\left.\mathrm{CDCl}_{3}\right) \delta$ 173.0, 154.3, 136.8, 136.3, 135.9, 129.7, 128.4, 128.2, 128.1, 128.0, 126.8, 117.5, 66.2, 65.3, 52.4, 40.5, 34.5, 25.9, 17.9; high resolution mass spectrum (ESI positive ion) $m / z 404.1835\left[(\mathrm{M}+\mathrm{Na})^{+}\right.$; calcd for $\mathrm{C}_{23} \mathrm{H}_{27} \mathrm{O}_{4} \mathrm{NNa:}$ 404.1837]. 


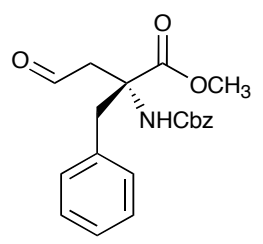

$(+)-\mathrm{C} 4$

Aldehyde (+)-C4. Ozone was passed through a solution of alkene (+)-C3 (10.6 g, $28 \mathrm{mmol})$ in dichloromethane $(300 \mathrm{~mL})$ at $-78{ }^{\circ} \mathrm{C}$ until the blue color of the reaction mixture became persistent. Argon was then bubbled through the mixture until the blue color disappeared, when most of the excess ozone was removed. A solution of triphenyl phosphine $(9.0 \mathrm{~g}, 34 \mathrm{mmol})$ in dichloromethane $(70 \mathrm{~mL})$ was added to the reaction mixture at $-78{ }^{\circ} \mathrm{C}$, and after warming to room temperature the solvent was evaporated in vacuo. The crude product was purified by flash chromatography using ethyl acetate-hexanes (1:4) as eluant to afford aldehyde (+)-C4 as a white solid $\left(8.9 \mathrm{~g}, 90 \%\right.$ yield). m.p. $81-83{ }^{\circ} \mathrm{C},[\alpha]_{\mathrm{D}}^{23}+96.2\left(c 1.00, \mathrm{CHCl}_{3}\right)$; IR (neat) 3419 (m), 3031 (w), 2953 (w), 1744 (s), 1724 (s), 1497 (s), 1455 (m), 1228 (s), 1078 (m), 1054 (m), 743 (w), 701 (m) $\mathrm{cm}^{-1}$; ${ }^{1} \mathrm{H}$ NMR $\left(500 \mathrm{MHz}, \mathrm{CDCl}_{3}\right.$ ) $\delta 9.67$ (broad s, $\left.1 \mathrm{H}\right)$, 7.45-7.35 $(4 \mathrm{H})$, 7.25-7.10 (3 H), 6.95-6.85 (2 H), 5.83 (broad s, $1 \mathrm{H}$ ), $5.21(\mathrm{~d}, J=12.3 \mathrm{~Hz}, 1 \mathrm{H}), 5.01(\mathrm{~d}, J=12.3 \mathrm{~Hz}, 1 \mathrm{H}), 3.90(\mathrm{~d}, J=17.9 \mathrm{~Hz}, 1 \mathrm{H}), 3.73(\mathrm{~s}, 3 \mathrm{H})$, $3.60(\mathrm{~d}, J=13.4 \mathrm{~Hz}, 1 \mathrm{H}), 3.10(\mathrm{~d}, J=17.9 \mathrm{~Hz}, 1 \mathrm{H}), 2.98(\mathrm{~d}, J=13.4 \mathrm{~Hz}, 1 \mathrm{H}) ;{ }^{13} \mathrm{C} \mathrm{NMR}\left(125 \mathrm{MHz}, \mathrm{CDCl}_{3}\right) \delta$ 198.6, 171.8, 154.5, 136.4, 134.5, 129.7, 128.5, 128.3, 128.1, 128.0, 127.3, 66.5, 61.0, 52.8, 48.7, 41.4; high resolution mass spectrum (ESI positive ion) $\mathrm{m} / \mathrm{z} 378.1314$ [(M+Na) ${ }^{+}$; calcd for $\mathrm{C}_{20} \mathrm{H}_{21} \mathrm{NO}_{5} \mathrm{Na}$ : 378.1317].

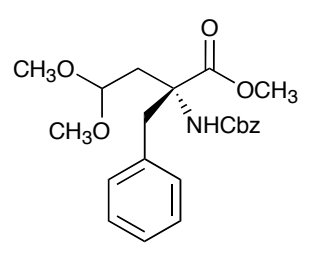

$(+)-\mathrm{C} 5$

Acetal (+)-C5. To a solution of aldehyde (+)-C4 $(8.9 \mathrm{~g}, 25 \mathrm{mmol})$ in $\mathrm{MeOH}(22 \mathrm{~mL})$ was added trimethyl orthoformate $(22 \mathrm{~mL}, 200 \mathrm{mmol})$ and a catalytic amount of $p$-toluenesulfonic acid. The reaction mixture was stirred at reflux for $2 \mathrm{~h}$. After cooling diethyl ether $(300 \mathrm{~mL})$ was added. The resulting organic solution was washed with saturated aqueous $\mathrm{NaHCO}_{3}$ and brine (100 mL each), dried over $\mathrm{Na}_{2} \mathrm{SO}_{4}$, and concentrated in vacuo. The crude product was purified by flash chromatography using ethyl acetate-hexane (1:9) to provide acetal (+)-C5 as a colorless oil $\left(9.4 \mathrm{~g}, 94 \%\right.$ yield). $[\alpha]_{\mathrm{D}}^{23}+69.8\left(\mathrm{c} 1.77, \mathrm{CHCl}_{3}\right)$; IR (neat) $3417(\mathrm{~m}), 3063(\mathrm{w})$, 3031 (w), 2951 (m), 2833 (w), 1738 (s), 1722 (s), 1497 (s), 1454 (m), 1214 (s), 1074 (s), 745 (m), 701 (m) cm; ${ }^{1} \mathrm{H}$ NMR $\left(500 \mathrm{MHz}, \mathrm{CDCl}_{3}\right) \delta$ 7.50-7.30 (5 H), 7.30-7.10 (3 H), 7.00-6.90 (2 H), 5.83 (broad s, $\left.1 \mathrm{H}\right), 5.09(\mathrm{~d}, J=$ $12.3 \mathrm{~Hz}, 1 \mathrm{H}$ ), 4.31 (dd, J = 8.2, 3.0 Hz, 1 H), 3.73 (s, $3 \mathrm{H}$ ), 3.58 (d, J=13.5 Hz, 1 H), 3.29 (s, $3 \mathrm{H}$ ), 3.25 (s, 3 H), $3.07(\mathrm{~d}, J=13.5 \mathrm{~Hz}, 1 \mathrm{H}), 2.83(\mathrm{dd}, J=14.2,3.0 \mathrm{~Hz}, 1 \mathrm{H}), 2.82(\mathrm{~d}, J=12.3 \mathrm{~Hz}, 1 \mathrm{H}), 2.29$ (dd, J=14.2, 8.2 
$\mathrm{Hz}, 1 \mathrm{H}) ;{ }^{13} \mathrm{C}$ NMR $\left(125 \mathrm{MHz}, \mathrm{CDCl}_{3}\right) \delta 172.8,154.3,136.8,135.6,129.8,128.5,128.3,128.1,128.1,126.9$, 102.6, 66.3, 62.5, 55.0, 53.6, 52.4, 41. 0, 39.1; high resolution mass spectrum (ESI positive ion) $\mathrm{m} / \mathrm{z} 424.1736$ $\left[(\mathrm{M}+\mathrm{Na})^{+}\right.$; calcd for $\left.\mathrm{C}_{22} \mathrm{H}_{27} \mathrm{O}_{6} \mathrm{NNa:} 424.1736\right]$.

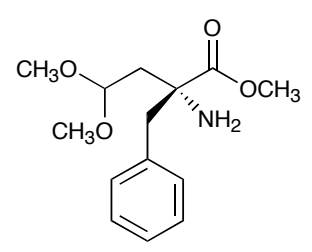

$(-)-\mathbf{C}$

Aminoester (-)-C. A solution of Cbz-protected amine (+)-C5 (2 g, $7.985 \mathrm{mmol})$ in ethanol (20 mL) was treated with $10 \%$ wt Pd on carbon (400 mg) and cyclohexene $(5 \mathrm{~mL}, 50 \mathrm{mmol})$. The mixtured was stirred at reflux for 2.5 h. After cooling to room temperature the reaction mixture was filtered through Celite, and concentrated in vacuo. The crude residue was purified by flash-chromatography using ethyl acetate-hexanes (1:1) as eluant to provide aminoester (-)-C as a colorless oil (1.2 g, 89\% yield). [ $\alpha]_{\mathrm{D}}^{23}-11.0\left(\mathrm{c} 0.74, \mathrm{CHCl}_{3}\right)$; IR (neat) $3389(\mathrm{~m}), 3323$ (m), $3062(\mathrm{~m}), 3029(\mathrm{~m}), 2948(\mathrm{~s}), 2832(\mathrm{~m}), 1738(\mathrm{~s}), 1603(\mathrm{~m}), 1495(\mathrm{w}), 1454(\mathrm{~m}), 1442(\mathrm{~m}), 1195(\mathrm{~s}), 1124$

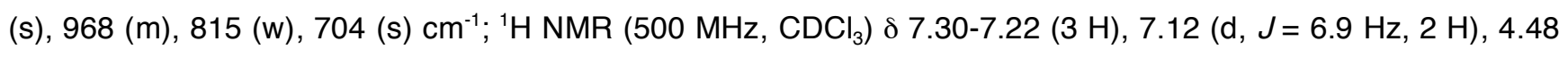
(t, J=5.6 Hz, $1 \mathrm{H}), 3.68(\mathrm{~s}, 3 \mathrm{H}), 3.32(\mathrm{~s}, 3 \mathrm{H}), 3.29(\mathrm{~s}, 3 \mathrm{H}), 3.13(\mathrm{~d}, J=13.1 \mathrm{~Hz}, 1 \mathrm{H}), 2.77(\mathrm{~d}, J=13.1 \mathrm{~Hz}, 1$ H), 2.29 (dd, $J=14.0,5.8 \mathrm{~Hz}, 1 \mathrm{H}$ ), 1.91 (dd, $J=14.0,5.4 \mathrm{~Hz}, 1 \mathrm{H}), 1.71$ (broad s, $2 \mathrm{H}$ ); ${ }^{13} \mathrm{C} \mathrm{NMR}(125 \mathrm{MHz}$, $\left.\mathrm{CDCl}_{3}\right) \delta 176.6,135.8,130.0,128.3,127.0,102.4,60.1,53.4,53.3,51.9,47.0,42.5$; high resolution mass spectrum (ESI positive ion) $\mathrm{m} / \mathrm{z} 268.1552\left[(\mathrm{M}+\mathrm{H})^{+}\right.$; calcd for $\left.\mathrm{C}_{14} \mathrm{H}_{22} \mathrm{O}_{4} \mathrm{~N}: 268.1548\right]$.

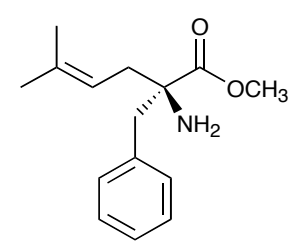

$(-)-\mathbf{D}$

Amino Ester Building Block (-)-D. ${ }^{3} \quad[\alpha]_{\mathrm{D}}^{23}-2.6$ (c 4.53, $\left.\mathrm{CHCl}_{3}\right)$; IR $\left(\mathrm{CHCl}_{3}\right) 3360(\mathrm{w}), 2980$ (m), 1735 (s),

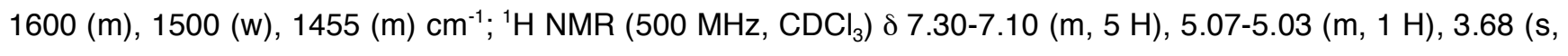
$3 \mathrm{H}), 3.18(\mathrm{~d}, J=13.1 \mathrm{~Hz}, 1 \mathrm{H}), 2.79(\mathrm{~d}, J=13.2 \mathrm{~Hz}, 1 \mathrm{H}), 2.60(\mathrm{dd}, J=6.7,14.1 \mathrm{~Hz}, 1 \mathrm{H}), 2.48(\mathrm{dd}, J=8.2$, $14.1 \mathrm{~Hz}, 1 \mathrm{H}), 1.73(\mathrm{~s}, 3 \mathrm{H}), 1.67(\mathrm{~s}, 3 \mathrm{H}), 1.53(\mathrm{br} \mathrm{s}, 2 \mathrm{H}) ;{ }^{13} \mathrm{C} \mathrm{NMR}\left(125 \mathrm{MHz}, \mathrm{CDCl}_{3}\right) \delta$ 176.92, 136.50, 136.37, 129.84, 128.32, 126.86, 117.95, 62.57, 51.84, 45.92, 38.173, 26.04, 18.05; high resolution mass spectrum $(\mathrm{Cl}$,

(3) Smith, A. B., III; Guzman, M. C.; Sprengeler, P. A.; Keenan, T. P.; Holcomb, R. C.; Wood, J. L.; Carroll, P. J.; Hirschmann, R. J. Am. Chem. Soc. 1994, 116, 9947-9962. 
$\left.\mathrm{NH}_{3}\right) \mathrm{m} / \mathrm{z} 248.1654\left[(\mathrm{M}+\mathrm{H})^{+}\right.$; calcd for $\mathrm{C}_{15} \mathrm{H}_{22} \mathrm{NO}_{2}$ : 248.1650]. Anal. Calcd for $\mathrm{C}_{15} \mathrm{H}_{21} \mathrm{NO}_{2}: \mathrm{C}, 72.84 ; \mathrm{H}, 8.56 ; \mathrm{N}$, 5.66. Found: C, 72.89; H, 8.70; N, 5.65 .

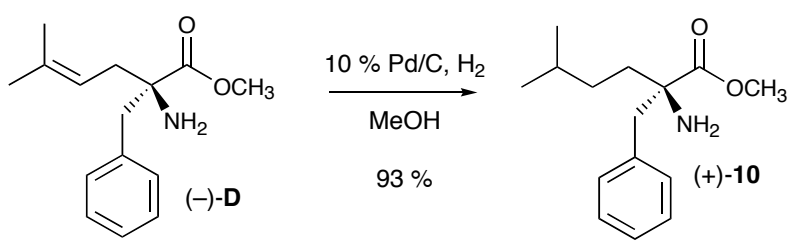

Aminoester (+)-10. To a solution of olefin (-)-D (110 mg, $0.445 \mathrm{mmol})$ in methanol $(4 \mathrm{~mL})$ was added $10 \%$ wt $\mathrm{Pd}$ on carbon $(70 \mathrm{mg}$ ). The mixture was briefly evacuated and opened to argon three times, then evacuated again and opened to hydrogen (1atm). After stirring for $22 \mathrm{~h}$ at room temperature, the reaction mixture was filtered through Celite, and concentrated in vacuo. The crude residue was purified by flash-chromatography using ethyl acetate-hexanes (1:4) as eluant to provide amino ester (+)-10 as a colorless oil (103 $\mathrm{mg}, 93 \%$ yield). $[\alpha]_{D}^{23}+31.3\left(c 01.04, \mathrm{C}_{6} \mathrm{H}_{6}\right)$; IR (neat) $3382(\mathrm{w}), 3085(\mathrm{~m}), 3029(\mathrm{~m}), 2954(\mathrm{~s}), 2927(\mathrm{~s}), 2870(\mathrm{~m}), 1737(\mathrm{~s})$, $1603(\mathrm{~m}), 1495$ (w), $1467(\mathrm{~m}), 1454(\mathrm{~m}), 1385(\mathrm{~m}), 1367(\mathrm{~m}), 1211(\mathrm{~s}), 1192(\mathrm{~s}), 1031(\mathrm{~m}), 702(\mathrm{~m}) \mathrm{cm}^{-1} ;{ }^{1} \mathrm{H}$ NMR $\left(500 \mathrm{MHz}, \mathrm{C}_{6} \mathrm{D}_{6}\right) \delta$ 7.40-7.15 $(5 \mathrm{H}), 3.40(\mathrm{~s}, 3 \mathrm{H}), 3.24(\mathrm{~d}, J=13.0 \mathrm{~Hz}, 1 \mathrm{H}), 2.81(\mathrm{~d}, J=13.0 \mathrm{~Hz}, 1 \mathrm{H})$, $1.98(\mathrm{td}, J=12.8,4.3 \mathrm{~Hz}, 1 \mathrm{H}$ ), 1.64 (td, $J=12.8,4.6 \mathrm{~Hz}, 1 \mathrm{H}$ ), 1.48 (thept., $J=6.7,6.7 \mathrm{~Hz}, 1 \mathrm{H}$ ), 1.45 (broad s, $2 \mathrm{H}), 1.19(\mathrm{~m}, 1 \mathrm{H}), 1.37(\mathrm{~m}, 1 \mathrm{H}), 0.93(\mathrm{~d}, J=6.7 \mathrm{~Hz}, 3 \mathrm{H}) 0.92(\mathrm{~d}, J=6.7 \mathrm{~Hz}, 3 \mathrm{H}) ;{ }^{13} \mathrm{C} \mathrm{NMR}\left(125 \mathrm{MHz}, \mathrm{C}_{6} \mathrm{D}_{6}\right) \delta$ 176.8, 137.4, 130.4, 128.5, 127.0, 62.5, 51.2, 46.7, 38.7, 33.4, 28.6, 22.7, 22.6; high resolution mass spectrum (ESI positive ion) $\mathrm{m} / \mathrm{z} 250.1801\left[(\mathrm{M}+\mathrm{H})^{+}\right.$; calcd for $\left.\mathrm{C}_{15} \mathrm{H}_{24} \mathrm{NO}_{2}: 250.1807\right]$. 